\title{
Short and long term recovery after total hip replacement : physiological, pathophysiological outcomes and clinical implications
}

Citation for published version (APA):

Pilot, P. (2006). Short and long term recovery after total hip replacement : physiological, pathophysiological outcomes and clinical implications. [Doctoral Thesis, Maastricht University]. Universiteit Maastricht. https://doi.org/10.26481/dis.20061006pp

Document status and date:

Published: 01/01/2006

DOI:

10.26481/dis.20061006pp

Document Version:

Publisher's PDF, also known as Version of record

Please check the document version of this publication:

- A submitted manuscript is the version of the article upon submission and before peer-review. There can be important differences between the submitted version and the official published version of record.

People interested in the research are advised to contact the author for the final version of the publication, or visit the DOI to the publisher's website.

- The final author version and the galley proof are versions of the publication after peer review.

- The final published version features the final layout of the paper including the volume, issue and page numbers.

Link to publication

\footnotetext{
General rights rights.

- You may freely distribute the URL identifying the publication in the public portal. please follow below link for the End User Agreement:

www.umlib.nl/taverne-license

Take down policy

If you believe that this document breaches copyright please contact us at:

repository@maastrichtuniversity.nl

providing details and we will investigate your claim.
}

Copyright and moral rights for the publications made accessible in the public portal are retained by the authors and/or other copyright owners and it is a condition of accessing publications that users recognise and abide by the legal requirements associated with these

- Users may download and print one copy of any publication from the public portal for the purpose of private study or research.

- You may not further distribute the material or use it for any profit-making activity or commercial gain

If the publication is distributed under the terms of Article 25fa of the Dutch Copyright Act, indicated by the "Taverne" license above, 


\section{SHORT AND LONG TERM RECOVERY AFTER TOTAL HIP REPLACEMENT;}

Physiological, pathophysiological, outcomes and clinical implications 



\section{SHORT AND LONG TERM RECOVERY AFTER TOTAL HIP REPLACEMENT; Physiological, pathophysiological, outcomes and clinical implications}

\section{Proefschrift}

ter verkrijging van de graad van doctor aan de Universiteit Maastricht, op gezag van de Rector Magnificus, prof. mr. G.P.M.F. Mols,

volgens het besluit van het College van Decanen,

in het openbaar te verdedigen

op vrijdag 6 oktober 2006 om 14.00 uur

door

Peter Pilot 


\section{Promotores:}

prof. dr. H.Kuipers

prof. dr. R.G.T. Geesink

\section{Co-promotores:}

dr. A.D. Verburg (Maasland ziekenhuis Sittard)

dr. J.J. Koolen (Catherina ziekenhuis Eindhoven)

\section{Beoordelingscommissie:}

prof. dr. A.M.W.J. Schols (voorzitter)

prof. dr. R.A. de Bie

prof. dr. S.K. Bulstra (Universitair Medisch Centrum Groningen)

prof. dr. H.E.M. Kerkkamp (Universitair Medisch Centrum Utrecht)

prof. dr. M. van Kleef 
Voor mijn ouders 


\section{Bibliografie:}

Pilot, Peter

Short and long term recovery after total hip replacement;

Physiological, pathophysiological, outcomes and clinical implications

Thesis Maastricht (UM) with ref.

ISBN-10: 90-8590-009-3

ISBN-13: 978-90-8590-009-2

(C) 2006, Pilot, Peter, Maastricht, The Netherlands

All right reserved. No part of this publication may be reproduced or transmitted in any form or by any means, electronic or mechanical, including photocopy, recording, or any information storage and retrieval system, without permission in writing from the copyright owner.

\section{Design and layout by:}

D\&L graphics, Kerkrade, The Netherlands

www.dlgraphics.nl

\section{Published by:}

D\&L graphics

\section{Printed by:}

Schrijen-Lippertz-Huntjens

\section{Publication of this thesis was supported by grants from:}

Stichting ter bevordering van de orthopaedische kwaliteit Sittard, Nederlandse Orthopaedische Vereniging (NOV), Anna-fonds Leiden, Astratech B.V., Astrazeneca B.V., Biomet Europe B.V., Boehringer-Ingelheim B.V., GlaxoSmithKline B.V.

Ortho-Biotech B.V., Penders voetzorg B.V., Pfizer B.V., Smeet Loopcomfort B.V., Somas B.V., Sproncken Orthopedie B.V., Stryker B.V., Westland orthopedie B.V., Zimmer B.V. 


\section{Contents}

Chapter 1 Introduction 9

Chapter 2 Rapid recovery; a critical review of the literature on 15 peri-operative care

Chapter 3 Critical pathway for hip and knee replacement;

Chapter 4 Feasibility of early maximal cardiopulmonary exercise testing after total hip replacement

Chapter 5 The influence of surgery induced anaemia on exercise capacity after total hip replacement

Chapter 6 The use of autologous blood to improve exercise capacity after total hip replacement. A preliminary report

Chapter 7 A functional physiological evaluation of recovery during the first year after total hip replacement

Chapter 8 Is minimal invasive surgery less invasive in total hip replacement? A pilot study

Chapter 9 Experience in the first four years of Rapid Recovery; is it safe?

Chapter 10 General Discussion

Summary/Samenvatting

Dankwoord

Curriculum Vitea

Publications 



\section{Introduction and research questions}




\section{INTRODUCTION}

Osteoarthritis $(\mathrm{OA})$ is a chronic disease of the joints and has an increasing prevalence with age. ${ }^{1}$ It is estimated that the incidence will increase by 38\% over the period 2000-2020.2 When pain and function severely impede patients to function in daily life, a total hip or knee replacement may be considered.

Total hip and knee replacement in osteoarthritis patients is considered as one of the most successful procedures in improving quality of life. The number of total hip replacements has been increased extensively since its introduction in 1960 by Charnley. ${ }^{3}$ This is due firstly to the improved survival rates which has led to the procedure being performed in younger patients. ${ }^{4}$ Secondly, the procedure is offered to an increasing number of patients, who were previously regarded as too old or too ill.

Besides the increasing number of total joint replacements, the process of total hip and knee implantation has changed significantly over the last decades. Whereas twenty years ago the length of stay (LOS) was two to six weeks, nowadays most patients are discharged within a week. There are even reports of hip joint replacement in day-care.5,6 Not only the process of care has been changed by the introduction of critical pathways, ${ }^{7}$ but the medical approach is also changing by introducing fast track surgery and the multi-modal approach.8,9

\section{Physical ReCOVERY}

Optimal balance between rehabilitation load and recovery is essential, especially in early recovery programs. Understanding of and ability to monitor these physical processes give us the tools to optimise the rehabilitation process.

Few reports have covered the subject of physiological recovery and the physical loads during rehabilitation. By knowing the changes in the various physiological systems involved in recovery it might be possible to investigate changes in surgical procedures, like minimal invasive surgery, or different rehabilitation programs.

\section{HYPOTHESIS}

The general hypotheses are as follows: (1) Economic factors dictate the medical and organisational changes in joint replacement, however insufficient knowledge of early and late physiological recovery after total hip replacement is available; (2) A restrictive blood transfusion policy is no limitation for the post-operative rehabilitation program. (3) The use of a critical pathway in total hip replacement does not compromise the clinical outcome in terms of complications.

\section{THE SCOPE OF THIS THESIS}

The scope of this thesis is the physiological recovery after total hip replacement in a critical pathway. All patients described in this thesis were treated in the Joint Care ${ }^{\circledR}$ program (Biomet, Dordrecht, The Netherlands). This critical pathway was adapted in the Maasland hospital in 2000. 


\section{RESEARCH QUESTIONS}

This thesis contains ten chapters, each chapter addresses a specific research question with the exception of Chapter 1, which contains the introduction. Chapter 2 contains a literature review, to discover if there is a general consensus on peri-operative care. Aspects of the critical pathway used in the Maasland Hospital (Joint Care ${ }^{\circledR}$ ) as well as a review of literature on critical pathways in orthopaedic surgery are presented in Chapter 3. In Chapter 4 the following research question was addressed: 'Is it possible to perform exercise testing as early as four days after replacement of a hip joint?' The feasibility of early post-operative, symptom-limited exercise testing is presented in this chapter, as nurses, medical staff and patients were unfamiliar with early exercise testing in the Maasland hospital. Post-operative anaemia, nausea, fatigue and fear were seen as interfering factors for early exercise testing. A cohort of 50 consecutive patients were tested at several time points after surgery. Values of the pre-operative tests were compared to the post-operative tests. The influence of post-operative blood loss on the capacity to perform exercise is investigated in Chapter 5.

This chapter presents a study of 200 test patients in which the correlation between the exercise capacity on the fourth post-operative day and the extent of post-operative anaemia is examined. Several sub-analyses were done including the influence of pre-operative physical condition, gender, age and the relative and absolute extent of anaemia.

The absence of a correlation between blood loss and exercise capacity, found in Chapter 5, was surprising. Therefore, a study was designed to compensate for the post-operative blood loss in an ethically well considered way. This study described in Chapter 6 considers the influence on exercise capacity when the post-operative Hb-drop is fully compensated by autologous blood. Chapter 7 addresses patient recovery after a total hip replacement focussing on pre-operative physical fitness, gender and age. Although many surgeons talk to patients about the 'normal' recovery time, not much evidence is present about the physical recovery. In Chapter 7 a large group of patients $(n=200)$ was followed for a year with maximum symptom-limited exercise testing to investigate the "normal' recovery time.

Does minimal invasive hip surgery have any advantage? During the last few years minimal invasive hip and knee replacement surgery has become a major issue. Apart from the fact that the excellent long-term results may be compromised through mal-positioning, is minimal invasive less traumatic? In Chapter $\mathbf{8}$ a pilot study was carried out to examine whether a smaller incision caused less tissue damage and inflammation. After Joint Care ${ }^{\circledR}$ had been introduced in the Maasland hospital it was declared a success by the management. But are the medical results satisfactory? Chapter 9 evaluates the results of the first five years of hip replacement in Joint Care, the critical pathway used in the Maasland hospital.

This thesis will end with a general discussion in Chapter 10 including directions for future research and organisation. As most chapters are based on published or submitted manuscripts and are intended to be read individually, some repetition is inevitable. 


\section{REFERENCES}

1. Felson DT, Zhang Y. An update on the epidemiology of knee and hip osteoarthritis with a view to prevention. Arthritis Rheum 1998 Aug;41(8):1343-55.

2. Schouten JASEG, Poos MJJC, Gijssen R. Neemt het aantal mensen met arthrose toe of af? Volksgezondheid toekomst verkenning, nationaal kompas volksgezondheid 2002; Bilthoven RIVM (2002). http://www.rivm.nl/vtv/object document/o1779n18371.html

3. Charnley J. Arthroplasty of the hip. A new operation. Lancet 1961;1(7187):1129-32.

4. Ostendorf M, Johnell O, Malchau H, Dhert WJ, Schrijvers AJ, Verbout AJ. The epidemiology of total hip replacement in The Netherlands and Sweden: present status and future needs. Acta Orthop Scand 2002;73(3):282-6.

5. Berger R. The technique and early results of the two-incision minimally invasive total hip arthroplasty, Thirty-first Open Meeting of the Hip Society, New Orleans, Feb 2003.

6. Mathias JM. MIS total hip implant speeds recovery. OR Manager 2001; 17:5-7.

7. Pearson SD, Goulart-Fisher D, Lee TH. Critical pathways as a strategy for improving care: problems and potential. Ann Intern Med 1995;123(12):941-8.

8. Kehlet H. Multimodal approach to control postoperative pathophysiology and rehabilitation. Br J Anaesth 1997;78(5):606-17.

9. Kehlet H, Wilmore DW. Fast-track surgery. Br J Surg 2005;92(1):3-4. 



\section{CHAPTER 2}

\section{Rapid recovery; a critical review of the literature on peri-operative care}

Pilot P, Arts SJ, Verburg AD, Kuipers H

Rapid recovery; a critical review of the literature on peri-operative care.

(submitted) 


\section{AbstRact}

Whereas a decade ago patients were hospitalised for weeks after total joint replacement, nowadays hospital stay is reduced to less than a week. Changes in insights and improvement in efficiency of the care process account for this reduction. The use of a critical pathway combining peri-operative pain management with a shift from general to local anaesthesia and opioid sparing, besides careful fluid management and restrictive transfusion policy, are the best options for most patients. The current tendency in fluid management is restrictive per-operative. A correct dosage of fluid therapy improves patient outcome after surgery, whereas correct fluid therapy is even more important when a restrictive blood transfusion policy is executed. The need for welldefined studies of intra-operative and post-operative fluid therapy are mandatory. Now most patients are treated in accelerated stay programs and even light morbidity like nausea and vomiting can prolong the length of stay. Pre-operative training does not seem to be beneficial except for anxiety reduction, whereas post-operative physical therapy is likely to be effective. Whether minimal invasive surgery contributes to faster recovery, remains to be established. Perioperative nutritional support has no place in elective hip and knee surgery. 


\section{INTRODUCTION}

Total hip replacement is the most successful major orthopaedic intervention of the last decades. Severe comorbidity and high age are no longer reasons for exclusion of surgery. Whereas a decade ago patients were hospitalised for weeks after total joint replacement, nowadays hospital stay is reduced to less than a week. Changes in insights and improvement in efficiency of the care process account for this reduction.

In the last two decades the care process has improved as most processes have been integrated in a better way. These programs were called critical pathways (or clinical pathways; CP) and were first developed and applied to health care in the 1980s. ${ }^{1}$ These first critical pathways were developed by nurses for nursing care alone, ${ }^{2}$ but multidisciplinary teams soon began developing pathways to encompass all aspects of care for hospitalised patients. ${ }^{1}$ Clinical pathways differ in several aspects from clinical guidelines. Firstly, CP focuses on the quality and efficiency of care after diagnosis and decisions of treatment have been made. Secondly, the CPs are multidisciplinary and are designed along specific timelines. A multidisciplinary group to develop a CP must have a physician-expert to lead the team, a group facilitator and a member of the quality management department. ${ }^{1}$

Osteoarthritis of the hip and knee leading to total hip or knee replacements are high-volume, high-cost diagnosis and procedures, likely to have an inefficient variation in the care process. Therefore these diagnoses are suited for CPs. ${ }^{1}$ These CPs mainly focus on the process of care and less on the medical improvements directly.

\section{Optimising PERI-OPERATIVE CARE}

To understand post-operative morbidity we first need to understand the patho-physiological role of various components of the surgical stress response. Secondly, we need to determine if modification of such responses may improve surgical outcomes. ${ }^{3-5}$ A pioneer in optimisation perioperative care for elective surgical patients has been Henrik Kehlet from Copenhagen. ${ }^{3-5}$ Kehlet and co-workers synthesised, integrated and applied research outcomes in a comprehensive programme, now commonly referred to as 'fast-track surgery'. 5 The thrust of this approach was to reduce the physiological and psychological stresses associated with operations, thereby reducing a number of potential minor complications. Fast-track surgery evolved as a co-ordinated effort, combining modern concepts of patient education with newer anaesthetic and analgesic methods. The intentions were to reduce stress response, and minimise pain and discomfort. This because the key pathogenic factor in post-operative morbidity, excluding failures of surgical and anaesthetic technique, is the surgical stress response with subsequent increased demands on organ function. ${ }^{3}$

\section{COMPOSITION OF REVIEW}

A brief description of surgical stress is presented and an overview of most factors influencing post-operative recovery is given. Expectations of patients, pre-operative training and anxiety reduction are discussed. Consecutively the multimodal approach, pain management, fluid balancing, anaemia and minimal invasive hip surgery are outlined. Finally physical recovery, physical therapy and nutritional support are discussed. 


\section{PhYSIOLOGY OF STRESS RESPONSE}

Following (surgical) trauma, patients are subjected to dynamic alterations in the haemodynamic, metabolic, and immune responses that are largely orchestrated by endogenous mediators referred to as cytokines. ${ }^{6}$ The development of this inflammatory response is part of the normal response to injury. This gives rise to the systemic inflammatory response syndrome (SIRS) followed by a period mediated by a compensatory anti-inflammatory response syndrome (CARS). ${ }^{7}$ Within this inflammatory process there is a delicate balance between the beneficial effects of inflammation and the potential for the process itself to cause remote tissue injury. ${ }^{7}$

\section{Psychological ASPECTS}

Expectations and anxiety are important psychological aspects influencing the surgical outcome. Patients' expectations of orthopaedic surgery impact the way patients view and assess their treatment. ${ }^{8}$ Hip and knee surgery is associated with multiple expectations like symptom relief, improvement in physical functioning, and improvement in psychological well-being. ${ }^{9}$ Expectations play a critical role in hip surgery in particular because total hip replacement (THP) is an elective procedure, chosen to a large extent because of patients' desires for improved function and quality of life. ${ }^{10}$ It has been established for over four decades that many patients fear the anaesthesia, the unconsciousness, the operation, the post-operative pain and nausea. ${ }^{11}$

\section{Peri-operative physiological changes}

Surgery evokes a series of well-characterized hormonal, metabolic, haematological and immunological changes that are often described as the 'stress response' to surgery. ${ }^{12}$ In elective clean surgery the main release mechanism of the stress response is afferent neural stimuli from the surgical area. ${ }^{3}$ Blocking this afferent neural stimulus with local anaesthetics is a very effective method in reducing the classical catabolic response to surgery. ${ }^{3}$ Most elective orthopaedic procedures of the lower extremity are suitable for regional anaesthetics. However, hypotension due to spinal and epidural anaesthetics is a common side effect. The sympathic blockage causes vasodilatation that leads to a decrease in blood pressure. This relative fluid loss is reinforced by the absolute fluid loss through the blood loss during and after surgery. During surgery fluid starts to transsudate to the "third space". After transsudation exsudation can occur, as a result of increased capillary permeability, which is a part of the stress response. ${ }^{13}$ Changes in blood pressure, circulating volume, changes in pulmonary resistance or cardiac function can occur suddenly in (older) patients during cementing or reaming. ${ }^{13}$ Careful monitoring of these parameters and urinary output is essential to monitor the fluid balance. ${ }^{13}$ After surgery fluid changes and low substitution rates can lead to hypo-tension, nausea and vomiting. Together with pain, nausea and vomiting are the most common post-operative complaints. In addition to being unpleasant they may also be important factors limiting early discharge due to impaired rehabilitation. ${ }^{3}$

\section{EXPECTATIONS OF PATIENTS}

Expectations play a critical role in THR patients. ${ }^{10}$ It is important that patients and surgeons have consistent expectations to jointly work toward the same goals. 
Pagnano et al. ${ }^{14}$ found that patients' expectations regarding surgery were not associated with their age, gender, joint involved, marital status, or race. Expectations were not correlated with pre-operative functional health status. However, the expectation of complete pain relief after surgery was an independent predictor of better physical function and improvement. Also expectation of low risk of complications from total hip replacement was an independent predictor of the degree of satisfaction.

\section{Pre-OPERATIVE tRaINING}

Little evidence supports the use of pre-operative education to improve post-operative outcomes in patients undergoing hip or knee replacement surgery. Pain, physical functioning and length of hospital stay are hardly influenced. There is evidence that pre-operative education has a modest beneficial effect on pre-operative anxiety. ${ }^{14,15}$ There may also be beneficial effects when preoperative education is tailored according to anxiety, or targeted at those most in need of support (e.g. those who are particularly disabled, or have limited social support structures). ${ }^{15,16}$

\section{ANXIETY REDUCTION}

Personality traits and emotional state have a high impact on surgical outcome. ${ }^{17}$ Most authors describe a linear relation between surgical outcome and anxiety, with the lowest levels of anxiety predicting the best outcome. ${ }^{18,19}$ One should account for gender, age and previous experiences as these are pre-disposing factors for pre-operative anxiety. 20 Walker 20 recommended that preoperative information is given verbally with written supplements and that the patient should be encouraged to ask questions. The use of videotape preparation has been shown to be effective in reducing anxiety and stress, measured in terms of urinary cortisol excretion and intraoperative systolic blood pressure increase. Finally it prepared patients better to cope with postoperative pain. ${ }^{17}$

\section{MULTI-MODAL INTERVENTIONS}

Multi-modal interventions may lead to a major reduction in the undesirable sequelae of surgical injury with improved recovery and reduction in post-operative morbidity and overall costs. ${ }^{3}$ In optimising peri-operative care many intra-operative and post-operative outcomes have to be influenced pre-operatively. The success of a fast-track surgery program requires a multi-disciplinary approach involving anaesthesiologists, surgeons, nurses, and physical therapists. 5 Probably the most important clinician in fast-track surgery is the anaesthesiologist. Because this specialist has the best overview of the total medical process.

Current anaesthesia practice emphasises pre-operative optimisation, patient selection and education, improved peri-operative monitoring, more responsive fluid therapy (i.e. avoidance of hypovolemia and hypervolemia), maintenance of normothermia, and prevention of post-operative nausea and vomiting. ${ }^{21,22}$

The multimodal analgesia technique is focussed on blocking the nociceptive as well as the inflammatory response. Furthermore pain relief has to be present during rest as well as during movement (movement-evoked pain) to be able to participate in an aggressive rehabilitation 
program to prevent a further setback in physical condition. By preventing this setback a reduction in morbidity and mortality may be achieved.

The analgesic modalities available for post-operative pain management include regional or local techniques such as neuraxial analgesia and peripheral nerve blocks as well as wound infiltration and intra-articular or intra-cavity administration of local anaesthetics. Furthermore the COX-2 specific inhibitors have become popular for post-operative pain management. The literature suggests that two routes of administration, when compared with a single route, may be more effective in providing peri-operative analgesia. ${ }^{23}$ Besides, opioids sparing analgesia is desirable 24 to prevent adverse effects like nausea, vomiting, sedation, dizziness, drowsiness, bladder dysfunction, and constipation, all of which may contribute to a delayed recovery. 25

\section{Pain management}

Acute pain in the peri-operative setting is defined as pain present in a surgical patient because of pre-existing disease, the surgical procedure (with associated drains or complications) or a combination of disease related and procedure-related sources. ${ }^{23}$ Post-operative pain is influenced by clinical factors, patient related and hospital related factors. Clinical factors are site of incision, nature of analgesia and comorbidity. Patient related factors are: expectations, fear, pain experiences, foregoing analgesic use, loosing control, socio-cultural factors and gender. Hospital related is the organisational structure of the hospital. ${ }^{26}$ Advances in our understanding of the pathophysiology of post-operative pain have led to the development of effective peri-operative analgesia regimens. ${ }^{27}$ Several authors have emphasised the multimodal approach.3,5,27 The concept of multimodal or 'balanced' analgesia suggests that combinations of several analgesics of different classes and different sites of analgesic administration rather than single analgesic or single technique provide superior pain relief with reduced analgesic related side effects.3,25,27,28

The prerequisites for peri-operative pain management should include (but are not limited to): 1) Education and training for healthcare providers, 2) Monitoring of patient outcomes, 3) Documentation of monitoring activities, 4) Monitoring of outcomes at an institutional level, 5) 24-hour availability of anaesthesiologists providing peri-operative pain management, and 6) Use of a dedicated acute pain service. ${ }^{23}$

\section{FLUID BALANCE}

Choice of fluid substitution in clinical practice should be guided by an understanding of the biological and physicochemical parameters. Haemorrheology, haemostasis, vascular integrity, inflammatory cell function, and the magnitude and duration of intra-vascular volume expansion are influenced to varying degrees by the donation of different fluids. ${ }^{29}$ It is almost impossible to define "balanced" fluid management in an area full of controversies in the use of crystalloids/ colloids and among the colloids themselves and about which a vivid discussion is still going on. 30 There is continuing debate with regard to the timing, quantity and type of fluid resuscitation during elective major surgery. An increasing number of reports warns for excessive peri-operative intra-vascular volume loading, leading to increased post-operative morbidity and mortality. 31 Neither crystalloid nor colloid solutions can be expected to be ideal for every patient and in every situation. Most authors recommend a balanced approach to fluid management with colloid 
administration to provide haemodynamic stability and maintain urine output of $0.5 \mathrm{ml} / \mathrm{kg} / \mathrm{h}$ and crystalloids administered as maintenance fluids. ${ }^{31}$ The conclusion of a Cochrane review concerning peri-operative fluid volume optimisation following proximal femoral fracture was: invasive methods of fluid optimisation during surgery may shorten hospital stay, although their effects on other important, patient-centred, longer-term outcomes are uncertain. Adverse effects on fatality cannot be excluded. ${ }^{32}$ Avoiding the replacement of third space losses and pre-loading can significantly reduce the crystalloid load. ${ }^{31}$ Albumin and dextranes have barely any indication anymore as a plasma substitute. It seems that the ideal colloid has to be found in the new generation medium molecular hydroxyethylstarch fluids. ${ }^{30}$

\section{AnAEMIA}

Prosthetic surgery is associated with considerable blood loss and blood transfusions are frequently necessary. Even with haemovigilance an overall transfusion rate of 25 to 30 percent is still present. 33 Generally transfusion rates in literature vary from "blood less" surgery to up to $70 \%$. Blood transfusion is associated with a number of well-recognized risks and complications, including allergic reactions, transmission of infectious agents, and immunomodulatory effects. 34,35

The first step in modern transfusion medicine is to implement a restrictive transfusion policy. The introduction of this policy should be accompanied by thorough education of both medical and nursing staff. The education should be repeated several times to prevent a relapse to the less rigid regiment and to support the current policy. 33

Besides the restrictive policy several interventions to diminish the use of allogeneic blood are commonly in use. Frequently used alternatives are pre-operative erythropoietin injections, 36-38 pre-operative autologous blood donation, ${ }^{37,39-41}$ peri-operative ${ }^{42,43}$ and post-operative cell saving. 44,45

There are however, limited data about the relationship between anaemia and functional recovery. In clinical practise fatigue, weakness, and diminished physical performance are widely accepted signs of anaemia. ${ }^{46}$ Although blood transfusion increases haemoglobin levels the benefit on physical performance after surgery is unclear. During treadmill testing in normal healthy, fit subjects who underwent phlebotomy a reduction in maximum oxygen consumption $\left(\mathrm{VO}_{2, \max }\right)$ is proportional to haemoglobin level after phlebotomy.47-49 However, currently there is little clinical evidence that post-operative haemoglobin levels above $8 \mathrm{~g} / \mathrm{dl}$ improve functional recovery. One retrospective trial published by Lawrence et al. 46 demonstrated that post-operative increased haemoglobin levels are associated with better short-term functional recovery after hip fracture repair. Most of the published data relating anaemia to function have come from clinical trials evaluating recombinant human erythropoietin in end stage renal failure, orthopaedic surgery, and patients undergoing cancer chemotherapy. Unfortunately most studies were small with low statistical power and data from prospective trials are lacking. 50 In a recent prospective trial evaluating 200 patients four days after total hip replacement, no correlation between blood loss and a decline in power output was detectable. ${ }^{51}$ 


\section{MinIMAL INVASIVE HIP SURGERY}

In other types of surgery (laparoscopic colorectal resection, appendicitis, splenectomy and inguinal hernia repair), meta-analyses have been published demonstrating that despite longer operative times, scopic surgery had significant fewer complications and shorter average length of stay. ${ }^{52-57}$ For orthopaedic surgery only few and contradictory reports have been published about the results of less invasive surgery. Whether minimal invasive surgery is really less traumatic surgery remains to be established. Goldstein et al. ${ }^{58}$ argued that a smaller incision does not necessarily mean less pain or faster recovery. Kennon et al.59 only found cosmetic advantages. Finally, does functional recovery improve? Lawlor et al. 60 did not find any difference between a standard incision of $16 \mathrm{~cm}$ compared to single incision minimal invasive hip replacement $(\leq 10.0$ $\mathrm{cm})$. This was a single surgeon, prospective randomised blinded trial with functional recovery as primary outcome. The other contrasting studies like Wenz et al. 61 used a historical cohort and multiple surgeons. Di Gioia et al. ${ }^{62}$ who detected significant differences used a retrospective design with small patient numbers $(\mathrm{n}=33)$.

Finally, conventional hip replacement already provides excellent pain relief, functional improvement, and durability with a low complication rate. One might question whether implant malposition, neurovascular injury, poor implant fixation or compromised long term results might be the result of the reduced visualisation. ${ }^{63}$ Fehring et al. ${ }^{64}$ reported a series of three serious complications to illustrate the fears of bluntly adapting a new technique. As it is not known whether lower-volume and less-experienced surgeons can achieve similar results, the miniincision technique merits further study before wide implementation of this family of surgical approaches can be recommended.60,65

\section{Physical ReCOVERY}

Orthopaedic surgery innovations like minimal invasive surgery may contribute positively to optimising quality of care and further reduction in length of stay. Unfortunately little is known about the load and loadability during the first days after surgery. To justify a further reduction in length of stay, knowledge about recovery and physical loadability is needed. However, objective measures are lacking to estimate the true value of expensive innovations like minimal invasive surgery. One of the functional outcome measures is physical fitness. This requires cardiopulmonary exercise testing (CPX). Maximal power output is the simplest way to reflect performance ability. However, pain and motivation influence performance. Therefore, one needs to re-define maximal performance in these patients. To monitor physical recovery, regular cardiopulmonary exercise testing can be useful. Maximum symptom-limited cardio-pulmonary exercise testing after total hip replacement has been reported.66,67 During early post-operative exercise testing it was shown that patients had a drop in physical condition of about $23 \%$ on day four. 51

\section{Post-operative PHYSICAL therapy (PT)}

Reports about the usefulness of post-operative physical therapy, the intensity and duration are conflicting. Some reports with relatively long length of stays (LOS) are mostly negative about the usefulness of PT. Liang et al.68 found no differences in LOS, functional status or surgical complications, and Lang69 found no differences in LOS or discharge outcome if 6-days a week 
PT was compared to 7-days a week PT. Rapoport et al. ${ }^{70}$ and Hughes et al. ${ }^{71}$ however, found that weekend coverage reduced LOS. More recent reports found positive effects of PT. Gilbey et al. ${ }^{72}$ found a positive effect of an 8-week customized exercise program applied to patients scheduled for THR, followed by a post-surgery exercise program, compared to controls who received only routine in-hospital physical therapy. Freburger ${ }^{73}$ found that PT intervention was directly related to the total costs of care. These costs were less than expected and clearly weighed up to an increased probability of faster discharge home. Although post-operative PT seems useful, more research is needed to determine the optimal frequency and dosing of this therapy.

\section{NUTRITIONAL SUPPORT}

Surprisingly little evidence is available to support a significant impact of nutritional support on post-operative clinical outcomes. ${ }^{74}$ In theory the goals of peri-operative specialized nutrition support (SNS) are first to restore the nutritional status of a depleted patient pre-operatively, reduce operational risks, then to support the depleted patient through the catabolic phase induced by surgery, and finally to enhance the healing process and the return of gastro-intestinal function so normal oral food intake can be restored. ${ }^{75}$ SNS pre-operatively can be parenteral or enteral. Howard et al. ${ }^{75}$ concluded that pre-operative parenteral is only indicated in severely malnourished patients. For mildly or moderately malnourished patients parenteral nutrition clearly created more risk than benefit. 75 Routine post-operative parenteral nutrition is inappropriate, unless long-time oral food intake is disturbed. Howard et al. ${ }^{75}$ concluded that preoperative enteral nutrition is of benefit in malnourished patients and the benefit may be enhanced by using of immune-enhancing diets. However, the pre-operative home build-up expensive immune-enhancing formula is not yet feasible, and post-operative SNS is generally not indicated after surgery. ${ }^{76}$

\section{CONCLUSION}

It is clear that a multi-modal approach is essential in rapid recovery. The use of a critical pathway combining peri-operative pain management with a shift from general to local anaesthesia and opioid sparing, besides careful fluid management and restrictive transfusion policy, are the best options for most patients. The current tendency in fluid management is restrictive per-operative. A correct dosage of fluid therapy improves patient outcome after surgery, whereas correct fluid therapy is even more important when a restrictive blood transfusion policy is executed. The need for well-defined studies of intra-operative and post-operative fluid therapy are mandatory. Now most patients are treated in accelerated stay programs and even light morbidity like nausea and vomiting can prolong the length of stay. Pre-operative training does not seem to be beneficial except for anxiety reduction, whereas post-operative physical therapy is likely to be effective. Whether minimal invasive surgery contributes to faster recovery, remains to be established. Perioperative nutritional support has no place in elective hip and knee surgery. 


\section{Reference}

1. Pearson SD, Goulart-Fisher D, Lee TH. Critical pathways as a strategy for improving care: problems and potential. Ann Intern Med 1995;123(12):941-8.

2. Ethridge P, Lamb GS. Professional nursing case management improves quality, access and costs. Nurs Manage 1989;20(3):30-5.

3. Kehlet H. Multimodal approach to control postoperative pathophysiology and rehabilitation. Br J Anaesth 1997;78(5):606-17.

4. Kehlet H. Surgical stress response: does endoscopic surgery confer an advantage? World J Surg 1999;23(8):801-7.

5. Kehlet H, Wilmore DW. Fast-track surgery. Br J Surg 2005;92(1):3-4.

6. Giannoudis PV, Hildebrand F, Pape HC. Inflammatory serum markers in patients with multiple trauma. Can they predict outcome? J Bone Joint Surg Br 2004;86(3):313-23.

7. Smith RM, Giannoudis PV. Trauma and the immune response. J R Soc Med 1998;91(8):417-20.

8. Furstenberg AL. Expectations about outcome following hip fracture among older people. Soc Work Health Care 1986;11(4):33-47.

9. Mancuso CA, Sculco TP, Salvati EA. Patients with poor preoperative functional status have high expectations of total hip arthroplasty. J Arthroplasty 2003;18(7):872-8.

10. Liang MH, Katz JN, Phillips C, Sledge C, Cats-Baril W. The total hip arthroplasty outcome evaluation form of the American Academy of Orthopaedic Surgeons. Results of a nominal group process. The American Academy of Orthopaedic Surgeons Task Force on Outcome Studies. J Bone Joint Surg Am 1991;73(5):639-46.

11. Mitchell M. Patient anxiety and modern elective surgery: a literature review. J Clin Nurs 2003;12(6):806-15.

12. Hall GM, Peerbhoy D, Shenkin A, Parker CJ, Salmon P. Hip and knee arthroplasty: a comparison and the endocrine, metabolic and inflammatory responses. Clin Sci (Lond) 2000;98(1):71-9.

13. Hennis PJ, Leusink JA. Anesthesiologie. 1st ed. Houten: Bohn Stafleu van Loghem; 2002.

14. Pagnano MW, McLamb LA, Trousdale RT. Primary and revision total hip arthroplasty for patients 90 years of age and older. Mayo Clin Proc 2003;78(3):285-8.

15. Ackerman IN, Bennell KL. Does pre-operative physiotherapy improve outcomes from lower limb joint replacement surgery? A systematic review. Aust J Physiother 2004;50(1):25-30.

16. McDonald S, Hetrick S, Green S. Pre-operative education for hip or knee replacement. Cochrane Database Syst Rev 2004(1):CD003526.

17. Doering S, Katzlberger F, Rumpold G, Roessler S, Hofstoetter B, Schatz DS, et al. Videotape preparation of patients before hip replacement surgery reduces stress. Psychosom Med 2000;62(3):365-73.

18. Johnston M, Carpenter L. Relationship between pre-operative anxiety and post-operative state. Psychol Med 1980;10(2):361-7.

19. Johnston M. Pre-operative emotional states and post-operative recovery. Adv Psychosom Med 1986;15:1-22.

20. Walker JA. Emotional and psychological preoperative preparation in adults. Br J Nurs 2002;11(8):567-75.

21. Kehlet H, Dahl JB. Anaesthesia, surgery, and challenges in postoperative recovery. Lancet 2003;362(9399):1921-8.

22. Kehlet $\mathrm{H}$. Effect of postoperative pain treatment on outcome-current status and future strategies. Langenbecks Arch Surg 2004;389(4):244-9.

23. Ashburn MA, Caplan RA, Carr DB, Connis RT, Ginsberg B, Green CR, et al. Practice guidelines for acute pain management in the perioperative setting: an updated report by the American Society of Anesthesiologists Task Force on Acute Pain Management. Anesthesiology 2004;100(6):1573-81.

24. Wheeler M, Oderda GM, Ashburn MA, Lipman AG. Adverse events associated with postoperative opioid analgesia: a systematic review. J Pain 2002;3(3):159-80. 
25. Joshi GP. Multimodal analgesia techniques and postoperative rehabilitation. Anesthesiol Clin North America 2005;23(1):185-202.

26. van Kleef M, Weber WEJ, F. W, (redactie). ZWWA. Handboek pijnbestrijding. 1st ed. Leusden: De Tijdstroom; 2000.

27. Woolf CJ, Hashmi M. Use and abuse of opioid analgesics: potential methods to prevent and deter non-medical consumption of prescription opioids. Curr Opin Investig Drugs 2004;5(1):61-6.

28. Kehlet H, Dahl JB. The value of "multimodal" or "balanced analgesia" in postoperative pain treatment. Anesth Analg 1993;77(5):1048-56.

29. Grocott MP, Mythen MG, Gan TJ. Perioperative fluid management and clinical outcomes in adults. Anesth Analg 2005;100(4):1093-106.

30. van Zundert AAJ, Rohof MHC, Grouls RJE, van Suijlekom JA, Klein J, Kerkkamp HEM, et al. [Plasmavervangingsmiddelen; Is er een colloideale oplossing?] Plasma substitutes; Is there a ideal slution? Ned T v Anesthesiologie 2003;16:43-60.

31. Joshi GP. Intraoperative fluid restriction improves outcome after major elective gastrointestinal surgery. Anesth Analg 2005;101(2):601-5.

32. Price JD, Sear JW, Venn RM. Perioperative fluid volume optimization following proximal femoral fracture. Cochrane Database Syst Rev 2004(1):CD003004.

33. Pilot P, Moonen AFCM, Stuart WC, Bell CAMP, Bogie R, Pinckaers JWM, et al. Limited blood use; Succes due to restrictive policy, education and awareness. [Bloedverbruik aan banden; Succes dankzij restrictief transfusiebeleid, scholing en bewustwording. Med contact 2005;60(37):1467-9.

34. Vamvakas EC, Moore SB. Total potential frequency of autologous blood transfusion in Olmsted County, MN. Mayo Clin Proc 1995;70(1):37-44.

35. Pola E, Papaleo P, Santoliquido A, Gasparini G, Aulisa L, De Santis E. Clinical Factors Associated with an Increased Risk of Perioperative Blood Transfusion in Nonanemic Patients Undergoing Total Hip Arthroplasty. J Bone Joint Surg Am 2004;86(1):57-61.

36. de Andrade JR, Jove M, Landon G, Frei D, Guilfoyle M, Young DC. Baseline hemoglobin as a predictor of risk of transfusion and response to Epoetin alfa in orthopedic surgery patients. Am J Orthop 1996;25(8):533-42.

37. Faris PM, Ritter MA, Abels RI. The effects of recombinant human erythropoietin on perioperative transfusion requirements in patients having a major orthopaedic operation. The American Erythropoietin Study Group. J Bone Joint Surg Am 1996;78(1):62-72.

38. Goldberg MA, McCutchen JW, Jove M, Di Cesare P, Friedman RJ, Poss R, et al. A safety and efficacy comparison study of two dosing regimens of epoetin alfa in patients undergoing major orthopedic surgery. Am J Orthop 1996;25(8):544-52.

39. Billote DB, Glisson SN, Green D, Wixson RL. A Prospective, Randomized Study of Preoperative Autologous Donation for Hip Replacement Surgery. J Bone Joint Surg Am 2002;84(8):1299-1304.

40. Forgie MA, Wells PS, Laupacis A, Fergusson D, for the International Study of Perioperative Transfusion Investigators. Preoperative autologous donation decreases allogeneic transfusion but increases exposure to all red blood cell transfusion: results of a meta-analysis. Arch Intern Med 1998;158(6):610-616.

41. Mercuriali F, Inghilleri G, Biffi E. New approach to preoperative autologous blood donation (PABD). Int J Artif Organs 2000;23(4):221-31.

42. Colwell CW, Jr., Beutler E, West C, Hardwick ME, Morris BA. Erythrocyte Viability in Blood Salvaged During Total Joint Arthroplasty with Cement. J Bone Joint Surg Am 2002;84(1):23-5.

43. Huet C, Salmi LR, Fergusson D, Koopman-van Gemert AW, Rubens F, Laupacis A. A meta-analysis of the effectiveness of cell salvage to minimize perioperative allogeneic blood transfusion in cardiac and orthopedic surgery. International Study of Perioperative Transfusion (ISPOT) Investigators. Anesth Analg 1999;89(4):861-9. 
44. Southern EP, Huo MH, Mehta JR, Keggi KJ. Unwashed wound drainage blood. What are we giving our patients? Clin Orthop 1995(320):235-46.

45. Strumper D, Weber EW, Gielen-Wijfels S, Van Drumpt R, Bulstra S, Slappendel R, et al. Clinical efficacy of postoperative autologous transfusion of filtered shed blood in hip and knee arthroplasty. Transfusion 2004;44(11):1567-71.

46. Lawrence VA, Silverstein JH, Cornell JE, Pederson T, Noveck H, Carson JL. Higher Hb level is associated with better early functional recovery after hip fracture repair. Transfusion 2003;43(12):1717-22.

47. Ekblom B, Wilson G, Astrand PO. Central circulation during exercise after venesection and reinfusion of red blood cells. J Appl Physiol 1976;40(3):379-83.

48. Gledhill N. The influence of altered blood volume and oxygen transport capacity on aerobic performance. Exerc Sport Sci Rev 1985;13:75-93.

49. Woodson RD, Wills RE, Lenfant C. Effect of acute and established anemia on $\mathrm{O} 2$ transport at rest, submaximal and maximal work. J Appl Physiol 1978;44(1):36-43.

50. Carson JL, Terrin ML, Jay M. Anemia and postoperative rehabilitation. Can J Anaesth 2003;50(6 Suppl):S60-4.

51. Pilot P, Verburg AD, Moonen AFCM, Koolen JJ, van Os JJ, Geesink RGT, et al. Feasibility of early cardiopulmonary exercise testing after total hip arthroplasty. TATM 2005;7(1 (suppl)):68 (A33).

52. Memon MA, Cooper NJ, Memon B, Memon MI, Abrams KR. Meta-analysis of randomized clinical trials comparing open and laparoscopic inguinal hernia repair. Br J Surg 2003;90(12):1479-92.

53. Schwenk W, Haase O, Neudecker J, Muller J. Short term benefits for laparoscopic colorectal resection. Cochrane Database Syst Rev 2005;3:CD003145.

54. Sauerland S, Lefering R, Neugebauer EA. Laparoscopic versus open surgery for suspected appendicitis. Cochrane Database Syst Rev 2004(4):CD001546.

55. Winslow ER, Brunt LM. Perioperative outcomes of laparoscopic versus open splenectomy: a meta-analysis with an emphasis on complications. Surgery 2003;134(4):647-53.

56. Karayiannakis AJ, Makri GG, Mantzioka A, Karousos D, Karatzas G. Systemic stress response after laparoscopic or open cholecystectomy: a randomized trial. Br J Surg 1997;84(4):467-71.

57. Goodney PP, Birkmeyer CM, Birkmeyer JD. Short-term outcomes of laparoscopic and open ventral hernia repair: a meta-analysis. Arch Surg 2002;137(10):1161-5.

58. Goldstein WM, Branson JJ, Berland KA, Gordon AC. Minimal-Incision Total Hip Arthroplasty. J Bone Joint Surg Am 2003;85(90004):33-38.

59. Kennon R, Keggi J, Zatorski LE, Keggi KJ. Anterior approach for total hip arthroplasty: beyond the minimally invasive technique. J Bone Joint Surg Am 2004;86(suppl_2):91-97.

60. Lawlor M, Humphreys P, Morrow E, Ogonda L, Bennett D, Elliott D, et al. Comparison of early postoperative functional levels following total hip replacement using minimally invasive versus standard incisions. A prospective randomized blinded trial. Clin Rehabil 2005;19(5):465-74.

61. Wenz JF, Gurkan I, Jibodh SR. Mini-incision total hip arthroplasty: a comparative assessment of perioperative outcomes. Orthopedics 2002;25(10):1031-43.

62. DiGioia AM, Plakseychuk AY, Levison TJ, Jaramaz B. Mini-incision technique for total hip arthroplasty with navigation. J Arthroplasty 2003;18(2):123-8.

63. Berry DJ, Berger RA, Callaghan JJ, Dorr LD, Duwelius PJ, Hartzband MA, et al. Minimally invasive total hip arthroplasty. Development, early results, and a critical analysis. Presented at the Annual Meeting of the American Orthopaedic Association, Charleston, South Carolina, USA, June 14, 2003. J Bone Joint Surg Am 2003;85(11):2235-46. 
64. Fehring TK, Mason JB. Catastrophic complications of minimally invasive hip surgery. A series of three cases. J Bone Joint Surg Am 2005;87(4):711-4.

65. Ogonda L, Wilson R, Archbold P, Lawlor M, Humphreys P, O'Brien S, et al. A minimal-incision technique in total hip arthroplasty does not improve early postoperative outcomes. A prospective, randomized, controlled trial. J Bone Joint Surg Am 2005;87(4):701-10.

66. Ries MD, Philbin EF, Groff GD, Sheesley KA, Richman JA, Lynch F, Jr. Effect of total hip arthroplasty on cardiovascular fitness. J Arthroplasty 1997;12(1):84-90.

67. Ries MD, Philbin EF, Groff GD, Sheesley KA, Richman JA, Lynch F, JR. Improvement in cardiovascular fitness after total knee arthroplasty. J Bone Joint Surg Am 1996;78(11):1696-1701.

68. Liang MH, Cullen KE, Larson MG, Schwartz JA, Robb-Nicholson C, Fossel AH, et al. Effects of reducing physical therapy services on outcomes in total joint arthroplasty. Med Care 1987;25(4):276-85.

69. Lang CE. Comparison of 6- and 7-day physical therapy coverage on length of stay and discharge outcome for individuals with total hip and knee arthroplasty. J Orthop Sports Phys Ther 1998;28(1):15-22.

70. Rapoport J, Judd-Van Eerd M. Impact of physical therapy weekend coverage on length of stay in an acute care community hospital. Phys Ther 1989;69(1):32-7.

71. Hughes K, Kuffner L, Dean B. Effect of weekend physical therapy treatment on postoperative length of stay following total hip and total knee arthroplasty. Physiother Can 1993;45(4):245-9.

72. Gilbey HJ, Ackland TR, Wang AW, Morton AR, Trouchet T, Tapper J. Exercise improves early functional recovery after total hip arthroplasty. Clin Orthop Relat Res 2003(408):193-200.

73. Freburger JK. An analysis of the relationship between the utilization of physical therapy services and outcomes of care for patients after total hip arthroplasty. Phys Ther 2000;80(5):448-58.

74. Huckleberry Y. Nutritional support and the surgical patient. Am J Health Syst Pharm 2004;61(7):671-82.

75. Howard L, Ashley C. Nutrition in the perioperative patient. Annu Rev Nutr 2003;23:263-82.

76. Fearon KC, Luff R. The nutritional management of surgical patients: enhanced recovery after surgery. Proc Nutr Soc 2003;62(4):807-11. 



\section{CHAPTER 3}

\section{Critical pathway for hip and knee replacement; \\ Faster home due to multidisciplinary cooperation}

Pilot P, Engelen M, Dreessen F, van Os JJ, Kuipers H 


\section{ABstRact}

Clinical pathways (CP) for hip and knee replacements appear to be successful in reducing costs and length of stay in the acute care hospital, with no compromise in patient outcomes. These programs are proven to score excellent on quality indicators as well as high patient and health care professional satisfaction. We describe the principles, advantages and outcomes of the $\mathrm{CP}$ used in our hospital. 


\section{INTRODUCTION}

In the next decade a significant increase in total hip and knee replacements is expected. Until the year 2020 an increase of 50 percent can be expected..$^{1}$ This prognosis can be made based upon the ageing of the population and the implantation of prosthesis's in younger patients. ${ }^{1}$ Whereas the number of hospital beds will decrease to fulfil the clinical capacity norm set by the government. ${ }^{2}$ If no adjustments will be made waiting lists will increase. On the other hand intense pressure to reduce health care costs have led many health care organizations to seek strategies that reduce resource utilization while maintaining the quality of care. ${ }^{3}$ One of these initiatives was the development of critical pathways, also known as clinical pathways or care pathways. Critical pathways are management plans that display goals for patients and provide the corresponding ideal sequence and timing of staff actions to achieve those goals with optimal efficiency. ${ }^{3}$ They are designed to minimise delays and resource utilization and to maximize quality of care. ${ }^{4}$ The approach and goals of critical pathways are consistent with those of total quality management (TOM) and can be an important part of an organization's TOM process. ${ }^{4}$ Also the introduction of diagnose related groups (DRC's) in many countries have intensified the process of cost reduction.

In a recent literature review Kim et a1. 5 concluded that clinical pathways for hip and knee replacements appear to be successful in reducing costs and length of stay in the acute care hospital, with no compromise in patient outcomes. However, interpretation of these studies is complicated by substantial methodological limitations, particularly the use of historical controls and failure to account for length of stay in rehabilitation facilities. ${ }^{5}$ At this moment about twothirds of the Dutch hospitals use some kind of clinical pathway for the treatment of total hip or knee replacement. Half of these hospitals scored very well when seventeen quality indicators were tested. 6

In 1998 we started to search for a way to reduce length of stay (LOS) for our hip and knee replacements without loosing quality of care, overloading the (para-)medical staff or shifting care to the general practitioners. Finally we started in February 2000 with our first patients treated in a critical pathway for total hip and knee replacement. The program was introduced by an industrial partner and launched under the name 'Joint Care Orbis'. Following other hospitals proceeding Sittard, the project was carried out with two major goals: Improving quality of patient care for patients awaiting hip or knee replacement surgery. And secondly, realising a more efficient level of co-operation in and outside the boundaries of the hospital setting.

First we will describe the concept of the critical pathway we used. Secondly, a short presentation of the medical outcomes over the first four years is given. Finally, we will discus the gains and future aspects. 
New aspects of this healthcare concept were:

- More extensive information to the patient. The pre-, peri- and post-operative level of communication and information was optimised.

- Pre clinical planning of the total care project, also outside the hospital.

- The patient is not seen as 'sick' but as disabled. During the total program a coach guides the client. This coach is someone close to the patient.

- Group therapy and hospitalisation in living room simulation

- Intensive after care. A 24-hour call centre after discharge is available for patients during the first weeks. In case of problems direct contact with physical therapist or medical doctor can be made.

From the beginning of the project all hospital partners like 'home care nurses' and general practitioners were involved in the project. Through this a solid base for cooperation was established. Education and collective treatment were the corner stones of this new treatment approach. After the decision about hip or knee replacement was made, the patient was optimally informed. This process started when patients left the consulting-room and received an information chart. After this the pre-operation visit was scheduled. During this consult patients saw the orthopaedic surgeon, the anaesthesiologist, a physical therapist and a nurse. In addition, once every month a collective information meeting was held. During this meeting patients saw an instruction video, presentations of the previous mentioned specialities and a patient with his coach. In this meeting patients were able to ask questions and saw a patient who just had hip or knee replacement surgery.

At the night of admission all patients were admitted jointly. This started with an information video about the clinic, routine check up and blood sampling. After surgery patients received written instructions with the daily program each day. This information was also available in their info chart. Active rehabilitation started the day after surgery and the day before discharge the patients were briefed by the ward doctor, physical therapist and the nurse about the time after hospitalisation. This session was ended with a video about the situation at home.

Maximum effort of the patient in arranging front care was the starting point in transmural healthcare planning (defined as the interface between primary and secondary health care). Wherever needed assistance was given. After discharge, a shift of hospital care towards home nursing care was prevented. During the pre clinical visit estimation was made about the care needed after discharge. The official government organ estimated home care neediness before admission instead of during admission. Clear criteria were present to make the judgement about the provided care. By doing so, a better capacity planning of the home care institution was possible. After the total care program was taken care of, the operation date was confirmed.

The patients started their rehabilitation the day after surgery. When they all walked to a living room. This room was patient friendly, without beds and patients stayed here all day in specially designed chairs. The chairs were designed in a way that patients could change the position to a supine one by their selves. In this room all activities took place like physical therapy, lunch and also the resting hours.

Early involvement of the relatives had two advantages. Firstly, the hospitalisation was less of a threat to the patient due to the presence of a coach. This coach could relieve the nursery 
from some tasks like handing coffee of walking the patient to the toilet. These things provided a confident return home for the patient and his relatives. Secondly, the nurse could shift her task during the hospitalisation from care to guiding tasks. The time won in this process could be used to answer the phone calls at the helpdesk or perform the telephonic interviews after discharge. In daily practise most patients were able to provide their own coach, if this was not possible other coaches of the group took over this role. In the daily process coaches made arrangements with each other about their presence. At discharge no other measures than in the old situation were taken.

One of the goals of the project was to prevent a shift of care towards the first line due to the shortening of LOS. Therefore the following measurements were taken: Two days after discharge the home nurse service provides wound care. They had received thorough instructions by the hospital. The coach took part in the communication with the care providers. A telephonic helpdesk is available 24-hours a day. Two weeks after surgery the stitches were removed at home.

\section{RESULTS}

The first consecutive series of patients were evaluated. ${ }^{7}$ These patients were operated on from February 2000 to February 2004. Because the Joint Care ${ }^{\circledR}$ program had limited capacity only $45 \%$ of all hips was treated in this critical pathway. Of these total hip replacements (THR) 92\% was discharged at the fifth post-operative morning. Half of all patients who were not discharged had wound related problems; most of these patients were discharged two days later. Readmission rate was 6.4 percent of all patients. Half of these patients were readmitted because they dislocated their hip prosthesis. Some of these dislocations were years after the operation. ${ }^{7}$ Surgical debridement was needed in $1.2 \%$ of all cases. None of these patients had an extraction of their prosthesis. Serious complications like infection, luxation and pulmonary embolism were comparable to literature. ${ }^{8-10}$

Because initially only ASA I and II patients were treated in Joint Care ${ }^{\circledR}$ we choose not to compare them with the patients treated outside the program. The selection bias can be a large confounder, especially for length of stay. But on the other hand we believe that compromised patients would benefit more from an accelerated stay program than the relatively fit patients. Because patients with very low physical conditions are more prone to serious complications. ${ }^{11}$ And after hip replacement surgery patients showed a major setback in physical condition, on average 23 percent. ${ }^{12}$ In regular treatment these compromised patients might suffer most from the tranquil period present during the first days after surgery. Whereas in accelerated stay programs this problem might be less.

\section{FUTURE}

Critical pathways are management plans to achieve goals with optimal efficiency ${ }^{3}$ and to maximize quality of care. ${ }^{4}$ Maybe a more extensive approach of the CP was made by Kehlet and co-workers who synthesized, integrated and applied research information in a comprehensive programme, now commonly referred to as 'fast-track surgery'.13 The success of a fast-track surgery program requires a multidisciplinary approach involving anaesthesiologists, surgeons, 
nurses, and physical therapists. ${ }^{13}$ The thrust of this fast track approach was to reduce the physiological and psychological stresses associated with operations, thereby reducing potential complications. In optimising peri-operative care many intra-operative and post-operative outcomes have to be influenced pre-operatively. ${ }^{14}$ Fast-track surgery evolved as a coordinated effort, combining modern concepts of patient education with newer anaesthetic and analgesic methods and minimally invasive surgical techniques; the intention was to reduce the stress response, and minimize pain and discomfort. The key pathogenic factor in post-operative morbidity, excluding failures of surgical and anaesthetic technique, is the surgical stress response with subsequent increased demands on organ function. ${ }^{14}$ Therefore pre-operative optimisation, improved peri-operative monitoring, early resuscitation, more responsive fluid therapy (i.e., avoidance of hypovolemia and hypervolemia), maintenance of normothermia, and prevention of post-operative nausea and vomiting 15,16 are the challenges.

\section{CONCLUSION}

In summery, if we evaluated the first four years of total hip and knee replacement in a critical pathway a continuum of the care chain was made. A reduction in the LOS without compromising the quality of care or reduction in the self-supportiveness of the patients was established. Patients treated outside the critical pathway are currently treated in almost the same way, except for the group treatment and the use of a coach. All other aspects are the same. For further reduction in LOS, without compromising the quality of care, reducing the surgical stress response might be the most logical step. 


\section{REFERENCES}

1. Ostendorf M, Johnell O, Malchau H, Dhert WJ, Schrijvers AJ, Verbout AJ. The epidemiology of total hip replacement in The Netherlands and Sweden: present status and future needs. Acta Orthop Scand 2002;73(3):282-6.

2. Wet ziekenhuisvoorziening richtlijnen ex artikel 3. Beleid ten aanzien van nieuwbouw Maasland ziekenhuis. 1994:blz 7.

3. Pearson SD, Goulart-Fisher D, Lee TH. Critical pathways as a strategy for improving care: problems and potential. Ann Intern Med 1995;123(12):941-8.

4. Coffey RJ, Richards JS, Remmert CS, LeRoy SS, Schoville RR, Baldwin PJ. An introduction to critical paths. Qual Manag Health Care 1992;1(1):45-54.

5. Kim S, Losina E, Solomon DH, Wright J, Katz JN. Effectiveness of clinical pathways for total knee and total hip arthroplasty. The Journal of Arthroplasty 2003;18(1):69-74.

6. Legierse C, Hardus K, van Rijnsoever M, Verbout A, Marting I, Matthijssen R, et al. Quality compared [kwaliteit vergeleken]. Med Cont 2004;59(50):1990-3.

7. Bogie R, Pilot P, van Os J, Draijer W. [Klinische resultaten van vier jaar totale heup plaatsing in een geïntegreerd heup- en knieprogramma] Clinical results of four years of THA in an intergrated hip- and knee programm. Medisch Contact 2005;60(12):496-8.

8. Blom AW, Taylor AH, Pattison G, Whitehouse S, Bannister GC. Infection after total hip arthroplasty. The Avon experience. J Bone Joint Surg Br 2003;85(7):956-9.

9. Phillips CB, Barrett JA, Losina E, Mahomed NN, Lingard EA, Guadagnoli E, et al. Incidence rates of dislocation, pulmonary embolism, and deep infection during the first six months after elective total hip replacement. J Bone Joint Surg Am 2003;85-A(1):20-6.

10. Williams O, Fitzpatrick R, Hajat S, Reeves BC, Stimpson A, Morris RW, et al. Mortality, morbidity, and 1-year outcomes of primary elective total hip arthroplasty. J Arthroplasty 2002;17(2):165-71.

11. Older P, Smith R, Courtney P, Hone R. Preoperative evaluation of cardiac failure and ischemia in elderly patients by cardiopulmonary exercise testing. Chest 1993;104(3):701-4.

12. Pilot P, Verburg A, Moonen A, Koolen J, van Os J, Geesink R, et al. Feasibility of early cardiopulmonary exercise testing after total hip arthroplasty. TATM 2005;7(1 (suppl)):68 (A33).

13. Kehlet H, Wilmore DW. Fast-track surgery. Br J Surg 2005;92(1):3-4.

14. Kehlet H. Multimodal approach to control postoperative pathophysiology and rehabilitation. Br J Anaesth 1997;78(5):606-17.

15. Kehlet H, Dahl JB. Anaesthesia, surgery, and challenges in postoperative recovery. Lancet 2003;362(9399):19218.

16. Kehlet $\mathrm{H}$. Effect of postoperative pain treatment on outcome-current status and future strategies. Langenbecks Arch Surg 2004;389(4):244-9. 



\section{CHAPTER 4}

\section{Feasibility of early maximal cardiopulmonary exercise testing after total hip replacement}

Pilot P, Verburg AD, Moonen AFCM, Koolen JJ, van Os JJ, Geesink RGT, Kuipers H

Feasibility of early maximal cardiopulmonary exercise testing after total hip (NTvO 2006;13(1):17-22) 


\section{Abstract}

\section{Background}

Total hip replacement has been the most successful orthopaedic operation of the last decades. Nowadays, most patients are treated in accelerated or short stay programs. To determine the success of modifications in surgical procedures and early rehabilitation programs a better knowledge of the physiologic alterations after surgery is necessary.

\section{Methods}

Cardiovascular fitness was assessed in 50 primary total hip patients. Patients performed an incremental increase exercise test on a cycle ergometer with continuous ECG and a metabolic cart. All patients were pre-operatively divided into three groups based on their physical condition.

\section{Results}

In all three groups a clear decline in exercise capacity shortly after surgery was seen, all groups showed a fast recovery in the first three weeks. After this period a steady recovery towards 'complete' recovery is seen. No exercise test had to be terminated premature due to adverse events.

\section{Conclusions}

Early post-operative exercise testing is feasible in patients shortly after total hip replacement. Patients showed a reduction in exercise capacity of 22 percent and this capacity had normalised almost completely after three months. No significant cardiac abnormalities were noticed during exercise testing of these healthy patients. 


\section{INTRODUCTION}

Total hip replacement has been the most successful major orthopaedic intervention of the last decades. Nowadays, most patients are treated in accelerated or short stay programs, in which hospital stay is reduced to five or six days. ${ }^{1}$ Besides the significant reduction in length of stay the transfusion policy is changed to a restrictive one due to the known risks of allogeneic blood transfusions. ${ }^{2}$ After total hip replacement patients suffer from so called 'surgical stress'. The body responds to the surgical stress with profound changes in neural, endocrine and metabolic systems in addition to alterations in organ function. ${ }^{3}$ Symptoms of surgical stress are nausea and vasovagal reactions.

Recent innovations like minimal invasive surgery might contribute positively to a further reduction in length of stay. However, little is known about the load and loadability during the first days after surgery. To justify a further reduction in length of stay, knowledge about recovery and physical loadability is needed. Unfortunately, objective measures are lacking to estimate the true value of expensive innovations like minimal invasive surgery. One of the functional outcome measures is physical fitness. This requires cardiopulmonary exercise testing (CPX). Although the feasibility of CPX testing in arthritis patients has already been established, ${ }^{4-8}$ no reports about CPX testing four days after surgery have been published.

Objectives of this study were to develop a test protocol and assess the feasibility of this early maximum symptom limited cardiopulmonary exercise testing. Furthermore we wanted to obtain reference values of cardiovascular fitness before and after surgery.

\section{MATERIALS AND METHODS}

After consenting, 50 patients were included in an accelerated stay program project (Joint Care ${ }^{\circledR}$, Biomet, The Netherlands) after total hip replacement. Excluded were patients with recent cardiac or pulmonary complaints. Well-regulated hypertension was no contra indication. Cardiovascular fitness was assessed in 50 healthy patients scheduled to undergo elective primary total hip surgery. Patients average age was 63, (range 39-82). The study was approved by the institutional review board of our hospital. All patients received written study information and signed an informed consent. After consenting, patients who volunteered to participate in the study, performed a symptom limited incremental exercise test on a cycle ergometer for assessment of cardiovascular fitness. This test was conducted within two weeks prior to surgery.

In the present study the cycle ergometer was preferred because work-out efficiency is more similar between trained and untrained, young and old, male and female subjects compared to a treadmill. Besides, patients with end stage osteoarthritis prefer cycling to walking and cycling is a familiar mode of exercise in Dutch patients.

Crank length was reduced from $17.5 \mathrm{~cm}$ to $8 \mathrm{~cm}$ to diminish range of flexion needed in the hip to be able to compare the subjects with total knee patients in a later stage. The frequency had to be more than 40 revolutions (rpm) per minute whereas no maximum rate was set. During testing, a multi-channel ECG was recorded. Patients performed a four stage, incremental increase exercise test on a Recohr P cycle ergometer (Lode, Groningen, the Netherlands). Crank length was reduced.

\section{Exercise protocol}

After calibration of the metabolic cart, the patient was seated on the ergometer. Each patient was instructed about the test and the stop criteria. The ECG electrodes and the metabolic cart were 
connected. The exercise protocol had four stages, warming-up, sub-maximal, incremental symptom limited maximal phase, cooling-down. After two minutes of warming up at 0 watt, the sub maximal phase consisted of 2 minutes at 20 watts, two minutes at 40 watts and two minutes at 60 watts. After the sub-maximal phase the workload was increased every minute, by 10 watts. After the incremental phase the cooling down was the same as the warming-up phase.

The test protocol was designed in such a way that most tests would take approximately 10 minutes after warming-up, which is considered an optimal test length. ${ }^{9}$ Stop criteria were defined: if the patient wants to stop, ST-depression of $>3 \mathrm{~mm}$, Significant T-top changes, increase in ectopic beats during incremental load, chest pain, decreased consciousness, or any negative observation that seems clinically relevant to the investigator.

Inspiratory and expiratory gases were analysed using a metabolic cart (Oxycon Delta, Jaeger Tonnies). 'Breath by Breath' analysis was used to measure the oxygen consumption $\left(\mathrm{VO}_{2} ; \mathrm{ml} / \mathrm{min}\right)$, carbon dioxide production $\left(\mathrm{VCO}_{2} ; \mathrm{ml} / \mathrm{min}\right)$ and minute ventilation (Ve; $\left.1 / \mathrm{min}\right)$. To assess cardiovascular fitness the maximum $\mathrm{VO}_{2}$, maximum Wattage and Wattage at $\mathrm{RER}=1.0$ were used as primary outcome parameters. The abbreviations of physiological variables used in study are listed in Table 1. Patients were tested pre-operatively, and on day 4, 23, 39, and day 90 post-surgery.

$\begin{array}{ll}\text { Table 1. } & \text { Abbreviations of the physiological variables } \\ & =\text { maximum power output produced by the patient } \\ \mathrm{W}_{\max } & =\text { maximum oxygen consumption }(\mathrm{ml} / \mathrm{min}) \\ \mathrm{VO}_{2, \max } & =\text { carbon dioxide production }(\mathrm{ml} / \mathrm{min}) \\ \mathrm{VCO}_{2} & =\text { minute ventilation }(\mathrm{L} / \mathrm{min}) \\ \mathrm{Ve} & =\text { Respiratoire exchange ratio } \\ \mathrm{RER} & =\text { Percentage of Age Predicted Maximum Target Heart Range } \\ \% \mathrm{APMTHR} & =\text { Metabolic equivalent of resting value }\end{array}$

Maximal exercise is defined as reaching 85 percent of the age predicted maximum target heart rate (APMTHR) ${ }^{10}$ or respiratory exchange ratio (RER) above 1.0. After the initial exercise test patients were classified according to the American Heart Association. ${ }^{9}$ This classification is based on oxygen uptake, age and gender. Dividing patients into the poor, average or good condition group.

\section{Surgery}

The majority of patients was operated on under spinal anaesthesia (90\%). The approach was in $72 \%$ straight lateral and $28 \%$ postero-lateral. In $46 \%$ uncemented, $30 \%$ cemented, $20 \%$ hybrid and $4 \%$ reversed hybrid. Head size was $28 \mathrm{~mm}$ in all cases.

\section{Data handling and statistical analysis}

The data were stored in a database and ANOVA analyses with post-hoc multiple comparisons, using the Bonferroni correction, were done. Alpha was set on 0.05 on the mean variables. The analysis was done with SPSS 10.0.5 (SPSS Inc. Chicago Illinois). 


\section{RESULTS}

50 patients were included in the study. During the study period two patients dropped out, one patient after the clinical period because of dislocation of the prosthesis, the other after a trauma at home, which had no relationship with the study. The data gather of these patients were analysed according to 'the intention-to-treat' principle.

Patient characteristics are shown in Table 2, and the exercise test values are presented in Table 3. Patients were stratified by pre-operative condition into groups according to the AHA classification. ${ }^{9}$ Age and gender were accounted for in this classification. These data are shown in Figures 1, 2.

Table 2. Patient characteristics of the patients divided into groups by pre-operative condition by criteria of the AHA

\begin{tabular}{|c|c|c|c|c|c|c|c|c|c|c|}
\hline & & \multicolumn{3}{|c|}{ poor/fair ( $\mathrm{N}=19)$} & \multicolumn{3}{|c|}{ Moderate $(\mathrm{N}=24)$} & \multicolumn{3}{|c|}{ Good (N=7) } \\
\hline & & Average & Range & STDEV & Average & Range & STDEV & Average & Range & STDEV \\
\hline Age (yr) & $y r$ & 66 & $39-82$ & 12.5 & 63 & $51-77$ & 6.5 & 61 & $51-67$ & 4.9 \\
\hline Weight & $\mathrm{kg}$ & 80 & $67-100$ & 8.2 & 74 & $57-94$ & 8.5 & 76 & $63-85$ & 9.6 \\
\hline Length & $m$ & 1.72 & $1.55-1.85$ & 0.081 & 1.69 & $1.55-1.80$ & 0.067 & 1.72 & $1.6-1.78$ & 0.059 \\
\hline $\begin{array}{l}\text { Body mass } \\
\text { index }\end{array}$ & $\mathrm{kg} / \mathrm{m}^{2}$ & 27.2 & $22.6-32.3$ & 2.4 & 25.9 & $22.8-31.4$ & 2.3 & 25.9 & $20.8-29.4$ & 3 \\
\hline $\begin{array}{l}\text { Harris Hip } \\
\text { Score }\end{array}$ & & 54 & $32-73$ & 12.3 & 60 & $44-79$ & 9.3 & 62 & $31-94$ & 21.8 \\
\hline
\end{tabular}

All patients showed a clear reduction of power output (Watt) and oxygen consumption $\left(\mathrm{VO}_{2, \max }\right)$ post-surgery. In all three groups a clear decline shortly after surgery was seen, all groups showed a fast recovery in the first three weeks (Figures 1,2). After this period a steady recuperation towards 'complete' recovery was seen. Only the recovery of the anaerobic threshold was not observed within this period (Table 3). It was notable that the patient group with a preoperatively good condition showed a power output on day 4 that was higher than the average value of the other two groups pre-operatively.

A number of patients did not achieve maximal effort, as defined, on the pre-test. These results were shown in Figure 3. These patients also had a major decline in power output early after surgery. Significant detail was the set back seen three months after an initial improvement during the weeks after surgery.

Cardiac events did not occur. No exercise test had to be terminated prematurely due to abnormalities on the ECG, sign of ischaemic heart disease or pain in the operated leg. None of the patients had a negative test, nor did any patient receive additional pain medication in order to be able to cycle.

All patients were able to perform the testing on day two after surgery. Not all patients reached the preset level (56\% achieved complete testing).

\section{Statistics}

For $\mathrm{VO}_{2, \max }$ the ANOVA was significant for all moments except day 90. Post-hoc analysis showed that the poor condition group was significantly different from the good condition group at all 
Table 3. Exercise variable.

\begin{tabular}{|c|c|c|c|c|c|c|c|c|}
\hline & & \multicolumn{3}{|c|}{ pre operative $(\mathrm{N}=50)$} & \multicolumn{3}{|c|}{ day $4(\mathrm{~N}=49)$} & \multirow[b]{2}{*}{$\%$ pre } \\
\hline & & Ave. & Range & SD & Ave. & Range & SD & \\
\hline Maximum workload & W & 106 & $(41-195)$ & 41.3 & 79 & $(22-138)$ & 30.9 & 78 \\
\hline Peak heart rate & BPM & 134 & $(96-167)$ & 18 & 132 & $(97-163)$ & 18 & 100 \\
\hline$\%$ predicted max. target HR & $\%$ & 86 & $(64-105)$ & 10.3 & 85 & $(62-100)$ & 10.2 & 99 \\
\hline Peak V02 & $\mathrm{ml} / \mathrm{min}$ & 1747 & $(820-3188)$ & 603 & 1381 & $(599-2436)$ & 375 & 79 \\
\hline $\begin{array}{l}\text { Peak V02 corr. Body weight } \\
\text { percentage of pred V02 }\end{array}$ & $\mathrm{ml} / \mathrm{kg} / \mathrm{min}$ & 22.5 & $(11.1-36.3)$ & 6.3 & 17.8 & $(9.5-26.4)$ & 4.0 & 79 \\
\hline total ventilation & $\mathrm{L} / \mathrm{min}$ & 56.1 & $(21.1-110)$ & 21.1 & 52.5 & $(17.9-91.3)$ & 16.1 & 94 \\
\hline oxygen pulse & $\mathrm{ml} /$ beat & 12.7 & $(6.5-22.3)$ & 3.5 & 10.3 & $(6.1-17.2)$ & 2.5 & 81 \\
\hline RER at peak exercise & & 1.04 & $(0.87-1.27)$ & 0.09 & 1.08 & $(0.81-1.26)$ & 0.1 & 104 \\
\hline Anaerobic threasurehold & $\mathrm{ml}$ & 1604 & $(919-3080)$ & 523 & 1214 & $(623-2162)$ & 322 & 76 \\
\hline AT corr. Body weight & $\mathrm{ml} / \mathrm{min} / \mathrm{kg}$ & 20.3 & $(12.3-26.2)$ & 5.54 & 15.2 & $(9.9-21.5)$ & 3 & 75 \\
\hline W at AT & W & 91 & $(25-195)$ & 37.5 & 64.7 & $(25-120)$ & 23.3 & 71 \\
\hline $\mathrm{HF}$ at AT & BPM & 126 & $(102-167)$ & 16.1 & 124 & $(75-156)$ & 15.7 & 98 \\
\hline percentage $R E R>1,0$ & $\%$ & 70 & & & 82 & & & 117 \\
\hline percentage $>85 \%$ APTHR & $\%$ & 48 & & & 53 & & & 110 \\
\hline$\%$ RER $>1,0$ of $>85 \%$ APTHR & $\%$ & 78 & & & 86 & & & 110 \\
\hline$\%$ RER $>1,0+>85 \%$ APTHR & $\%$ & 40 & & & 51 & & & 128 \\
\hline
\end{tabular}

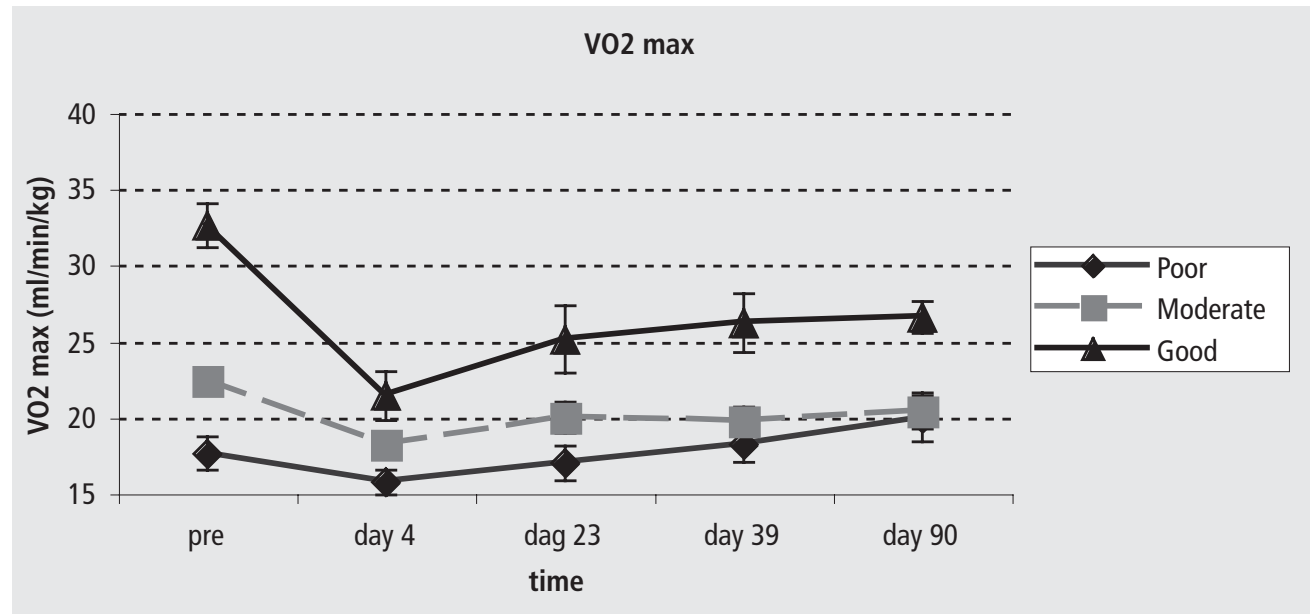

Figure 1. $\quad \mathrm{VO}_{2, \max }$ values of the three patient groups as function over time. All points are \pm S.E.M. 


\begin{tabular}{cccccccccccc}
\multicolumn{1}{c}{ day $23(\mathrm{~N}=40)$} & \multicolumn{1}{c}{ day 39 $(\mathrm{N}=45)$} & \multicolumn{3}{c}{3 months(N=41) } \\
Ave. & Range & SD & \% pre & Ave. & Range & SD & $\%$ pre & Ave. & Range & SD & $\%$ pre \\
\hline 94 & $(44-153)$ & 32.6 & 87 & 100 & $(45-170)$ & 33 & 94 & 107 & $(47-181)$ & 36.2 & 102 \\
138 & $(102-167)$ & 16.5 & 103 & 139 & $(106-173)$ & 17.0 & 103 & 137 & $(101-161)$ & 16.3 & 102 \\
88 & $(67-109)$ & 10 & 102 & 89 & $(71-105)$ & 9.9 & 103 & 87 & $(61-105)$ & 9.9 & 101 \\
1559 & $(848-3024)$ & 484 & 89 & 1612 & $(842-3084)$ & 507 & 92 & 1660 & $(925-2903)$ & 515 & 95 \\
20.1 & $(12.1-32.2)$ & 5.2 & 89 & 20.6 & $(12.0-32.8)$ & 5 & 92 & 21.2 & $(12.1-35.1)$ & 5.3 & 94 \\
& & & & & & & & & & & \\
57.9 & $(28.9-110)$ & 20.2 & 103 & 58.6 & $(27.8-112)$ & 19.6 & 104 & 61.9 & $(29.9-108)$ & 20.5 & 110 \\
11.1 & $(6.6-20.0)$ & 3.1 & 87 & 11.4 & $(6.8-19.2)$ & 2.9 & 90 & 12.0 & $(7.5-19.0)$ & 3.1 & 95 \\
1.12 & $(0.97-1.26)$ & 0.10 & 108 & 1.14 & $(0.98-1.38)$ & 0.09 & 110 & 1.16 & $(0.99-1.37)$ & 0.10 & 112 \\
1239 & $(734-2625)$ & 482 & 77 & 1260 & $(772-2506)$ & 367 & 78.6 & 1307 & $(767-2421)$ & 394 & 82 \\
15.8 & $(10.1-27.9)$ & 4.3 & 78 & 16.3 & $(9.7-28.0)$ & 3.6 & 80.3 & 15.9 & $(10.2-28.2)$ & 4.5 & 78 \\
64 & $(20-115)$ & 25.5 & 70 & 73 & $(40-132)$ & 26.1 & 80.2 & 71 & $(25-150)$ & 30.2 & 78 \\
122 & $(87-158)$ & 15.4 & 97 & 121 & $(81-158)$ & 15.7 & 96 & 117 & $(73-142)$ & 16.1 & 93 \\
88 & & & 126 & 89 & & & 127 & 98 & & & 140 \\
68 & & & 142 & 67 & & & 140 & 63 & & & 131 \\
95 & & & 122 & 93 & & & 119 & 98 & & & 126 \\
59 & & & 148 & 64 & & & 160 & 63 & & & 158 \\
\hline
\end{tabular}

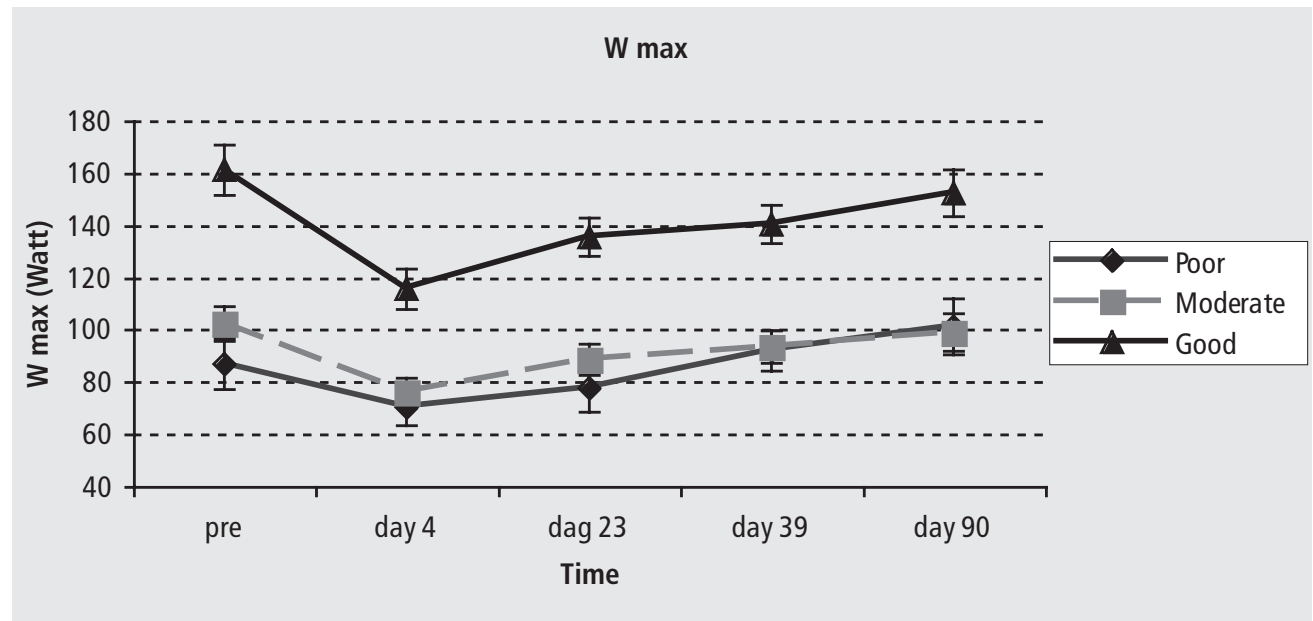

Figure 2. Maximum power output (Watt) of the three patient groups as function of time. All points are \pm S.E.M. 


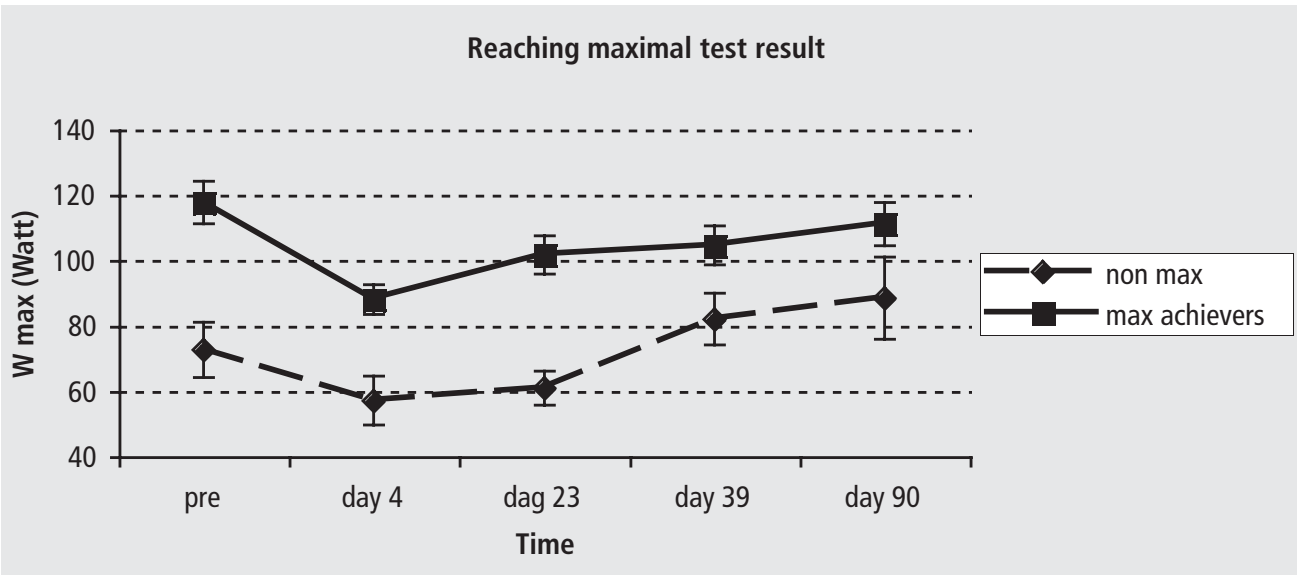

Figure 3. The total patient group divided into two groups; Maximal achiever reached a maximum test result on the pre test and day 4 test. Maximum test was defined as reaching 85\% APMTHR or RER above 1.0. All points are \pm S.E.M.

moments except from day 90 (all $\mathrm{p}<0.01$ ). The average condition group was only pre-operatively significantly different $(p<0.001)$ from the other two groups. This difference was not significant after surgery except for day 39 ( $p=0.007)$.

For $\mathrm{W}_{\max }$ the ANOVA was significant for all moments. Post-hoc analysis showed that the poor condition group was significantly different from the good condition group at all moments (all $p<0.022$ ). The poor and average group did not. The average and good groups were significantly different at all moments $(p<0.01)$.

\section{Discussion}

The feasibility of pre-operative and three months post-operative exercise testing in patients with osteoarthritis has been shown in several studies.4-8 In this study it was shown that it is also feasible and safe to perform CPX testing in healthy patients on the fourth post-operative day. Pain in the operated leg was no limiting factor. On average, patients showed a decrease in power output of about $22 \%$, independent of their ability to perform maximal effort.

On day four patients showed a reduction of 22 percent in power output, $21 \%$ in maximum oxygen transport capacity and a 24 percent decrease in anaerobic threshold (AT). Because peak heart rate in these patients was the same and total ventilation only decreased six percent it can be said that patients had a similar maximum test but reached a lower output. Blood loss and surgical stress probably explain this reduction. The pre-operative values we measured were slightly higher than found by Philbin et al. ${ }^{5}$ (106 vs. 83 Watt and 22.5 vs. $15.1 \mathrm{ml} / \mathrm{min} / \mathrm{kg}$ ). This difference is probably because we used a younger patient population (64 vs. 68 Yrs; BMI: 26.4 vs. 30.3). Also the reduction in crank length might have contributed positively.

The reason that the pre-operatively fit patients have a larger decline in exercise capacity and oxygen consumption may be explained by the fact that physically active patients suffer more 
from this quiescent period. This, in contrast to patients with a fair or poor condition, who are activated by the rehabilitation process.

Most patients function normally three to six months after surgery. Although routines in daily life can be performed without limitations, it is to be expected that a further recovery of exercise capacity can be seen after three months. $6,8 \mathrm{~A}$ possible confounder can be other joint involvement. Most patients in our study population presented an exercise capacity comparable to a normal nonosteoarthritis population. For this reason, it is difficult to predict the final 'endpoint' of activity level.

Post-operative (day 4) fitness parameters in physically fit patients were higher than preoperative values of the rest of the group (Figure 1). Besides family care, the two important factors influencing time of discharge from hospital are wound healing and physical recovery. In our normal population 92 percent is discharged, according to protocol, on the fifth post-operative morning. ${ }^{1}$ When LOS is further reduced, physical load during rehabilitation will increase. The use of pre-operative exercise testing might be helpful to judge whether patients are suited for faster discharge than the regular set duration of five days. Because the non-maximal achiever showed similar decline in exercise capacity (Figure 3), motivation is also an important factor. This motivation can be tested with CPX testing.

One of the most demanding activities of daily life (ADL) is climbing stairs. This exercise starts on day three of rehabilitation and takes four times the resting metabolic rate (4 METs). ${ }^{10}$ For patients with a moderate or good physical condition this is below anaerobic threshold. For most patients in the fair or poor condition group this is below peak oxygen consumption but above AT and must be classified as strenuous exercise. It is clear that in our healthy group this exercise can be done early after surgery without cardiac risks because no relevant cardiac abnormalities were manifest at exercise testing. However, if this is also true for total joint replacement patients with serious co-morbidity remains to be seen. Older et al. ${ }^{11}$ reported a three times higher mortality rate in major abdominal surgery for patients with an anaerobic threshold below $11 \mathrm{ml} / \mathrm{min} / \mathrm{kg}(5.9 \%$ versus $18 \%)$, and a ten times higher mortality in patients with a known ischaemic cardiac history (4\% versus $42 \%$ ). In our data almost all patients had an AT above $11 \mathrm{ml} / \mathrm{kg} / \mathrm{min}$ and showed no pre-operative ischaemia.

In conclusion, our results show that it is feasible and safe to perform maximum symptom limited CPX testing in patients four days after total hip replacement. It is safe to test a larger population. Exercise capacity of patients is reduced by 22 percent early after surgery and normalises in the following three months. During this period the anaerobic threshold remains lower, especially in the fit patients. No significant cardiac abnormalities have been noticed during exercise testing of this healthy patient group, nor did any patient complain about pain during or after cycling. Larger patient groups are needed to determine the influence of post-operative blood loss and physiological condition. For this purpose a further stratification of age, gender and pre-operative condition is needed. 


\section{REFERENCES}

1. Bogie R, Pilot P, van Os J, Draijer W. [Klinische resultaten van vier jaar totale heup plaatsing in een geïntegreerd heup- en knieprogramma] Clinical results of four years of THA in an intergrated hip- and knee programm. Medisch Contact 2005;60(12):496-8.

2. Mallett SV, Peachey TD, Sanehi O, Hazlehurst G, Mehta A. Reducing red blood cell transfusion in elective surgical patients: the role of audit and practice guidelines. Anaesthesia 2000;55(10):1013-9.

3. Kehlet H. Multimodal approach to control postoperative pathophysiology and rehabilitation. Br J Anaesth 1997;78(5):606-17.

4. Philbin EF, Groff GD, Ries MD, Miller TE. Cardiovascular fitness and health in patients with end-stage osteoarthritis. Arthritis Rheum 1995;38(6):799-805.

5. Philbin EF, Ries MD, French TS. Feasibility of maximal cardiopulmonary exercise testing in patients with end-stage arthritis of the hip and knee prior to total joint arthroplasty. Chest 1995;108(1):174-81.

6. Ries MD, Philbin EF, Groff GD. Relationship between severity of gonarthrosis and cardiovascular fitness. Clin Orthop 1995(313):169-76.

7. Ries MD, Philbin EF, Grof GD, Sheesley KA, Richman JA, Lynch F jr. Improvement in Cardiovascular Fitness after Total Knee Arthroplasty. J Bone Joint Surg Am 1996;78(11):1696-1701.

8. Ries MD, Philbin EF, Groff GD, Sheesley KA, Richman JA, Lynch F jr. Effect of total hip arthroplasty on cardiovascular fitness. J Arthroplasty 1997;12(1):84-90.

9. Cooper C, Storer. T. Exercise testing and interpretation. Cambridge: University press; 2001.

10. Wilmore JH, D.L. C. Physiology of sport and exercise. Champaign IL,: Human Kinetics; 1994.

11. Older P, Smith R, Courtney P, Hone R. Preoperative evaluation of cardiac failure and ischemia in elderly patients by cardiopulmonary exercise testing. Chest 1993;104(3):701-4. 



\section{CHAPTER 5}

\section{The influence of surgery induced anaemia on exercise capacity after total hip replacement}

Pilot P, Moonen AFCM, Verburg AD, van Os JJ, Koolen JJ, Geesink RGT, Kuipers H

The influence of blood loss on exercise capacity after total hip replacement (submitted) 


\section{ABSTRACT}

To determine the success of modifications in surgical procedures and early rehabilitation programs a better knowledge of the physiologic alterations after surgery is necessary. Cardiovascular fitness, with an incremental cycle ergometer exercise test, was assessed in 200 primary total hip patients. Maximum power output $\left(\mathrm{W}_{\max }\right)$ oxygen uptake $\left(\mathrm{VO}_{2, \max }\right)$ were recorded. In general $23 \% \mathrm{~W}_{\max }\left(20 \% \mathrm{VO}_{2 \text {,max }}\right)$ decline after surgery was seen. The physically fittest patients had a decline of $28 \% \mathrm{~W}_{\max }\left(28 \% \mathrm{VO}_{2 \text { max }}\right)$, whereas patients with a poor condition only had a decline of $11 \% \mathrm{~W}_{\max }\left(3 \% \mathrm{VO}_{2 \text {,max }}\right)$. Patients with a good or average condition had a significantly lower exercise capacity during the first weeks compared with pre-operative, while the poor group had no significant decline. At twelve months, the poor condition group was the only group with a significant increase in exercise capacity compared to preoperative level. No significant cardiac abnormalities were noted during exercise testing of these healthy patients. 


\section{INTRODUCTION}

Comorbidity or high age are no longer reasons for exclusion from major orthopaedic surgery. Together with modern transfusion policies and short stay programs, in which hospital stay is reduced to less than six days, ${ }^{1}$ cardiovascular work load is increased.

Major surgery causes a variety of physiological, subjective and behavioural changes that are collectively known as surgical stress, being the stress response to surgery. ${ }^{2,3}$ Surgical stress combined with aging, comorbidity and moderate post-operative anaemia increases the energy demands. If the patient is unable to compensate for the anaemia during increased circulatory demands, this may lead to serious cardiac adverse events. Although reinfusion of autologous blood in sports to enhance aerobic performance is well recognised, ${ }^{4}$ little is known about the decline in haemoglobin level and possible changes in exercise capacity the first days after surgery. If no blood transfusion is given in patients with post-operative haemoglobin $(\mathrm{Hb})$ levels above $8.0 \mathrm{~g} / \mathrm{dl}$ or higher this does not influence the risk of 30- or 90-day mortality in an elderly population. ${ }^{5}$ However, morbidity and mortality in Jehovah's Witness, who refuse blood transfusions for religious reasons, does increase when untreated $\mathrm{Hb}$ levels below $7.0 \mathrm{~g} / \mathrm{dl}$ do occur after surgery. ${ }^{6}$ However, these extreme Hb levels are exceptional in clinical practice and the question arises to what extent exercise capacity and morbidity are influenced by moderate anaemia.

During treadmill testing in normal healthy subjects that underwent phlebotomy a reduction in maximum oxygen consumption $\left(\mathrm{VO}_{2 \text {,max }}\right)$ is proportional to haemoglobin level after phlebotomy. ${ }^{7-9}$ There are however limited data concerning the relationship between anaemia and functional recovery, and in clinical practice fatigue, weakness, and diminished physical performance are widely accepted signs of anaemia. ${ }^{10}$ Although blood transfusion increases haemoglobin levels the benefit on physical performance after surgery is unclear. Currently there is little clinical evidence that post-operative haemoglobin levels above $8.0 \mathrm{~g} / \mathrm{dl}$ improve functional recovery. One retrospective trial published by Lawrence et al. ${ }^{10}$ demonstrated that post-operative increased haemoglobin levels are associated with better short-term functional recovery after hip fracture repair. Unfortunately data from prospective trials are lacking.

The current prospective trial was designed to investigate the relationship between power output and the severity of anaemia after total hip surgery. The pre-operative exercise capacity is compared with day four and 23. Because all patients were ambulant for several days, one might assume normovolemia on the day (4) of post-operative exercise testing. Our objective was to establish the relationship between post-operative decrease in haemoglobin concentration and the decline in power output on a bicycle ergometer four days after surgery.

\section{MATERIALS AND METHODS}

Cardiovascular fitness was assessed in 200 healthy patients (ASA I \& II) scheduled for elective primary total hip replacement. All patients were treated in an accelerated stay program (Joint Care ${ }^{\circledR}$, Biomet, the Netherlands). In this program patients start their rehabilitation (e.g. walking) on the first day after surgery. Patients with severe cardiovascular abnormalities or pulmonary abnormalities were excluded. If post-operative haemoglobin level dropped below 8.0 or $8.8 \mathrm{~g} / \mathrm{dl}-^{-1}$ patients were transfused. This decision was made by the anaesthesiologist based on the ASA classification and the course of the operation.

The institutional review and ethics board of our hospital approved the study. All patients received oral and written information and signed an informed consent. After consenting, patients 
who volunteered to participate in the study performed a symptom limited incremental exercise test (CPX) on a cycle ergometer to assess cardiovascular fitness. This test was conducted within two weeks prior to surgery. During testing, a multi-channel ECG was recorded. Patients performed four stages incremental exercise testing on a Recohr P bicycle ergometer (Lode, Groningen, The Netherlands). Crank length was reduced from $17.5 \mathrm{~cm}$ to $8 \mathrm{~cm}$ to limit the range of flexion needed in the hip. The frequency had to be more than 40 revolutions (rpm) per minute whereas no maximum rate was set.

\section{Exercise protocol}

After calibration of the metabolic cart, the patient was seated on the ergometer and the appropriate saddle height was set. Each patient was instructed about the test and the stop criteria. Stop criteria were defined as: ST-depression exceeding two millimetres, ST-elevation greater than one millimetres, significant T-top changes, increase in ectopic beats during incremental load, relevant clinical chest pain, decreased consciousness and if the patient wanted to stop. The ECG electrodes and the metabolic cart were connected. The exercise protocol included four stages, warming-up, sub-maximal, incremental symptom limited maximal phase, cooling-down. After two minutes of warming-up at 0 watts, the sub-maximal phase consisted of 2 minutes at 20 watts, two minutes at 40 watts and two minutes at 60 watts. After the submaximal phase the workload was increased every minute by 10 watts. After the incremental phase has been completed the cooling-down was the same as the warming-up phase.

The test protocol was designed in such a way that most tests would take approximately 10 minutes after warming-up, which is considered an optimal test length for maximum power output. ${ }^{11}$

\section{Exercise data}

Inspiratory and expiratory gases were analysed using a metabolic cart (Oxycon Delta, Jaeger Tonnies). 'Breath by Breath' analysis was used to measure the oxygen consumption $\left(\mathrm{VO}_{2}\right.$; $\mathrm{ml} / \mathrm{min})$, carbon dioxide production $\left(\mathrm{VCO}_{2} ; \mathrm{ml} / \mathrm{min}\right)$ and minute ventilation (Ve; $\left.1 / \mathrm{min}\right)$. To assess cardiovascular fitness the maximum $\mathrm{VO}_{2}$ and maximum Wattage were used. The abbreviations of physiological variables used in study are listed in Table 1. Patients performed maximum CPX testing pre-operatively and on day 4 and 23 after surgery. On day 2 and 3 patients were tested sub-maximal.

Maximal exercise was defined as reaching 85 percent of the age predicted maximum target heart rate $(A P M T H R)^{12}$ or respiratory exchange ratio (RER) above 1.0. After the initial exercise

\section{Table 1. Abbreviations of the physiological variables used}

$\begin{array}{lll}\mathrm{W}_{\max } & =\text { maximum power output produced by the patient } \\ \mathrm{VO}_{2, \max } & =\text { maximum oxygen consumption per kilogram body-weight }(\mathrm{ml} / \mathrm{min} / \mathrm{kg}) \\ \mathrm{VCO}_{2} & =\text { carbon dioxide production }(\mathrm{ml} / \mathrm{min}) \\ \mathrm{RER} & = & \text { Respiratory exchange ratio }\left(\mathrm{VCO}_{2, \max } / \mathrm{VO}_{2, \max }\right) \\ \% \mathrm{APMTHR} & = & \text { Percentage of Age Predicted } \mathrm{Maximum} \text { Target Heart Rate } \\ \mathrm{METs} & =\text { Metabolic equivalent of resting value }\end{array}$


test patients were classified for their level of exercise capacity according to the American Heart Association. ${ }^{13}$ Gender and age were accounted for by this scoring system.

\section{Statistical analysis}

The data were stored in a database and correlations were calculated with SPSS 11.0 (SPSS Inc. Chicago Illinois). The correlations were calculated with the Pearson Correlation Coefficients. All variables were tested for homogeneity of variance and normal distribution before statistical analysis was applied. A Repeated Measurement Analyses was done with post-hoc analysis with Hochberg's procedure. When appropriate, the tests involving the within-subject factor(s) were adjusted for heterogeneity of variances and covariances using the Greenhouse-Geisser corrected significance values (Mauchly's test). Alpha was set on 0.05. Data are expressed as mean \pm S.D. unless otherwise stated.

\section{RESULTS}

\section{Patient characteristics}

Patients had an average age of $64.5 \pm 8.6$ (39-82). There were 121 female vs 79 male. The body mass index (BMI) was $26.4 \pm 3.0$ (18.4-35.5). Five patients were diabetic, 39 had wellcontrolled hypertension and four had a history of trombo-embolic events.

\section{Surgical procedure}

$92 \%$ of the patients were operated under spinal analgesia usually combined with sedation. The others underwent general anaesthesia. The approach was in 70\% straight lateral and 30\% postero-lateral. Mean duration of surgery was 65.5 minutes (SD:13.6; range 40-120 min). The anatomic ABG II prosthesis (Stryker ${ }^{\circledR}$, Waardenburg, the Netherlands) was used in all patients i.e. $52 \%$ uncemented, $22 \%$ cemented, $19 \%$ hybride and $7 \%$ reversed hybride. The prosthesis head size was $28 \mathrm{~mm}$ in all cases.

\section{Haemoglobin levels and blood transfusions}

The mean pre-operative Hb was $14.4 \pm 1.03$ (range: 10.9-17.6) g/ $\mathrm{dl}^{-1}$. On the first day after surgery, Hb decreased significantly $(\mathrm{p}<0.01)$ to $10.2 \pm 1.36(7.2-13.9) \mathrm{g} / \mathrm{dl}^{-1}$. On the third day after surgery $\mathrm{Hb}$ was $9.8 \pm 1.26(7.4-14.4) \mathrm{g} / \mathrm{dl}^{-1}$. At day 5 after surgery the Hb level was 9.8 $\pm 1.12(7.7-14.4) \mathrm{g} / \mathrm{dl}^{-1}$ (because there were too many values missing at this time point, this day was not taken into account for statistical analysis) On the 23rd day after surgery the haemoglobin level increased to $12.4 \pm 0.94$ (10.0-15.5) g/ $\mathrm{dl}^{-1}$ (Figure 1). The $\mathrm{Hb}$ significantly differed at all moments in time (all $p<0.01$, except for a difference between day 1 and 3 , this was $\mathrm{p}=0.037)$.

45 patients $(22.5 \%)$ received at least one allogeneic blood transfusion.

\section{Exercise performance}

Two patients had no pre-operative $\mathrm{VO}_{2}$ values as a result of technical problems with the metabolic cart. They performed their CPX test without the metabolic cart but power output and ECG was recorded. These patients were included for analysis.

Maximum power output $\left(\mathrm{W}_{\max }\right)$ and Maximum oxygen uptake $\left(\mathrm{VO}_{2, \max }\right)$ are shown in Table 2. 


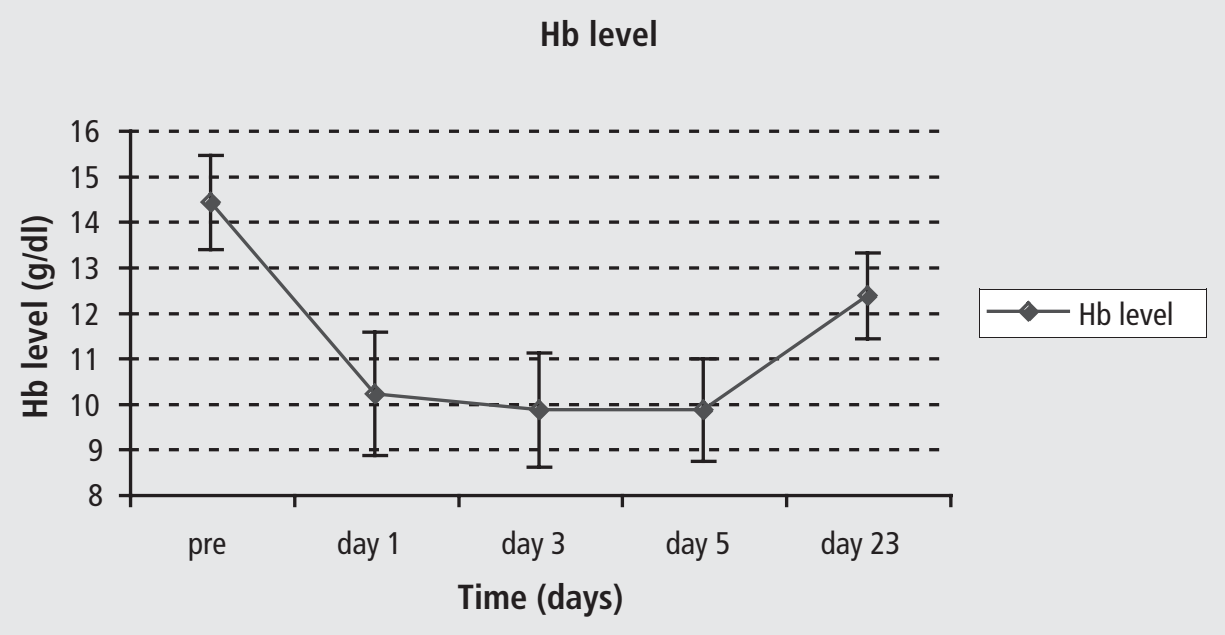

Figure 1. Course of haemoglobin level pre surgery and 1, 3, 5 and 23 days post surgery. Each point $\pm S D$.

and Figure 2. Data were corrected for patients who were unable to perform maximum exercise or being short of motivation. Patients who were pre-operatively the fittest, based on the AHA classification, are shown separately. Figures 3 and 4 show the scatter plots of haemoglobin level as percentage of pre-operative value versus $\mathrm{VO}_{2, \max }$ as percentage of pre-operative value $(\mathrm{r}=0.10$, $\mathrm{p}=0.25 ; \mathrm{r}=0.02, \mathrm{p}=0.90$ ). If the maximum power output was plotted versus changes in $\mathrm{Hb}$ level the same plots were seen. The scatter plot of the absolute haemoglobin level (g/dl) versus

Table 2. $\quad$ Exercise variables for all patients, patients who met criteria for maximum performance, and the sub group of patients who were rated by the American Heart Association classification in physical good fitness pre-operatively.

\begin{tabular}{|c|c|c|c|c|c|c|c|c|c|}
\hline \multirow{3}{*}{ (n=patients) } & \multicolumn{3}{|c|}{ All patients } & \multicolumn{3}{|c|}{$\begin{array}{l}\text { Patients who met criteria for } \\
\text { maximum performance }\end{array}$} & \multirow{2}{*}{\multicolumn{3}{|c|}{$\begin{array}{l}\text { Patients classified as } \\
\text { having a good physical } \\
\text { condition and meeting } \\
\text { criteria maximum } \\
\text { performance }(n=36)\end{array}$}} \\
\hline & \multicolumn{3}{|l|}{$(n=200)$} & \multicolumn{3}{|l|}{$(n=150)$} & & & \\
\hline & Average & SD & Range & Average & SD & range & Average & SD & Range \\
\hline Wmax pre (W) & 106 & 40.2 & $21-237$ & 115 & 38.7 & $45-237$ & 139 & 39.4 & $60-206$ \\
\hline$W_{\max }$ day 4 & 81.2 & 31.6 & $16-164$ & 88.2 & 28.6 & $40-164$ & 102 & 29.2 & $41-164$ \\
\hline $\mathrm{W}_{\max }$ day 23 & 89.7 & 32.6 & $25-267$ & 98.6 & 31.4 & $44-185$ & 114 & 34.0 & $49-170$ \\
\hline $\mathrm{VO}_{2 \max }$ pre & & & & & & & & & \\
\hline$(\mathrm{ml} / \mathrm{min} / \mathrm{kg})$ & 22.4 & 5.9 & $7.5-38.2$ & 23.5 & 5.8 & $11.1-38.2$ & 29.5 & 5.3 & $20.5-38.2$ \\
\hline $\mathrm{VO}_{2, \max }$ day 4 & 17.9 & 4.5 & $8.9-28.9$ & 18.6 & 4.1 & $9.4-28.9$ & 21.2 & 4.1 & $14.0-28.9$ \\
\hline $\mathrm{VO}_{2, \text { max }}$ day 23 & 20.2 & 5.3 & $8.4-39.4$ & 20.9 & 5.2 & $10.4-39.4$ & 23.2 & 5.8 & $10.5-33.2$ \\
\hline
\end{tabular}




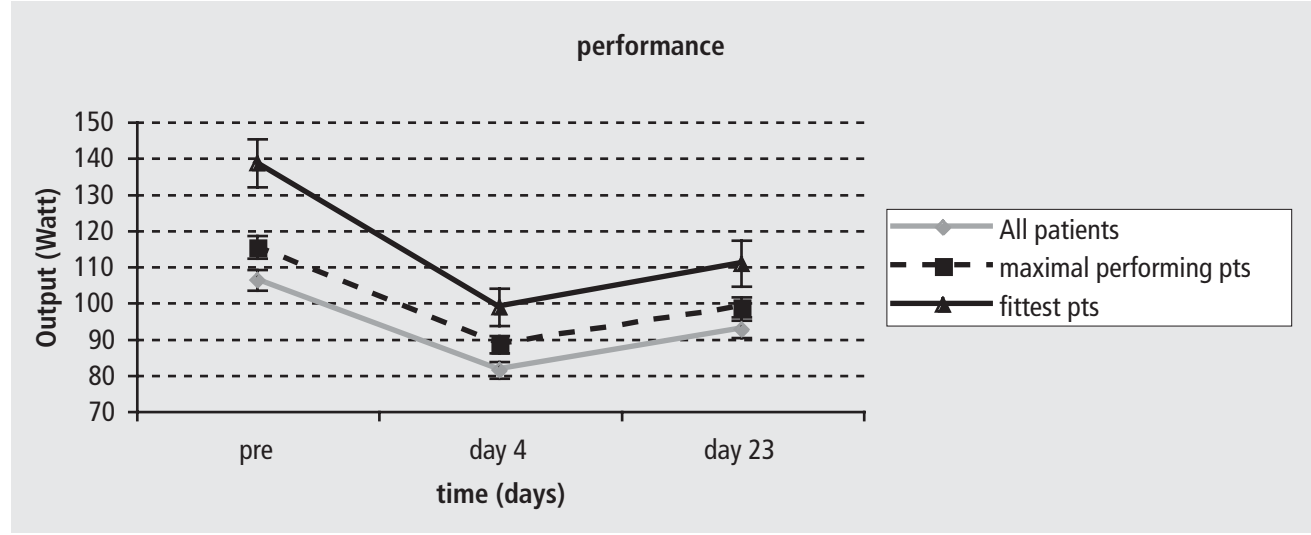

Figure 2. Power output from all patients, patients performing maximum exercise and the pre-operative physical fittest group of patients. All points \pm SEM

$\mathrm{VO}_{2, \max }(\mathrm{ml} / \mathrm{min} / \mathrm{kg})$ for patients who reached maximum effort at all moments is shown in Figure $6(\mathrm{r}=0.13, \mathrm{p}=0.12)$. In Figure 5 the scatter plot of percentage $\mathrm{VO}_{2, \max }$ versus percentage $\mathrm{Hb}$ on day 23 is plotted $(\mathrm{r}=-0.06, \mathrm{p}=0.55)$.

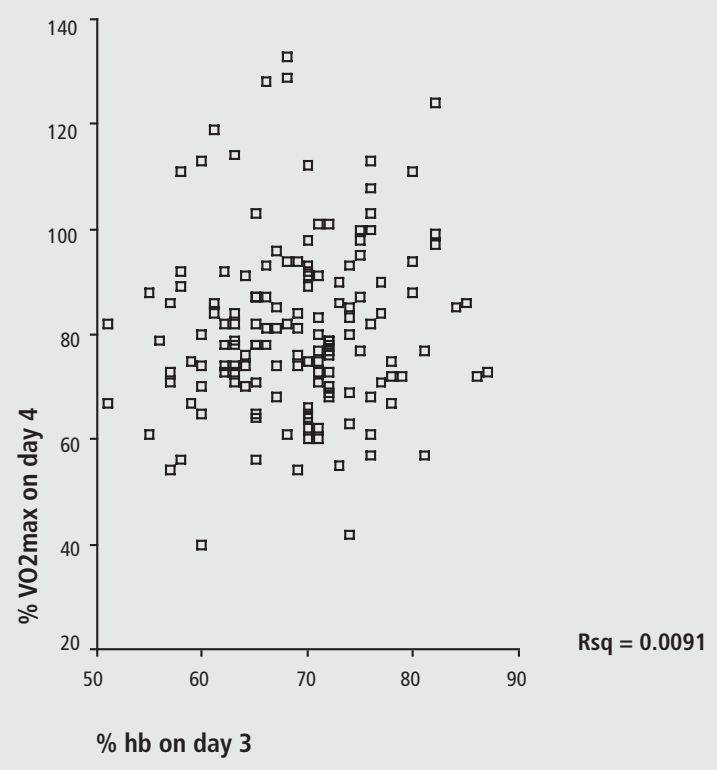

Figure 3. Scatter plot of haemoglobin level as percentage of pre value plotted versus $\mathrm{VO}_{2, \text { max }}$ as percentage of pre-operative value for all patients on day 3 or 4 . Only the patients who reached maximum effort $(r=0.10, p=0.25)$. 


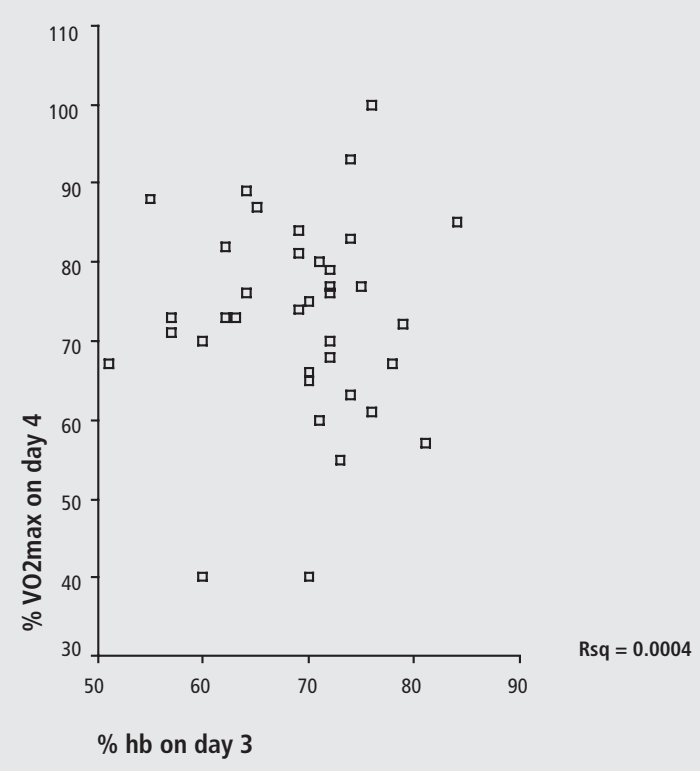

Figure 4. Scatter plot of haemoglobin level as percentage of pre value plotted versus $\mathrm{VO}_{2, \max }$ as percentage of preoperative value for all patients on day 3 or 4 ; for patients who are in good condition ( $r=0.02, p=0.90)$.

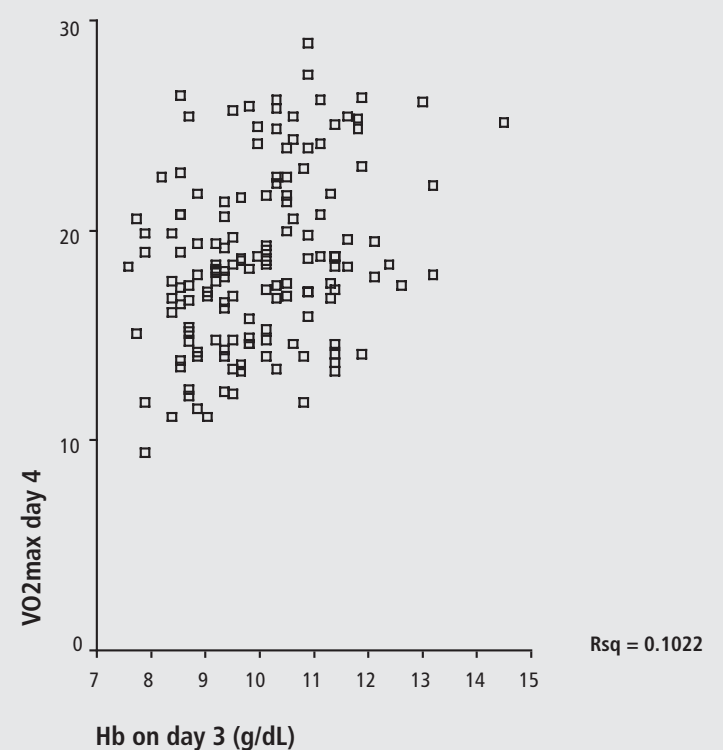

Figure 5. Scatter plot of absolute haemoglobin level $(\mathrm{g} / \mathrm{dl})$ versus $\mathrm{VO}_{2, \max }(\mathrm{ml} / \mathrm{min} / \mathrm{kg})$ for patients who reached maximum effort at al moments ( $r=0.13, p=0.12$ ). 


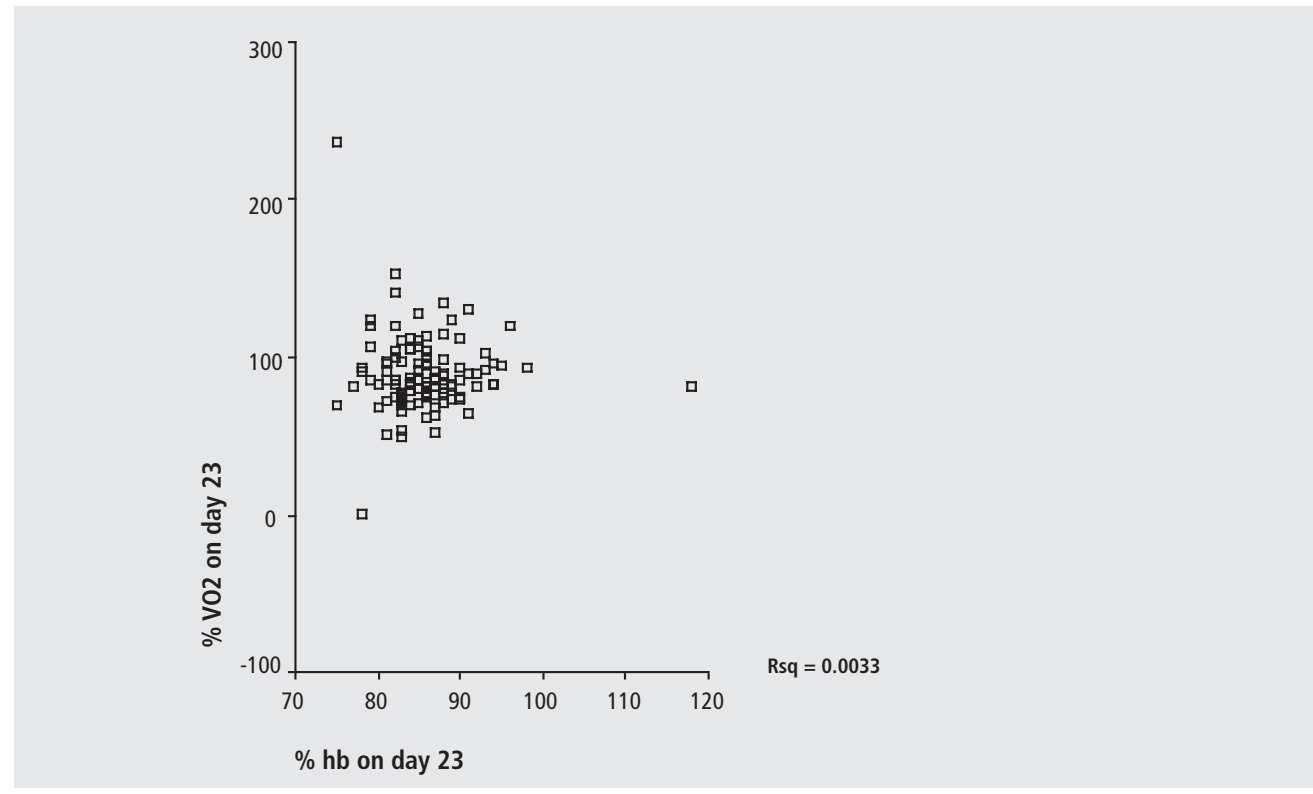

Figure 6. Scatter plot of percentage $\mathrm{VO}_{2}$ max versus percentage $\mathrm{Hb}$ on day 23. All percentages are versus preoperative values ( $r=-0.06, p=0.55)$.

\section{Complications}

There were 27 (13.5\%) clinical complications or complications leading to readmission. More than half of them were wound associated (8.0\%). From these wound problems $1.5 \%$ was a deep infection treated with wound debridement without extraction of the prosthesis. Two percent of the patients had cardiovascular complications. Dislocations were seen in 2 patients (1\%). There were no complications during or directly after exercise testing, or any complications that could be related to exercise testing.

\section{DISCUSSION}

In this study we have shown that there was no relationship between the seriousness of postoperative anaemia and decrease in exercise performance in patients with clinically accepted anaemia. This applies for oxygen consumption and for power output. Even in the groep of physical fittest patients were analysed no significant correlation was seen. These results are not in line with the general opinion that post-operative higher haemoglobin levels enhance recovery. ${ }^{10}$

A post-operative decline in power output and oxygen uptake of over $23 \%$ was observed. This decline was most pronounced in the physically fittest group (27\%). Although $25 \%$ of all patients did not meet the criteria of maximum performance, these results were not different from the total group (Figure 2).

The scatter plots of the decline in maximum oxygen uptake versus decline in haemoglobin level (Figures 3 and 4 ) show no significant correlation. This was also true if maximum power output was taken instead of $\mathrm{VO}_{2 \text {,max }}$. The same is true for the correlation between the absolute haemoglobin level $(\mathrm{g} / \mathrm{dl})$ and decline in $\mathrm{VO}_{2, \max }(\%)$ for patients who reached maximum effort 
at all moments (Figure 5). Although the study has some limitations, we believe these limitations cannot account for the total absence of correlations in all analyses.

The results we found were surprising as during testing of normal subjects, the reduction in maximum oxygen consumption $\left(\mathrm{VO}_{2, \max }\right)$ was proportional to haemoglobin level after phlebotomy. ${ }^{7-9}$ A possible confounder is surgical stress response with subsequent increased demands on organ function, resulting in a decrease in exercise capacity. These changes in organ function are thought to be mediated by trauma-induced endocrine metabolic changes and activation of several biological cascade systems (cytokines, complement, arachidonic acid metabolites, nitric oxide and free oxygen radicals). ${ }^{3}$ This is supported by the finding that the absolute haemoglobin level after surgery showed no statistical correlation with the decline in maximum oxygen consumption (Figure 5) and power output.

Whether a correlation can be detected if $\mathrm{Hb}$ levels below $8.0 \mathrm{~g} / \mathrm{dl}$ are accepted remains unknown. In this study patients were transfused when $\mathrm{Hb}$ levels dropped below $8.0 \mathrm{~g} / \mathrm{dl}^{-1}$

Maximum power output reflects performance ability. However, performance is also influenced by pain and motivation. To adjust for these limitations, data were corrected for patients who could not perform maximum exercise or were short of motivation. In this study, maximum exercise was defined as RER above $1.0^{11}$ or reaching 85 percent of APMTHR. ${ }^{12}$ The metabolic process explains the RER. During rest, the body's energy demand is fully supplied by fat oxidation $(R E R \approx 0.70)$. When energy demands rise carbohydrate oxidation becomes the major source for energy and the RER increases toward 1.0. Anaerobic processes compensate for even higher energy demands. During this type of ATP production, pyruvate is released and converted into lactate. The hydrogen ions react with the bicarbonate buffers. The resulting carbodioxine elevates the RER above 1.0.

In the present study the cycle ergometer was preferred to measure exercise performance since work efficiency is similar in trained and untrained, young and old, male and female subjects, when compared with a treadmill. Kuipers et al. found a variation in maximal workload on a cycle ergometer of around $5 \%$ in trained subjects. ${ }^{14}$ Besides, patients with end stage osteoarthritis prefer cycling to walking, and cycling is also a familiar mode of exercise in Dutch people in general.

From measurements of energy metabolism in surgical patients during the early (24 to $48 \mathrm{~h}$ ) post-operative period it can be concluded that the early post-operative period of uncomplicated surgery is associated with approximately $7 \%$ increase in energy metabolism compared with the overnight fasted, resting healthy individual. 15 This increase appears to be an effect of surgery itself, not predicted by Harris-Benedict equations. ${ }^{15}$ Fredrix et al. ${ }^{16}$ reported that at the seventh or eighth post-operative day after uncomplicated gastric or colorectal surgery 16 patients continue to have a mild (3\%) but significant increase in resting energy level. Minor or major complications increased the resting energy expenditure with $10 \%$. The elevated energy expenditure is probably a confounding factor explaining the poor correlation between anaemia and performance seen in this study.

In conclusion, severe anaemia is undesirable after major orthopaedic surgery. Morbidity and mortality increase when haemoglobin levels below $7.0 \mathrm{~g} / \mathrm{dl}$ are accepted after surgery. 6 In contrast to this, the present study shows no correlation of post-operative haemoglobin levels and physical performance. Multifactorial surgical stress responses are the most likely explanation. Based on these observations, we believe that restrictive transfusion policy in healthy patients is not a problem for early rehabilitation after major orthopaedic surgery. Measures to raise postoperative haemoglobin levels others than to prevent blood transfusions might not be indicated. 


\section{REFERENCES}

1. Bogie R, Pilot P, van Os J, Draijer W. [Klinische resultaten van vier jaar totale heup plaatsing in een geïntegreerd heup- en knieprogramma] Clinical results of four years of THA in an intergrated hip- and knee programm. Medisch Contact 2005;60(12):496-8.

2. Hall GM, Peerbhoy D, Shenkin A, Parker CJ, Salmon P. Relationship of the functional recovery after hip arthroplasty to the neuroendocrine and inflammatory responses. Br J Anaesth 2001;87(4):537-42.

3. Kehlet H. Multimodal approach to control postoperative pathophysiology and rehabilitation. Br J Anaesth 1997;78(5):606-17.

4. Gaudard A, Varlet-Marie E, Bressolle F, Audran M. Drugs for increasing oxygen and their potential use in doping: a review. Sports Med 2003;33(3):187-212.

5. Carson JL, Duff A, Berlin JA, Lawrence VA, Poses RM, Huber EC, et al. Perioperative blood transfusion and postoperative mortality. Jama 1998;279(3):199-205.

6. Carson JL, Noveck H, Berlin JA, Gould SA. Mortality and morbidity in patients with very low postoperative Hb levels who decline blood transfusion. Transfusion 2002;42(7): 812-8.

7. Ekblom B, Wilson G, Astrand PO. Central circulation during exercise after venesection and reinfusion of red blood cells. J Appl Physiol 1976;40(3):379-83.

8. Woodson RD, Wills RE, Lenfant C. Effect of acute and established anemia on $\mathrm{O} 2$ transport at rest, submaximal and maximal work. J Appl Physiol 1978;44(1):36-43.

9. Gledhill N. The influence of altered blood volume and oxygen transport capacity on aerobic performance. Exerc Sport Sci Rev 1985;13:75-93.

10. Lawrence VA, Silverstein JH, Cornell JE, Pederson T, Noveck H, Carson JL. Higher Hb level is associated with better early functional recovery after hip fracture repair. Transfusion 2003;43(12):1717-22.

11. Wasserman K, Hansen J, Sue D, Whipp B, R. C. Principles of exercise testing and interpretation. Philadelphia: Williams \& Wilkins, 1994.; 1994.

12. ACSM. ACSM's guidelines for exercise testing and prescription. first ed. Philadelphia: Lippincott Williams \& Wilkins; 2000.

13. Cooper C, Storer T. Exercise testing and interpretation. Cambridge: University press; 2001.

14. Kuipers H, Verstappen FT, Keizer HA, Geurten P, van Kranenburg G. Variability of aerobic performance in the laboratory and its physiologic correlates. Int J Sports Med 1985;6(4):197-201.

15. Brandi LS, Oleggini M, Lachi S, Frediani M, Bevilacqua S, Mosca F, et al. Energy metabolism of surgical patients in the early postoperative period: a reappraisal. Crit Care Med 1988;16(1):18-22.

16. Fredrix EW, Soeters PB, von Meyenfeldt MF, Saris WH. Resting energy expenditure in cancer patients before and after gastrointestinal surgery. JPEN J Parenter Enteral Nutr 1991;15(6):604-7.

\section{ACKNOWLEDGEMENT:}

This study was conducted with a research grant by Ortho-biotech, a division of Janssen-Cilag. There were no restrictions regarding publication. 



\section{CHAPTER 6}

\section{The use of autologous blood to improve exercise capacity after total hip replacement. A preliminary report}

Pilot P, Bols EMJ , Verburg AD, Bell CAMP, Moonen AFCM, van Os JJ, Koolen JJ, Geesink RGT, Kuipers H

The use of autologous blood to improve exercise capacity after total hip arthroplasty.

(Transfusion 2006;46(8)1267-70) 


\section{Abstract}

\section{Background}

Venesection of red blood cells in healthy well-trained subjects decreased the maximum oxygen uptake parallel with the reduction in $\mathrm{Hb}$ level. Based on the large Hb-drop that is seen after total joint surgery, one could expect a drop in performance as well. We investigated whether transfusion of autologous blood enhanced performance on a bicycle ergometer in patients after total hip replacement.

\section{Study design and methods}

Nine patients scheduled for elective total hip replacement in an accelerated stay program participated in a PABD program. Weeks before the scheduled surgery patients donated four units of blood and received standard erythropoietin treatment. Physical fitness was assessed during exercise testing on a bicycle ergometer. Each patient was matched with three previously tested patients.

\section{Results}

Patients in both groups were 69.0 years old (range 66-74 vs 61-77). None of the patients had relevant cardiovascular abnormalities. On average patients received 3.3 units of blood because 3 units were not transfused. The PABD group showed an Hb-drop of $0.5 \mathrm{~g} / \mathrm{dl}$ (4\%) on the fourth post-operative day vs $4.4 \mathrm{~g} / \mathrm{dl}(31 \%)$ in the control group. The decline in power output on day four was significantly less in the PABD group compared with the control group (students T-test: $\mathrm{p}=0.026)$

\section{Conclusion}

From this pilot study we may conclude that correction of the post-operative Hb-drop was associated with a lower drop in maximum power output, compared to the control group. However, on days 23 and 39 the difference in performance between the PABD group and control group had disappeared. 


\section{INTRODUCTION}

In recent years, with the development of peri-operative blood conservation programs, a restrictive blood transfusion policy has become standard in health care. Data concerning the tolerability of severe anaemia were collected from patients who refused transfusions for religious reasons. ${ }^{1}$ Outcomes of those patients have shown that morbidity and mortality increased when Hb levels dropped below $8.0 \mathrm{~g} / \mathrm{dl}^{-1}$. $^{1}$

Since hospitalisation was reduced extensively over the last decade intense rehabilitation is generally started the day after surgery, irrespective of the $\mathrm{Hb}$ level. Whether below normal $\mathrm{Hb}$ levels will affect the patients' ability to participate in a rehabilitation program is unknown. In contrast to sports anaemia,2,3 little is known about a decrease in performance in patients with anaemia induced by major surgery.

It has been established that venesection in healthy, well-trained subjects decreased the maximum oxygen uptake $\left(\mathrm{VO}_{2 \text {,max }}\right)$ parallel with the decrease of $\mathrm{Hb}$ level. Knowing that prosthetic surgery, such as total hip or knee replacement, may also cause a significant decrease in $\mathrm{Hb}$ level one might anticipate a significant drop in exercise performance as well. Although a relationship between post-operative anaemia and exercise capacity was only reported in some studies with limited statistical power, ${ }^{5-7}$ this relationship could not be confirmed in a recent, prospective observational study. ${ }^{8}$

By using post-operative retransfusion of pre-operatively donated autologous blood one might compensate for the surgery-induced anaemia. This may provide the answer to the question whether normalization of Hb levels can normalize exercise capacity post-surgery.

At present, in the Netherlands, pre-operative autologous blood donation (PABD) is not a standard procedure in orthopaedics because of the doubtful cost effectiveness. To avoid wasting of costly blood, the threshold for PABD in primary total hip replacement may increase the likelihood of autologous transfusion. ${ }^{9}$ Other than to prevent homologous transfusion, the application to correct the surgery-induced anaemia is new. PABD may provide information on the influence of anaemia and normalisation of anaemia after major orthopaedic surgery on recovery and functional exercise capacity.

The feasibility of pre-operative exercise testing has been demonstrated by several authors and we previously showed that early post-operative maximum exercise testing on a bicycle ergometer with shortened crank was feasible. ${ }^{8}$

In this pilot study we investigated whether correction of the haemoglobin drop after total hip replacement would enhance performance on a cycle ergometer in patients. Because of the high costs associated with PABD a non-randomised design was used. The PABD were matched with a control group from a previously tested cohort consisting of 200 total hip replacement patients without PABD. 8 


\section{MATERIALS AND METHODS}

\section{Study population}

Healthy patients scheduled for primary total hip replacement and willing to volunteer were asked to participate. The study patients were randomly selected to participate. The study was approved by the local ethics committee. After signing informed consent ${ }^{9}$ patients were included in the study as PABD group. For every PABD patient three patients were matched from a cohort of previously operated patients. Matching variables were: gender, age, body mass index (BMI), maximum power output and $\mathrm{VO}_{2 \text {,max }}$ corrected for body weight. Control patients did not receive an allogeneic blood transfusion post-operative, because $\mathrm{Hb}$ levels did not drop below the threshold for transfusion. In addition, the duration of surgery did not exceed 90 minutes. All patients receiving surgery followed an accelerated release program (Joint Care ${ }^{\circledR}$, Biomet, the Netherlands).

\section{Donation and retransfusion autologous blood}

The procedure was enhanced by using erythropoietin alpha (Eprex $\left.{ }^{\circledR}\right)$, four injections of 40,000 IU (three pre-operatively and one directly post-operatively), supported by iron supplementation with $200 \mathrm{mg}$ ferrofumerate three times a day until the day of surgery.

By way of double erythrocytaferesis patients donated two standardized units of erythrocytes during each blood bank visit. In this procedure, the erythrocytes were separated from the blood plasma, leucocytes and platelets. The remaining blood components were given back to the patient in a saline solution. During the two blood bank visits a maximum of 4 units were donated. Depending on availability at the blood bank, venesection sessions were four and two weeks prior to surgery. At the day of donation, some patients complained about fatigue. Furthermore, no complications were seen.

\section{Surgical procedure}

In the PABD group the average duration of surgery was 80.4 min (range: 74-90) and the estimated blood loss during surgery was on average $561 \mathrm{ml}$ (300-1000). One patient had general anaesthesia and 8 had a single shot spinal anaesthesia. For the control group the average duration of surgery was $61.1 \mathrm{~min}$ (50-90) and the estimated blood loss during surgery was on average $400 \mathrm{ml}$ (200-850). Two patients had general anaesthesia and 25 had a single shot spinal anaesthesia. No intra- or post-operative cell-savers were used in either group.

\section{Post-operative autologous transfusion}

If post-operative $\mathrm{Hb}$ level dropped below 8.0 or $8.8 \mathrm{~g} / \mathrm{dl}^{-1}$ patients were transfused with autologous blood. Before returning to the ward the anaesthesiologist on clinical judgement decided whether the post-operative trigger was 8.0 or 8.8. This decision was made depending on co-morbidity classified in the ASA classification and intra-operative blood loss. Regardless of the $\mathrm{Hb}$ level on day two and three, patients of the study population received their own previously donated blood.

\section{Haemoglobin}

$\mathrm{Hb}$ level was recorded peri-operative i.e. -65 days before surgery (screening), day -1 (baseline), day 0 (surgery) and post-operative days 1, 3, 4, 5, and 23. 


\section{Exercise testing}

On day -1, 4, 23 and 39 after surgery the patients performed a maximal exercise test. On day 2 and day 3 after surgery the patients performed a sub-maximal exercise test to familiarise with the ergometer.

After calibration, the patient was seated on the ergometer. Each patient was instructed about the test and about the stop criteria. Stop criteria were defined as: ST-depression greater than two millimetres, ST-elevation exceeding one millimetres, significant T-top changes, increase in ectopic beats during incremental load, relevant clinical chest pain, decreased consciousness and independent decision of the patient to stop.

Before starting the exercise the patient was connected to ECG electrodes and to the metabolic cart. The patient's interface to the metabolic cart consisted of a respiratory mask, which was carefully positioned to ensure a leak-free connection. The exercise protocol consisted of four stages: warming-up, sub-maximal incremental symptom limited maximal phase and cooling down. After two minutes of warming-up at 0 Watt, the sub-maximal phase took 6 minutes. These 6 minutes consisted of 2 minutes at 20 Watt, two minutes at 40 Watt and two minutes at 60 Watt. After the sub-maximal phase the workload was increased every minute with 10 Watts, until the patient was exhausted. After the incremental phase, the cooling-down was the same as the warming-up phase.

Crank length was reduced from $17.5 \mathrm{~cm}$ to $8.0 \mathrm{~cm}$ to diminish range of hip flexion. Seat height was set, allowing a knee bend of $5-10^{\circ}$ when the pedal was at its lowest position. The pedal rate had to be above 40 revolutions per minute (rpm), whereas no maximum rate was set.

Inspiratory and expiratory gases were analysed using a metabolic cart (Oxycon Delta, Jaeger Tonnies). Gas analysis was used to measure oxygen consumption $\left(\mathrm{VO}_{2} ; \mathrm{ml} / \mathrm{min}\right)$, carbon dioxide production $\left(\mathrm{VCO}_{2} ; \mathrm{ml} / \mathrm{min}\right)$ and minute ventilation (Ve;1/min). The metabolic cart had been calibrated before each test session. Abbreviations are listed in Table 1.

Table 1. Abbreviations of the physiological variables

\begin{tabular}{ll}
$\mathrm{W}_{\max }$ & $=$ maximum power output produced by the patient \\
$\mathrm{VO}_{2, \max }$ & $=$ maximum oxygen consumption $(\mathrm{ml} / \mathrm{min})$ \\
$\mathrm{VCO}$ & $=$ carbon dioxide production $(\mathrm{m} / / \mathrm{min})$ \\
$\mathrm{VE}$ & $=$ minute ventilation $(\mathrm{L} / \mathrm{min})$ \\
$\mathrm{RER}$ & $=$ Respiratory exchange ratio \\
$\%$ APMTHR & $=$ Percentage of Age Predicted Maximum Target Heart Range \\
$\mathrm{METS}$ & $=$ Metabolic equivalent of resting value \\
\hline
\end{tabular}

Maximum exercise was defined as reaching 85 percent of age predicted maximum target heart rate (APMTHR) ${ }^{10}$ or respirator exchange ratio (RER) above 1.0 . In this way, data was corrected for patients who were unable to perform maximum exercise or being short of motivation. 


\section{Statistical analysis}

The data were stored in a database and correlations were calculated with SPSS 11.0 (SPSS Inc. Chicago Illinois). All patients were analysed using the 'intention-to-treat' principle. Analysing the course of Hb levels an Independent-Samples T-test analysis was done with SPSS. Primary outcome was cardiovascular fitness measured by maximum $\mathrm{VO}_{2}$ and maximum Wattage. All efficacy endpoints were evaluated using the 95\% confidence interval approach. Adjustments with Hochberg correction for multiple comparisons were made concerning mean $\mathrm{Hb}$ levels and exercise variables. Tests were 2 -tailed with alpha set on 0.05 .

The control group was assumed to have a post-operative Hb-drop of 30 percent. The PABD group was assumed to have a drop in $\mathrm{Hb}$ level at admission of about $1.6 \mathrm{~g} / \mathrm{dl}^{-1}$. It was expected that the four pre-operative units of blood would be sufficient to restore post-operative Hb levels to admission level. With alpha set on 0.05 and a power of 0.80 it was calculated that 9 patients in the PABD group were needed.

\section{RESULTS}

The nine patients in the PABD group had an average age of 69 (66-74). The 27 patients in the control group also had an average of 69 (61-77). Body Mass Index (BMI) was 26.2 (22-31) versus 26.2 (19-33). All patients were ASA I or II. In the control group 2 patients had well regulated hypertension.

The mean Hb levels are shown in Table 2. The Hb course over time is shown in Figure 1.

Table 2. Mean Hb levels $(\mathrm{g} / \mathrm{dl})$ in the experimental and control group

\begin{tabular}{|c|c|c|c|c|c|c|c|}
\hline & \multicolumn{3}{|c|}{ Experimental group } & \multicolumn{4}{|c|}{ Control group } \\
\hline & Mean & Range & SD & Mean & Range & SD & $p^{*}$ \\
\hline Day -65 & 14.4 & $13.4-15.6$ & 0.88 & 14.4 & $12.7-16.1$ & 0.95 & 0.88 NS \\
\hline Day -1 & 13.1 & $11.4-14.2$ & 0.95 & 14.4 & $12.7-16.1$ & 0.95 & 0.001 \\
\hline Day 1 & 10.3 & $9.0-11.8$ & 0.75 & 10.5 & $7.9-12.4$ & 1.14 & $0.613 \mathrm{NS}$ \\
\hline Day 3 & 11.6 & $10.8-12.7$ & 0.63 & 10.0 & 7.7-13.2 & 1.40 & 0.000 \\
\hline Day 4 & 12.6 & $11.4-14.0$ & 0.76 & & & & \\
\hline Day 5 & 13.4 & $12.4-15.3$ & 1.01 & 10.3 & $8.4-12.9$ & 1.42 & 0.000 \\
\hline Day 23 & 14.5 & $11.9-17.2$ & 1.84 & 12.4 & $10.0-13.8$ & 1.04 & 0.001 \\
\hline
\end{tabular}

NS = not significant * Hochberg correction was used for multiple testing.

\section{Autologous transfusions}

3 patients received one unit of autologous packet cells (PC) on the day of surgery. All patients received 2 units of autologous PC on day 2 . On day 3 post-operatively the remaining PCs were given. 3 patients did not receive 4 units of PC, because in 2 patients the transfusion back was damaged and in 1 patient the reinfusion did not run well. These 3 patients received 3 units of PC. No allogeneic transfusions were needed. 


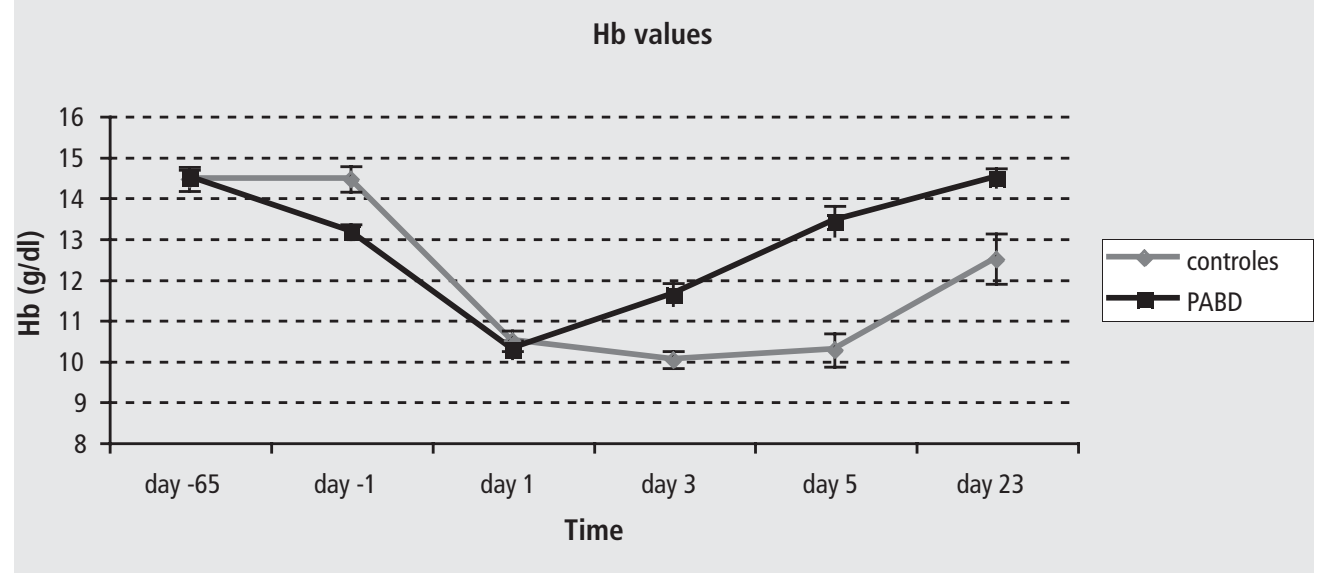

Figure 1. Mean Hb levels $( \pm S E M)$ in the experimental and control group before and after surgery (=day 0)

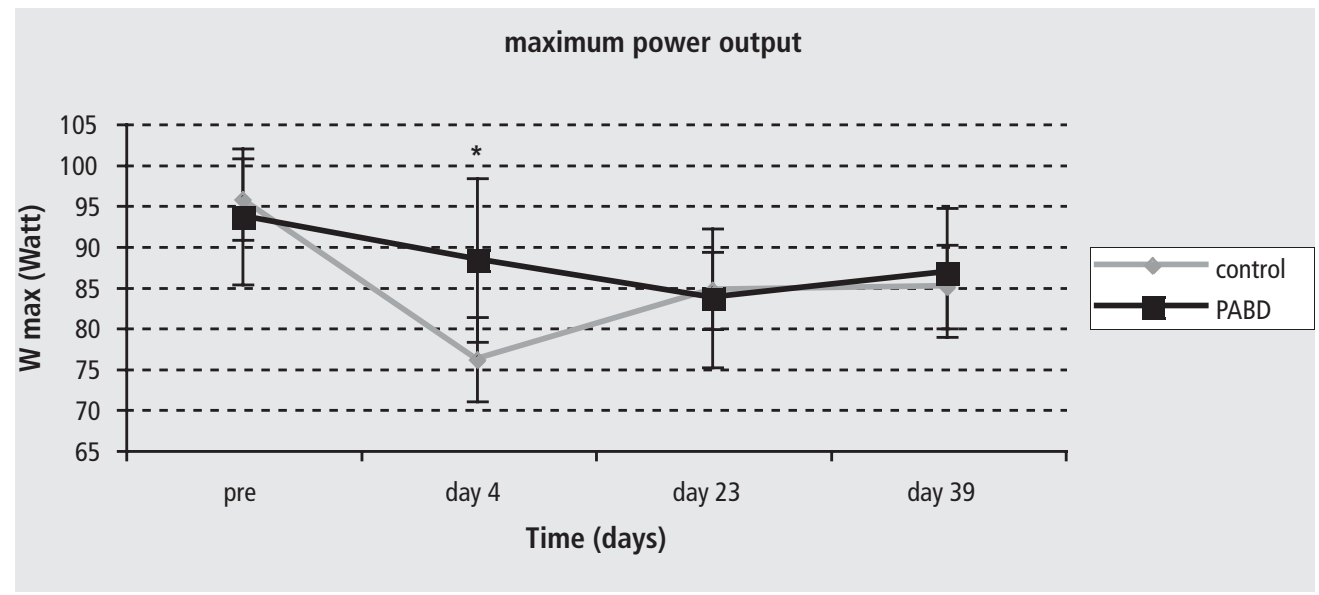

Figure 2. Maximum workload \% pre in the experimental and the control group. ${ }^{*}$ significant ( $\left.p=0.026\right)$. 


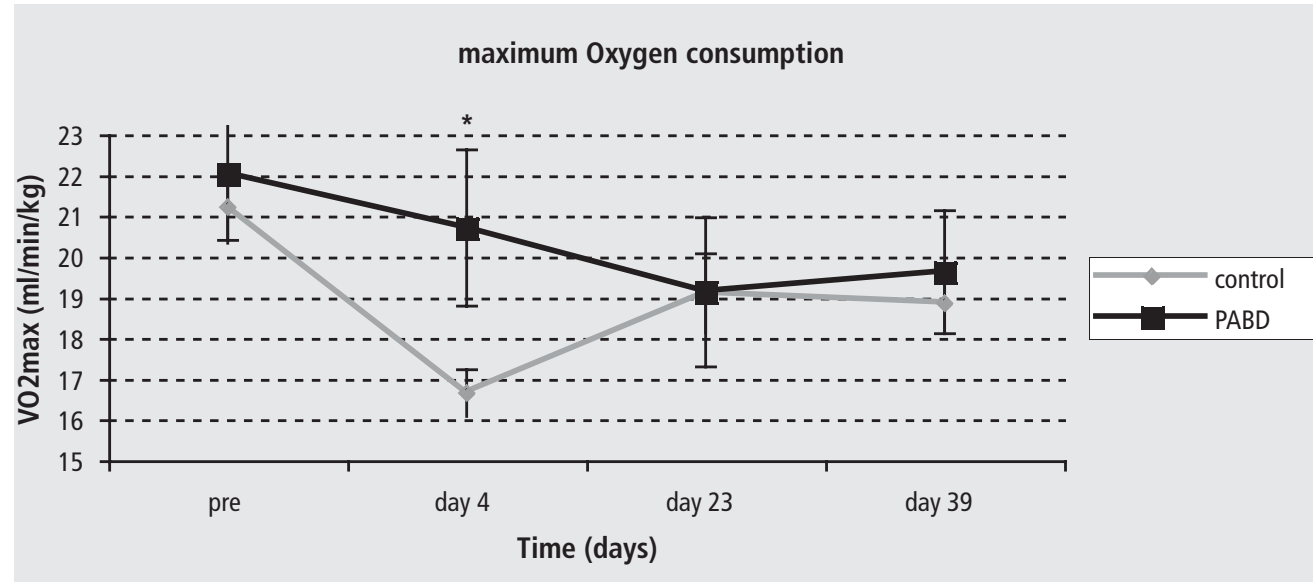

Figure 3. $\quad P e a k \mathrm{VO}_{2}$ in the experimental and the control group.

* significant ( $p=0.026)$.

\section{Cardiovascular fitness}

The results of the exercise variables in the experimental and control group are shown in Table 3. Primary outcome measures were maximum workload and maximum $\mathrm{VO}_{2}$ adjusted for weight. Figures 2 and 3 illustrate the results concerning both groups.

Although primary results of the pre-test in the control group were slightly higher they were not statistically significant. The drops in exercise capacity and oxygen consumption were significantly less in the experimental group on day $4(p=0.026$ and $p=0.026)$. These differences were no longer significant on day 23.

\section{Discussion}

Little is known about the influence of surgery-induced decreased Hb levels on (early) exercise capacity during rehabilitation after total hip replacement. In this study we attempted to correct the Hb-drop after total hip replacement by autologous blood transfusion, irrespective of medical indication. The restoration of the post-operative $\mathrm{Hb}$ level was associated with a significantly smaller decline in power output and oxygen uptake (6\% vs. 22\%) at day four. However, this difference was not found anymore on days 23 and 39.

Based on studies using erythropoietin and blood aid in healthy volunteers ${ }^{10,11}$ it has been established that elevated $\mathrm{Hb}$ levels and an increased blood volume increase oxygen transport capacity and may improve cardiovascular performance in non-surgical patients. However, little is known about the influence of surgery-induced changes in Hb levels on exercise capacity in patients. A major difference between healthy subjects and surgical patients is the so-called surgical stress response. ${ }^{13,14}$ Surgical stress results from increased demands on organ function with subsequent changes in metabolic, neural and endocrine systems. ${ }^{13,14}$ From measurements of energy metabolism in surgical patients during the early (24 to $48 \mathrm{~h}$ ) post-operative period it has been established that the early post-operative period of uncomplicated surgery is associated 
with approximately 7\% increase in energy metabolism compared with the overnight fasted, resting healthy individual. 15 In addition, minor or major peri-operative complications induced an increase in resting energy expenditure of $10 \% .{ }^{16}$ Clinical signs of surgical stress are nausea, dizziness and weakness. This surgical stress response and elevated energy expenditure may be major confounders in interpreting post-operative cardiopulmonary exercise testing.

The PABD group showed a significantly smaller decline in exercise capacity and oxygen uptake capacity on day four compared to their matched controls. Therefore there may be a direct relation between decline in exercise capacity and drop in Hb level after surgery. However on day 23 this difference in performance capacity was not present anymore, and on days 23 and 39 the PABD patients performed less than at day four, and similar to the control group (Figure 2 and 3). When looking at total ventilation $\left(V_{e}\right)$, total $V_{e}$ in the PABD group was significantly lower than pre-operatively. Therefore it may not be ruled out that this inferior performance of the PABD group on days 23 and 39 could be explained by lower motivation.

In addition, the positive effect of the PABD on exercise performance on day four may be caused by an increased motivation (placebo effect) from the intervention. Maximal symptom limited exercise testing requires maximal effort from the patient and maximal performance is determined by the subject's ability and motivation to sustain discomfort as fatigue (exhaustion), muscle discomfort, and breathlessness. ${ }^{17}$ In general short exercise tests in untrained patients are more prone to placebo effects than longer tests used for aerobic testing. ${ }^{17}$ This is supported by a previous prospective clinical trial ${ }^{8}$ in which no correlation between surgery-induced blood loss and exercise capacity was found. Also the design of the present study consisting of a nonrandomised, non-blinded, trial may be associated with bias. From several doping affairs with erythropoietin in the media, many patients may assume that high haemoglobin levels may enhance performance, which may cause motivational bias. Therefore a randomised, double blinded, dummy controlled trial would have been preferable. However, because of the high costs associated with PABD we chose for the design as used here. For conclusive data a larger randomised trial is needed to assess whether increasing haemoglobin levels after surgery may enhance performance capacity.

A possible explanation of the PABD group performing better on day four than the control group might be an increased blood volume induced by the blood transfusion. It is generally accepted that blood volume (BV) is an important factor for cardiac function and aerobic performance. Changes in blood volume affect can influence oxygen transport by altering stroke volume (SV) and cardiac output (Q). Coyle et al. ${ }^{18}$ observed in untrained men that 200-300 ml of plasma volume expansion increases SV, measured during sub-maximal exercise, yet this plasma volume expansion caused only a small amount of haemodilution. As a result, $\mathrm{VO}_{2, \max }$ was increased slightly and performance was improved. Krip et al. ${ }^{19}$ confirmed this finding and found that blood volume expansion in untrained men gave an acute increase in maximal diastolic filling rate, maximum stroke volume, maximum cardiac output and $\mathrm{VO}_{2, \max }$.

The PABD group received blood transfusions on day two and three, whereas the control group did not receive additional fluid on day two or three. This may have caused a better hydration and a favourable effect on exercise performance in the PABD group. This is supported by the observation that the differences were not found anymore after three weeks, although there was still a difference in haemoglobin concentration.

Knowing that prosthetic surgery may cause a significant decrease in Hb level one might 
expect a serious drop in exercise performance. Although a relationship between post-operative anemia and exercise capacity has been reported, 5 this relationship was questioned in a recent, prospective observational study, and in line with the results of the present study. ${ }^{8}$ Although a direct relationship between $\mathrm{Hb}$ level and exercise performance is not that clear, the results suggest that maximum workload can predict whether a patient is able to participate successfully in the rehabilitation program after total hip replacement or not. When comparing the oxygen uptake at maximum workload in both groups with Metabolic Equivalents (1 MET = $3.5 \mathrm{ml}$ $\mathrm{O}_{2} / \mathrm{kg} / \mathrm{min}$ ), both groups achieved 4.8-5.9 METs on day four. Daily physical activity accounts for 3-6 METs, which enabled both groups to participate in the rehabilitation program. Although there was a statistically significant difference in oxygen uptake on day four, this has no clinical relevance because patients are still able to participate in the rehabilitation program. However, in less fit patients, statistical significance may also have clinical relevance.

We were able to restore the Hb levels on day four post-operatively, compared to the values at admission. However, by using the PABD procedure Hb levels at admission were significantly $(p=0.001)$ lower than the controls. This is a well-known disadvantage of PABD and makes the patient more prone to blood transfusions, autologous and homologous.

In conclusion, PABD as an ergogenic aid after major orthopaedic surgery suggests that complete restoration of the haemoglobin drop after surgery positively influences performance. However, this preliminary report has shortcomings such as its design, the small number of patients, and the untrained patient population. The present study and previous observational findings 8 necessitate a larger randomised trial to collect conclusive data. 


\section{REFERENCES:}

1. Carson JL, Noveck H, Berlin JA, Gould SA. Mortality and morbidity in patients with very low postoperative Hb levels who decline blood transfusion. Transfusion 2002;42-7:812-8.

2. Ekblom BT. Blood boosting and sport. Baillieres Best Pract Res Clin Endocrinol Metab 2000;14-1:89-98.

3. Gaudard A, Varlet-Marie E, Bressolle F, Audran M. Drugs for increasing oxygen and their potential use in doping: a review. Sports Med 2003;33-3:187-212.

4. Buick FJ, Gledhill N, Froese AB, Spriet L, Meyers EC. Effect of induced erythrocythemia on aerobic work capacity. J Appl Physiol. 1980 Apr;48-4:636-42.

5. Lawrence VA, Silverstein JH, Cornell JE, Pederson T, Noveck H, Carson JL. Higher Hb level is associated with better early functional recovery after hip fracture repair. Transfusion 2003;43-12:1717-22.

6. Gruson KI, Aharonoff GB, Egol KE, Zuckerman JD, Koval KJ. The relationship between admission hemoglobin level and outcome after hip fracture. J Orthop Traum 2002;16-1:39-44.

7. Halm EA, Wang JJ, Boockvar K, Penrod J, Silberzweig SB, Magaziner J, Koval KJ, Siu AL.Effects of blood transfusion on clinical and functional outcomes in patients with hip fracture. Transfusion 2003; 43-10:1358-65.

8. Pilot P, Verburg A, Moonen A, Koolen J, van Os J, Geesink R, Kuipers H. Feasibility of early cardiopulmonary exercise testing after total hip arthroplasty. TATM 2005;7-1 (suppl):68 (A33).

9. Forgie MA, Wells PS, Laupacis A, Fergusson D, for the International Study of Perioperative Transfusion Investigators. Preoperative Autologous Donation Decreases Allogeneic Transfusion but Increases Exposure to All Red Blood Cell Transfusion: Results of a Meta-analysis. Arch Intern Med 1998;158-6:610-6.

10. Aerican College of Sports Medicine. ACSM's guidelines for exercise testing and prescription., first ed. Philadelphia: Lippincott Williams \& Wilkins, 2000.

11. Sawka MN, Joyner MJ, Miles DS, Robertson RJ, Spriet LL, Young AJ. American College of Sports Medicine position stand. The use of blood doping as an ergogenic aid. Med Sci Sports Exerc 1996;28-6:i-viii.

12. Berglund B, Ekblom B. Effect of recombinant human erythropoietin treatment on blood pressure and some haematological parameters in healthy men. J Intern Med 1991;229-2:125-30.

13. Hall GM, Peerbhoy D, Shenkin A, Parker CJ, Salmon P. Relationship of the functional recovery after hip arthroplasty to the neuroendocrine and inflammatory responses. Br J Anaesth 2001;87-4:537-42.

14. Kehlet H. Multimodal approach to control postoperative pathophysiology and rehabilitation. Br J Anaesth 1997;785:606-17.

15. Brandi LS, Oleggini M, Lachi S, Frediani M, Bevilacqua S, Mosca F, Ferrannini E. Energy metabolism of surgical patients in the early postoperative period: a reappraisal. Crit Care Med 1988;16-1:18-22.

16. Fredrix EW, Soeters PB, von Meyenfeldt MF, Saris WH. Resting energy expenditure in cancer patients before and after gastrointestinal surgery. JPEN J Parenter Enteral Nutr 1991;15-6:604-7.

17. Cooper C, Storer. T. Exercise testing and interpretation. Cambridge: University press, 2001.

18. Coyle EF, Hopper MK, Coggan AR. Maximal oxygen uptake relative to plasma volume expansion. Int J Sports Med 1990; 11-2:116-9.

19. Krip B, Gledhill N, Jamnik V, Warburton D. Effect of alterations in blood volume on cardiac function during maximal exercise. Med Sci Exerc 1997;29-11: 1469-76.

\section{ACKNOWLEDGEMENT:}

This study was conducted with a research grant by Ortho-biotech, a division of Janssen-Cilag. There were no restrictions regarding publication. 



\section{CHAPTER 7}

\section{A functional physiological evaluation of recovery during the first year after total hip replacement}

Pilot P, Verburg AD, Os JJ van, Koolen JJ, Geesink RGT, Kuipers H

A functional physiological evaluation of recovery during the first year after total hip replacement (submitted) 


\section{AbstRact}

Major surgery is accompanied by a significant decrease in haemoglobin concentration. It is generally assumed that a high postoperative haemoglobin level enhances recovery. Objectives of this study were to determine the influence of blood loss on exercise capacity. All patients scheduled for elective primary total hip replacement in a critical pathway, from April 2002 to February 2004. Cardiovascular fitness was assessed in 200 patients with an incremental exercise test on a cycle ergometer with continuous ECG and metabolic cart. A clear decline in exercise capacity shortly after surgery was seen $\left(23 \% \mathrm{~W}_{\max } ; 20 \% \mathrm{VO}_{2, \max }\right)$. The fittest patients had the largest relative decline. Patients who were not able to perform maximal exercise showed the same decline in power output. No relationship between the decrease in haemoglobin concentration and decline in power output or oxygen consumption was noted. Neither when absolute nor with relative decline in haemoglobin was taken. One exercise test had to be terminated prematurely due to a-symptomatic ST-depression. On average, patients showed a reduction in exercise capacity of $23 \%$ shortly after total hip replacement. No relationship between the decrease in haemoglobin concentration and exercise capacity was found in haemoglobin levels above $8.0 \mathrm{~g} / \mathrm{dl}$. 


\section{INTRODUCTION}

Osteoarthritis (OA) of the hip is a major cause of pain and disability in the elderly. Prevalence of $\mathrm{OA}$ is increasing due to an aging population. Patients with OA are most likely to be obese and have more impairments of aerobic capacity than normal subjects.1,2 Since in 1960 Charnley $^{3}$ started with his total hip replacement for painful and severely impaired patients, the number of hip and knee replacements has rapidly increased. Both due to excellent results and an aging population a widening of indications for total hip replacment (THR). ${ }^{4}$ High age, poor physical condition or comorbidity are no longer a reason to refuse a patient for surgery. However, it is known that in patients who are severely deconditioned the morbidity after surgery is higher. ${ }^{5}$

How physical condition influences the rehabilitation and clinical outcome is unknown. Although several authors have demonstrated the feasibility of symptom limited exercise testing in OA patients, limited information is available about physical recovery early after surgery. 1,2,6,7 The limited knowledge can be partly explained by the small number of patients in the published studies making it impossible to stratify for pre-operative condition. In addition nowadays most patients are treated in clinical pathways in which length of stay (LOS) is reduced to three to six days whereas previously patients were hospitalised for weeks. Another major change is that patients start their intensive rehabilitation on the day after surgery.

Objectives of this study were to obtain values of functional physiological recovery after total hip replacement in patients with different levels of pre-operative physical condition. This was tested with (early) maximum symptom limited cardiopulmonary exercise testing on a bicycle ergometer.

\section{MATERIALS AND METHOdS}

Cardiovascular fitness was assessed in 200 healthy patients scheduled for elective primary total hip replacement. All patients were treated in an accelerated stay program (Joint Care ${ }^{\circledR}$, Biomet, the Netherlands). In this program patients start their rehabilitation (e.g. walking) on the first day after surgery. If postoperative haemoglobin level dropped below 8.0 or $8.8 \mathrm{~g} / \mathrm{dl}^{-1}$ patients received blood transfusion. This decision was made by the anaesthesiologist based on ASA grading and the course of surgery.

All patients received oral and written information and signed an informed consent. After consenting, patients who volunteered to participate in the study performed a symptom limited incremental exercise test (CPX) on a cycle ergometer to assess cardiovascular fitness. This test was conducted within two weeks prior to surgery. During testing, a multi-channel ECG was recorded. Patients performed four stages incremental exercise testing on a Recohr P bicycle ergometer (Lode, Groningen, The Netherlands). Crank length was reduced from $17.5 \mathrm{~cm}$ to 8 $\mathrm{cm}$ to limit the range of flexion needed in the hip. The frequency had to be at least 40 revolutions (rpm) per minute whereas no maximum rate was set.

The institutional review and ethics board of our hospital approved the study.

\section{Exercise protocol}

After calibration of the metabolic cart, the patient was seated on the ergometer and the appropriate saddle height was set. Each patient was instructed about the test and the stop criteria. Stop criteria were defined as: ST-depression exceeding two millimetres, ST-elevation 
greater than one millimetre, significant T-top changes, increase in ectopic beats during incremental load, relevant clinical chest pain, decreased consciousness or if the patient wanted to stop. The ECG electrodes and the metabolic cart were connected. The exercise protocol consisted of four stages, warming-up, sub-maximal, incremental symptom limited maximal phase, cooling-down. After two minutes warming-up at 0 watt, the sub-maximal phase consisted of 2 minutes at 20 watt, two minutes at 40 watt and two minutes at 60 watt. After the submaximal phase the workload was increased every minute by 10 watts. After the incremental phase was completed the cooling-down was the same as the warming-up phase.

The test protocol was designed in such a way that most tests would take approximately 10 minutes after warming-up, which is considered an optimal test length for maximum power output. ${ }^{8}$

\section{Exercise data}

Inspiratory and expiratory gases were analysed using a metabolic cart (Oxycon Delta, Jaeger Tonnies). 'Breath by Breath' analysis was used to measure the oxygen consumption $\left(\mathrm{VO}_{2}\right.$; $\mathrm{ml} / \mathrm{min}$ ), carbon dioxide production $\left(\mathrm{VCO}_{2} ; \mathrm{ml} / \mathrm{min}\right.$ ) and minute ventilation (Ve; $\left.1 / \mathrm{min}\right)$. To assessing cardiovascular fitness the maximum $\mathrm{VO}_{2}$ and maximum Wattage were used. The abbreviations of physiological variables used in study are listed in Table 1 . Patients performed maximum CPX testing preoperatively and on day 4, 23, 39, 90 and 365 after surgery. On day 2 and 3 patients were tested sub-maximal.

Table 1. Abbreviations of the physiological variables used

\begin{tabular}{ll}
\hline $\mathrm{W}_{\max }$ & $=$ maximum power output produced by the patient \\
$\mathrm{VO}_{2, \max }$ & $=$ maximum oxygen consumption $(\mathrm{ml} / \mathrm{min})$ \\
$\mathrm{VCO}_{2}$ & $=$ carbon dioxide production $(\mathrm{ml} / \mathrm{min})$ \\
$\mathrm{RER}$ & $=$ Respiratory exchange ratio $\left(\mathrm{VCO}_{2 \max } / \mathrm{VO}_{2, \max }\right)$ \\
$\%$ APMTHR & $=$ Percentage of Age Predicted Maximum Target Heart Range \\
METs & $=$ Metabolic equivalent of resting value
\end{tabular}

Maximal exercise is defined as reaching 85 percent of the age predicted maximum target heart rate (APMTHR) ${ }^{9}$ or respiratory exchange ratio (RER) above 1.0. After the initial exercise test patients were classified for their level of exercise capacity according to the American Heart Association. ${ }^{10}$ Gender and age were accounted for by this scoring system.

\section{Statistical analysis}

The data were stored in a database and correlations were analysed with SPSS 11.0 (SPSS Inc. Chicago Illinois). All variables were tested for homogeneity of variance and normal distribution before statistical analysis was applied. A Repeated Measurement Analysis was done with post hoc analysis with Hochberg's procedure. When appropriate, the tests involving the withinsubject factor(s) were adjusted for heterogeneity of variances and covariances using the Greenhouse-Geisser corrected significance values (Mauchly's test). Alpha was set on 0.05. Data are expressed as mean \pm S.D. unless otherwise stated. 
If one of the six assessments was missing, except from day 0 or day 4 , this missing value was substituted with the average value of the assessments before and directly after. If the last value was missing the last measurement was carried forward.

\section{RESULTS}

200 patients were included in the study. The data gathered in these patients were analysed according to 'the intention-to-treat' principle. If patients missed just one follow up moment this value was replaced by the average of the previous and following value. If patients did not have the pre-operative or day four test than they were excluded, leaving 156 patients for repeated measurement analysis.

Patient characteristics are shown in Table 2, and the exercise test values are presented in Table 3. Patients were stratified by pre-operative condition into groups according to the AHA classification. ${ }^{10}$ Age and gender was accounted for in this classification. These data are shown in Figures 1 and 2. In Figure 3 the patients performing maximal exercise are compared to patients not performing maximal exercise. Power output for males versus females is shown in Figure 4.

Table 2. Patient characteristics

\begin{tabular}{lcccc}
\hline & Unit & Average & SD & Range \\
\hline Age & Years & 64.5 & 8.6 & $39-82$ \\
Gender & Male / female & $79 / 121$ & & \\
Length & $\mathrm{Cm}$ & 170 & 8.0 & $150-194$ \\
Weight & $\mathrm{Kg}$ & 75.3 & 11.0 & $47-110$ \\
BMl & $\mathrm{kg} / \mathrm{m}^{2}$ & 26.4 & 3.0 & $18.4-35.5$ \\
Medical history & $\mathrm{DM} \mathrm{(n)}$ & 5 & & \\
& $\mathrm{HT}(\mathrm{n})$ & 39 & & \\
& DVT/PE (n) & 4 & & \\
& & & & \\
\hline
\end{tabular}

\section{Surgery}

Average time of surgery was 65.5 min (SD:13.6; range 40-120) and 92\% had spinal anaesthesia. In $52 \%$ an uncemented prosthesis was used, in $25 \%$ an hybrid or reversed hybrid and $23 \%$ a cemented prosthesis was used. All patients received an anatomically shaped Anatomic Benoist Girard (ABG) I stem and ABG II cup (Stryker ${ }^{\circledR}$, Waardenburg, the Netherlands).

\section{Exercise testing related complications}

In one patient the first sub-maximal test, two days after surgery was terminated because patient showed a-symptomatic ST depression. This patient had a haemoglobin level of $8.2 \mathrm{~g} / \mathrm{dl}$. After transfusion of one unit of allogeneic blood this ST-depression was unchanged during rest and sub-maximal testing. Echo evaluation of the heart, Thallium scan and catheterisation were all negative. At two years follow-up this patient had no cardiac complaints. 
maximum oxygen consumption/kg body weight

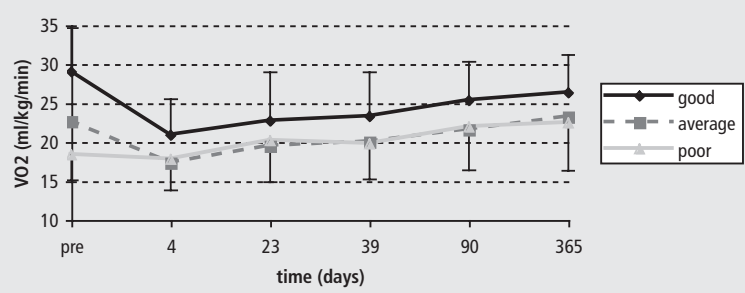

maximum oxygen consumption/kg body weight

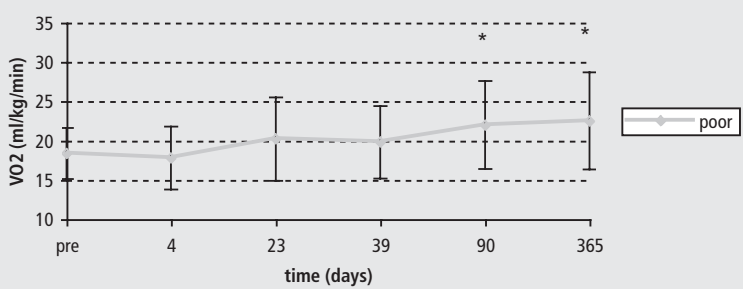

maximum oxygen consumption/kg body weight

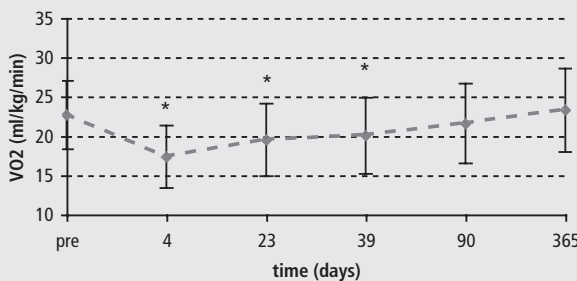

$-\rightarrow-$ - average

maximum oxygen consumption/kg body weight

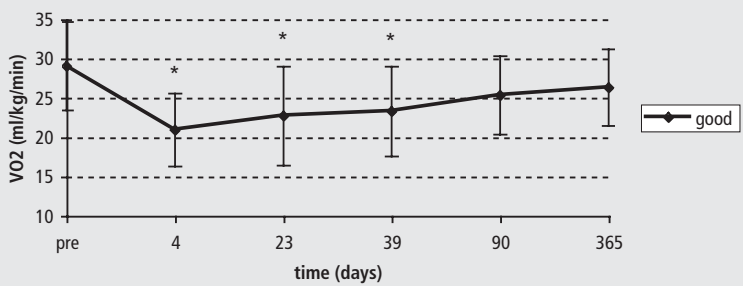

Figure 1a-d. 1a) Maximum oxygen consumption corrected for body weight for the total group (n=156), 1b) The physical poor condition group showing no statistical siginificant decline after surgery. From day 90 and on this group shows a significant improvement of condition ( $n=43)$. 1c) The physical average group showing a significant decline after surgery from day 4 to day 39. This decline disappears at day 90 ( $n=80) 1$ ) The physical good condition group also shows the significant decline after surgery on to day 39. This difference also disappears from day 90 and on ( $n=33$ ). 
power output

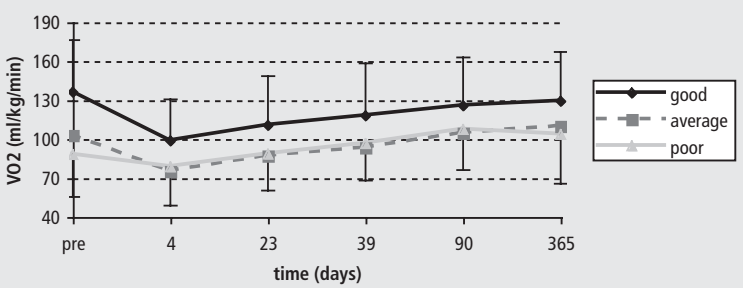

power output (poor group)

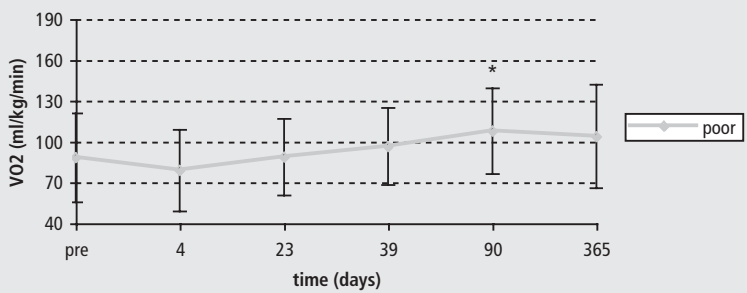

power output (average group)

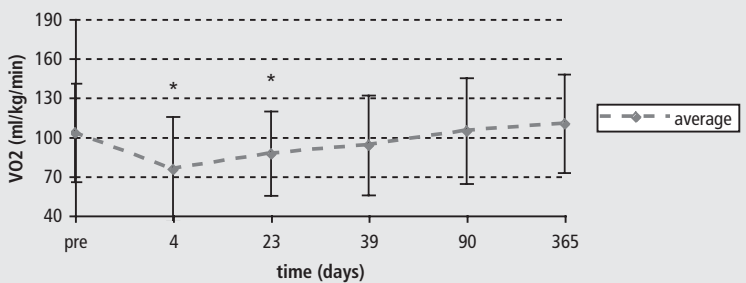

power output (good group)

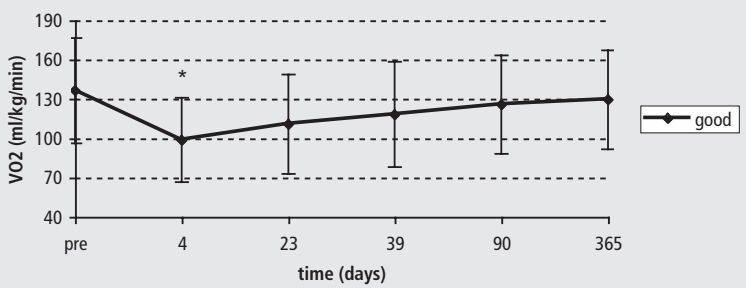

Figure 2a-d. 1a) Maximum power output for the total group (n=156), 1b) The physical poor condition group ( $n=43)$ showing no statistical significant decline after surgery. On day 90 this group shows a significant improvement of condition that disappears at day 365. 1c) The physical average group $(n=80)$ showing a significant decline after surgery from day 4 to day 23. This decline disappears from day 90 and on. 1d) The physical good condition group( $n=33$ ) also shows the significant decline only on day 4 after surgery. This difference disappears from day 23 and on. 


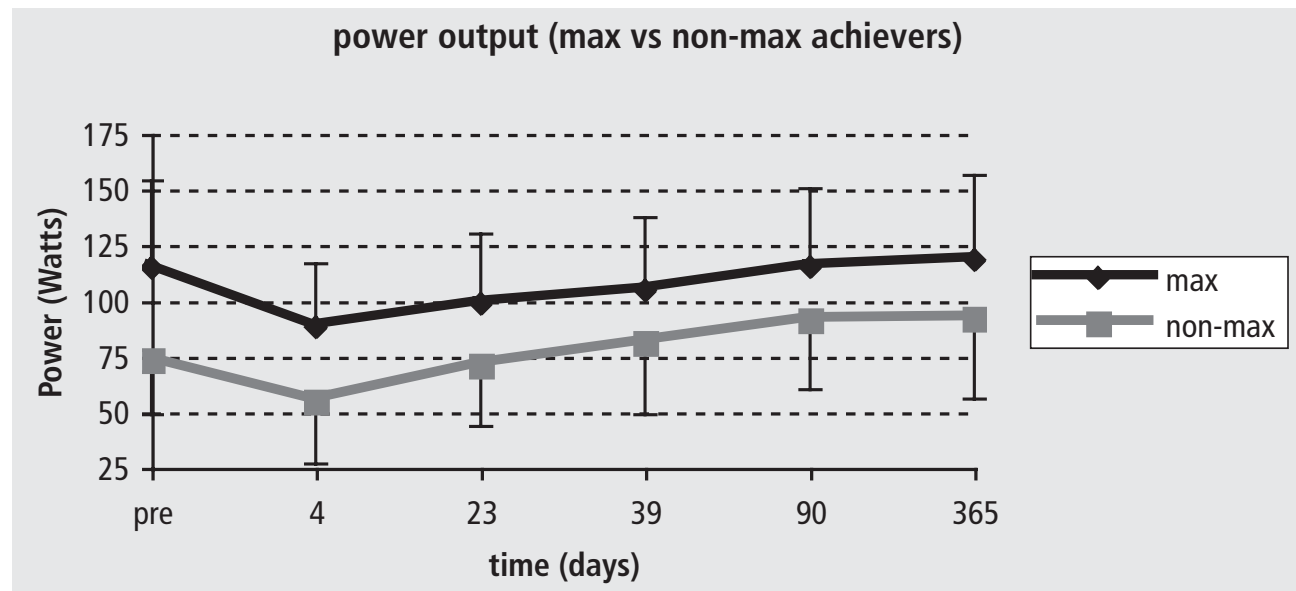

Figure 3. Maximum power output is shown for the group achieving maximum effort preoperative and on day 4 and 23 after surgery (max) compared to the group who did not achieve maximum effort as defined by reaching $85 \%$ of APMTHR or RER $>1.0$. Maximal achievers are shown plus SD, non-maximal achievers are shown minus $S D$.

\section{Power output by Gender}

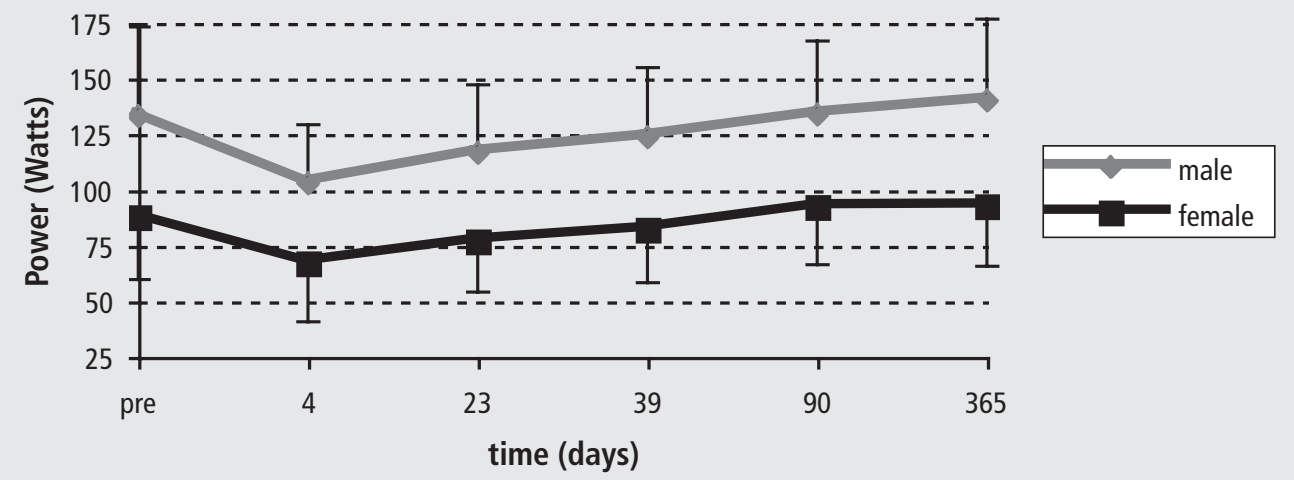

Figure 4. Maximum power output for male versus female in all patients. Male are shown plus SD, female minus $S D$.

\section{Complications}

There were 27 (13.5\%) clinical complications or complications leading to readmission. More than half of them were wound associated (8.0\%). From these wound problems $1.5 \%$ was a deep infection treated with wound debridement without extraction of the prosthesis. Two percent of the patients had cardiovascular complications. Dislocations were seen in 2 patients (1\%). These were no complications during or directly after exercise testing, or any complications that could be related to the exercise testing. 


\section{DISCUSSION}

Early after total hip replacement patients showed an average decline of $23 \%$ in exercise capacity. The physically fittest patients had the largest decline $(28 \%)$ in power output compared to the unfit patients (11\%). This contrast was even larger in oxygen uptake capacity ( $28 \%$ vs $3 \%$ ). The patients with average to good condition had regained their pre-operative values after three months, whereas the physical poor group reached surprisingly and consistently higher values, compared to pre-operative, at three months after surgery, although the level of statistical significance was not reached. No influences of gender or ability to perform maximum exercise were seen.

It seems that the patients with a good condition 'suffer' most from the impaired period after surgery. The rehabilitation process probably slowed down these patients whereas patients with poor pre-operative condition were stimulated by rehabilitation. The critical pathway, which was used for all patients, started with intense mobilisation the day after surgery. During this rehabilitation phase patients with a poor pre-operative condition probably equalled or even exceeded their normal daily life energy expenditure. This in contrast to the patients with average or good condition who probably are limited in their daily activities causing limited energy expenditure compared to their normal daily life.

Peak (or maximum) oxygen consumption is an indicator of a subject's maximal exercise capability; changes in this measure tend to be affected primarily by changes in the frequency or intensity of vigorous physical activity. ${ }^{2}$ However the maximum power output during testing reflects the patients actual exercise capacity and might especially during rehabilitation be of greater importance than maximum oxygen consumption. The combination of oxygen consumption and workload reflects the efficiency of the musculoskeletal system. An inefficient system will require greater muscular energy consumption (and thus oxygen consumption) to perform a given task than an efficient (or normal) one will. ${ }^{2}$

Maximum workload determines what patients are able to achieve in rehabilitation after total hip replacement, irrespective of their peak $\mathrm{VO}_{2}$ or AT. If we compare the maximum workload of all groups with Metabolic Equivalents (MET's) ( 1 MET $=3.5 \mathrm{ml} / \mathrm{kg} / \mathrm{min})$, the physical poorest group achieved 5.0 MET's on day four. Daily physical activity accounts for 3-6 MET's, ${ }^{11}$ which enabled all groups to participate in rehabilitation. From this we conclude that almost all patients tested were able to participate in rehabilitation. In our population only patients without a history of cardiovascular abnormalities were tested.

In major abdominal surgery Older et $a 1.5$ reported a three times higher mortality rate for patients with a poor physical condition (5.9\% versus 18\%), and a ten times higher mortality in patients with a poor condition associated with pre-operative ischaemia (4\% versus $42 \%$ ). They concluded that pre-operative ischaemia and pre-operative cardiac failure are independent risk factors for peri-operative mortality in the elderly. Hardly any of our patients had the low condition grade as the population used by Older et al. ${ }^{5}$ Moreover no patient in our series was pre-operatively diagnosed with cardiac ischaemia. Cardiopulmonary exercise testing might be a good and inexpensive instrument for pre-operative risk evaluation and decision-making in patients scheduled for total hip replacement. Patients with cardiac abnormalities during exercise testing can be monitored with Holter analysis or prophylacticly treated with beta-blockers.

We did not see any influence of patients who did not perform maximal exercise, nor in gender if looked at the changes in exercise capacity over time. On average patients who are 
unable to perform maximal exercise have the same decline in power output compared to the maximal achievers. So on top of their inability to perform maximal exercise they have their regular decline after surgery making their exercise capacity very low, thereby decreasing their ability to rehabilitate. Besides screening for cardiac abnormalities, pre-operative exercise testing might be a good screening tool for these patients. Non maximal achievers combined with a poor condition might participate in a pre-operative training program.

Kehlet et al. and Anderson et al. showed that using fast track surgery (critical pathway), post-operative organ dysfunction appears attenuated, as demonstrated in studies evaluating pulmonary function, ileus, fatigue, the cardiovascular responses to exercise, preservation of body composition and generation of muscle force. ${ }^{12-15}$

As a consequence, post-operative hospital stay has been reduced considerably. These observations suggest that the risk of 'medical' complications, such as post-operative cardiopulmonary dysfunction, was reduced. ${ }^{13,15,16}$ These observations are supported by our findings because we saw no cardiac abnormalities during exercise testing and by the fact that the physical poor group had no significant decline after surgery. We believe that the absence of this setback in physically poor patients was caused by the critical pathway patients were treated in.

CPX testing early after total hip replacement has not previously been reported. We believe that early CPX testing on a stationary bike, with reduced crank does not compromise prosthesis survival in any way. During stand up from a chair larger forces are applied to the hip joint than during cycling.

In conclusion, early post-operative exercise testing in patients shortly after total hip replacement shows that the physical fit patients have the largest decline due to surgery. Patients with a poor physical condition, treated in an accelerated stay program had no significant decline in condition after surgery. This absence of set back might prevent these patients from morbidity due to the surgical stress. No significant cardiac abnormalities were noted during exercise testing of these healthy patients. 


\section{REFERENCES}

1. Philbin EF, Ries MD, French TS. Feasibility of maximal cardiopulmonary exercise testing in patients with end-stage arthritis of the hip and knee prior to total joint arthroplasty. Chest 1995;108(1):174-81.

2. Ries MD, Philbin EF, Groff GD, Sheesley KA, Richman JA, Lynch F, Jr. Effect of total hip arthroplasty on cardiovascular fitness. J Arthroplasty 1997;12(1):84-90.

3. Charnley J. Arthroplasty of the hip. A new operation. Lancet 1961;1(7187):1129-32.

4. Ostendorf M. Outcome assessment of total hip arthroplasty in the Netherlands and Sweden. Utrecht: University medical centre Utrecht; 2004.

5. Older P, Smith R, Courtney P, Hone R. Preoperative evaluation of cardiac failure and ischemia in elderly patients by cardiopulmonary exercise testing. Chest 1993;104(3):701-4.

6. Ries MD, Philbin EF, Groff GD, Sheesley KA, Richman JA, Lynch F, Jr. Improvement in cardiovascular fitness after total knee arthroplasty. J Bone Joint Surg Am 1996;78(11):1696-701.

7. Philbin EF, Groff GD, Ries MD, Miller TE. Cardiovascular fitness and health in patients with end-stage osteoarthritis. Arthritis Rheum 1995;38(6):799-805.

8. Wasserman K, Hansen J, Sue D, Whipp B, R. C. Principles of exercise testing and interpretation. Philadelphia: Williams \& Wilkins, 1994.; 1994.

9. ACSM. ACSM's guidelines for exercise testing and prescription. first ed. Philadelphia: Lippincott Williams \& Wilkins; 2000.

10. Cooper C, Storer. T. Exercise testing and interpretation. Cambridge: University press; 2001.

11. Wilmore JH, DL. C. Physiology of sport and exercise. Champaign IL,: Human Kinetics; 1994.

12. Kehlet H,Wilmore DW. Multimodal strategies to improve surgical outcome. Am J Surg 2002; 183: 630-641.

13. Kehlet H, Dahl JB. Anaesthesia, surgery, and challenges in postoperative recovery. Lancet 2003; 362: 1921-1928.

14. Anderson ADG, McNaught CE, MacFie J, Tring I, Barker P, Mitchell CJ. Randomized clinical trial of multimodal optimization and standard perioperative surgical care. Br J Surg 2003; 90: 1497-1504. .

15. Kehlet H, Wilmore DW. Fast-track surgery. Br J Surg 2005;92(1):3-4.

16. Basse L, Thorbøl JE, Løssl K, Kehlet H. Colonic surgery with accelerated rehabiliation or conventional care. Dis Colon Rectum 2004; 47: 271-278. 



\section{CHAPTER 8}

\section{Is minimal invasive surgery less invasive in total hip replacement? A pilot study.}

Pilot P, Kerens B, Draijer WF, Kort NP, ten Kate J, Buurman WA, Kuipers H

Is minimal invasive surgery less invasive in total hip replacement? A pilot study.

(submitted) 


\section{Abstract}

\section{Introduction}

Minimal invasive surgery (MIS) in THR is said to be less traumatic. This study was designed to answer the question whether anterior MIS generates less inflammation and muscle damage than a standard posterolateral (PL) approach.

\section{Materials and methods}

Inflammation parameters (IL-6), muscle damage parameters (H-FABP) and $\mathrm{Hb}$ values were determined pre-operative and at five consecutive moments post-operative in 10 patients operated through a MIS anterior approach compared with 10 patients operated through a PL approach.

\section{Results}

The mean IL-6 concentration increased from $3 \mathrm{pg} / \mathrm{ml}$ pre-operative for both groups to 78.5 (PL) vs 74.8 (MIS) pg/ml 6 hours post-operative and reached a maximum of $100 \mathrm{vs} 90.5 \mathrm{pg} / \mathrm{ml}$ after 24 hours. After this there was a decrease in both groups. The post-operative mean H-FABP concentration increased to 10.7 in the PL group vs 15.8 in the MIS group ng/l. It formed a plateau and decreased after 24 hours post-operative. The Hb levels were $14.5 \mathrm{~g} / \mathrm{dl}$ pre-operative and decreased to 10.7 (PL) and $10.0 \mathrm{~g} / \mathrm{dl}$ (MIS) 72 hours post-operative.

\section{Conclusion}

We noticed no significant differences in inflammation and muscle damage between the two approaches. No difference in blood loss was seen post-operatively. Although a learning curve may be present this does not explain the absence of a difference between both techniques. We feel that the term MIS is at least doubtful as it does not seem to be less traumatic. 


\section{INTRODUCTION}

Total hip replacement has become one of the most frequently and successfully performed reconstructive procedures in orthopaedic surgery since its introduction more than forty years ago. 1,2 The purpose of total joint replacement of hip and knee is to safely and effectively relieve pain, restore motion, and improve function. ${ }^{3}$ Surgery evokes a series of well-characterized hormonal, metabolic, haematological and immunological changes that are often described as the 'stress response' to surgery. 4,5 This response is often considered essential for survival and is similar to stress response as found in trauma, giving birth and exercise. 6 There has been considerable interest in techniques that ameliorate stress responses, they may enhance recovery after surgery. ${ }^{5}$

Decreased blood loss, less tissue damage and less inflammation should all lead to faster recovery. These arguments are used by industrial companies and several orthopaedic surgeons to promote minimal or less invasive surgical techniques.

For surgery like laparoscopic colorectal resection, appendicitis, splenectomy and inguinal hernia repair ${ }^{7-10}$ meta-analyses have been published showing that despite longer operative times, scopic surgery has advantages like faster recovery and shorter average length of hospital stay. As for orthopaedic surgery, few reports have been published about the results of less invasive surgery. Advantages are varying from cosmetic advantages ${ }^{11}$ to exceptional low complication rates and quick recovery times. ${ }^{1}$

In conventional posterolateral (PL) approach for total hip replacement a large incision is made across the greater trochanter, bluntly dissecting the gluteal muscles and external rotators. Using the PL approach, the muscle layer that has to be opened is the thickest of all described approaches to the hip. In minimal invasive hip technique no muscles are cut; however, considerable traction has to be applied to obtain good exposure. Applying tension on the soft tissues might cause comparable tissue damage, leading to a large inflammatory reaction. We questioned whether surgical trauma in the minimal invasive anterior approach was less compared to surgical trauma in the conventional posterolateral approach. Minimal invasive hip surgery is defined as surgery with an incision smaller than ten centimetres.

Heart type fatty acid binding protein (HFABP) was used as a parameter for muscle damage. HFABP is a sensitive marker for muscle tissue damage. The aqueous cytoplasm of muscle cells contains a marked quantity of $14.5-\mathrm{kDa}$ H-FABP. This small molecule rapidly diffuses out of the damaged muscle tissue. Because of its small molecular weight and large quantity present in the cytoplasm it is considered as a good marker for tissue damage. ${ }^{12}$

Myoglobin was also measured for muscle damage to compare with the H-FABP and to confirm or discuss possible outliers. Creatine kinase (CK), ASAT and LDH were measured to detect possible tissue damage, other than damaged muscle cell.

C-reactive protein (CRP) is the most used parameter in hospital for inflammation, but is rather a-specific whereas IL-6 is a useful sensitive parameter to detect the severity of the inflammatory response to surgery. It is recognized that IL-6 is a main factor in determining the insult induced both by surgery and trauma. ${ }^{13}$

Interleukin-10 (IL-10) is a pleiotropic cytokine and its main function is to limit and terminate inflammatory responses. ${ }^{14}$ To monitor a possible counter regulatory response, this IL-10 was determined.

This pilot study was performed in preparation of a planned randomized clinical trial (RCT) 
comparing tissue damage and inflammation in conventional versus less invasive hip surgery. To diminish the chance of a type II error in the RCT, reference values about the primary outcome variables (muscle damage and inflammation reaction) were collected.

\section{Materials And Methods}

Twenty patients in the Maasland Hospital Sittard admitted for unilateral total hip replacement were enrolled in this non-randomised, non-blinded study between November 2004 and January 2005. Oral and written study information was given and informed consent was obtained from all patients. Pre-operatively, demographic data, body mass index, grade according to the system of the American Society of Anaesthesiologists (ASA) were recorded.

Blood was taken before and at 2, 4, 6, 24 and 72 hours after incision. Immediately after the sample was taken the blood was centrifuged at 3000 rotations per minute for twelve minutes. Plasma was separated from the lower part and stored in a spare tube. The procedure was repeated and plasma was divided over multiple tubes. The samples were kept at minus 20 degrees Celsius. After completion of the study the samples were stored at minus 80 degrees Celsius. The whole procedure was performed with a transportable centrifuge at the patients' bed to keep the time between sampling and centrifuging as short as possible, because IL-6 is an instable cytokine. Haemoglobin levels were determined at 6, 24 and 72 hours after incision at the local laboratory (Abbott Celldyn 4000). Myoglobine, creatine kinase (CK), ASAT, LDH levels were als determined at the local laboratory (Beckmann-Coalter Synchron LXi 725). IL-6 and IL-10 were analysed with ELISA analysis (Immulite 1000; kindly provided by DPC). The H-FABP ELISA was kindly provided by Hbt (Uden, The Netherlands) and performed at the University Maastricht.

\section{Surgical procedures}

All five experienced surgeons perform more than 50 hip replacements a year routinely. Two surgeons use the postero-lateral approach as basic approach and three the straight lateral one. Before performing the minimal invasive approach on patients all surgeons attended a cadaver course. The first three hips were assisted by an experienced MIS surgeon. Each MIS patient was operated by two staff members. The posterior approach, done by two surgeons individually, served as control group.

\section{Posterolateral approach ${ }^{15}$}

Control group surgery was performed through a posterolateral approach. Patients were placed in lateral decubitus. The curved incision was made posterior and across the greater trochanter. Gluteal muscles were dissected bluntly and external rotators were dissected. Next the posterior capsule was incised H-shaped. The hip was luxated and a collum osteotomy was performed with an oscillating saw and the femoral head removed. Acetabular osteophytes and labrum were removed and the acetabulum was reamed. The cup was put in position.

Exposure of the entrance of the femoral shaft was obtained by adduction and endorotation. The femoral shaft was reamed and the prosthesis was put in position. After final reduction, a capsular repair was performed using reefing sutures. The exorotators were reinserted and the fascia reapproximated. Finally subcutis and skin were closed. 


\section{Anterior approach ${ }^{16}$}

Minimal invasive surgery was performed through a single incision anterior approach with specially designed retractors for Stryker ${ }^{\circledR}$ (Precimed, Switzerland) to obtain good exposure. Patients were placed supine on the operation table with both legs draped free. The incision was made 3 to $4 \mathrm{~cm}$ distal to the spina iliaca anterior superior (SIAS) in the palpable gap between the muscles tensor fascia lata and the sartorius. Incision length was approximately half of the expected cup circumference. Subcutaneous fat was bluntly dissected with special care for lateral cutaneus femoral nerve. After cutting the fascia at the medial side of muscle tensor fascia lata and ligating the ascending branches of the lateral femoral circumflex vessels the joint capsule was incised in an H-shape. The capsule was detached at the intertrochanteric line as far as possible to medial and lateral and the anterior part of the labrum was removed. With the femur in neutral position the femoral neck was cut with an oscillating saw and a disc of bone was removed. The head was removed using a corkscrew extractor. After exciding the remnants of the labrum and acetabular osteophytes the acetabulum was reamed and the cup put in position.

Exposure of the entrance of the femoral shaft was obtained by putting a rest under the proximal thigh and extending the femur and by pulling up the calcar ventral with a hook with the leg in a figure four position. At the base of the greater trochanter a capsulotomy was performed and a retractor was placed around the greater trochanter. The femoral shaft was rasped and the prosthesis inserted. After the final reduction a capsular repair was performed using reefing sutures. Finally the skin was closed

\section{Statistics}

The data were stored in a database and correlations were calculated with SPSS 11.0 (SPSS Inc. Chicago Illinois). All variables were tested for homogeneity of variance and normal distribution before statistical analysis was applied. The Student's T-test was used for patient characteristics and surgical outcomes. The haemoglobin levels and markers were tested with a GLM Repeated Measurement Analyses with post-hoc analysis with Hochberg's procedure. When appropriate, the tests involving the within-subject factor(s) were adjusted for heterogeneity of variances and co-variances using the Greenhouse-Geisser corrected significance values (Mauchly's test). Alpha was set on 0.05. Data are expressed as mean \pm S.D. unless otherwise stated.

\section{RESULTS \\ Patient characteristics}

There where no differences between both groups regarding age (67.5 vs 67.9; $\mathrm{p}=0.92$ ) or height (167 cm vs $169 \mathrm{~cm} ; \mathrm{p}=0.68$ ). The body mass index (BMI) was significantly higher in the MIS group (26.4 vs 29.1; $p=0.048$ ). In the posterolateral group were 2 male and 8 female patients. In the MIS group were 4 male and 6 female patients. In the PL group 7 patients had spinal anaesthesia, three patients had general anaesthesia. In the posterolateral group this was 9 vs. 1 . The ASA grading (1-4) for patients in the posterolateral group was 3/7/0/0 versus 4/5/1/0 in the MIS group. 


\section{Operative data}

Duration of the procedure was longer in MIS (81.0 vs $99.5 \mathrm{~min} ; \mathrm{p}=0.056$ ) and the estimated blood loss during the operation was more (540 vs $699 \mathrm{ml}$; =0.28). Incision length was significantly shorter in the MIS group (17.4 vs $8.6 \mathrm{~cm}$; $\mathrm{p}=0.000$ ).

Muscle damage and inflammation The H-FABP data (Fig. 1) shows that the surgical procedure leads to a rapid significant increase in circulating H-FABP $(\mathrm{p}=0.001)$. This represents the damage done to the muscles leading to death of muscle cells. The damage to muscle cells was similar in both surgical groups $(\mathrm{p}=0.44)$. The total amount of muscle tissue damaged after surgery, reflected in the area under the curve, is also similar in both groups. The standard deviation in the MIS group is much larger than in the PL group.

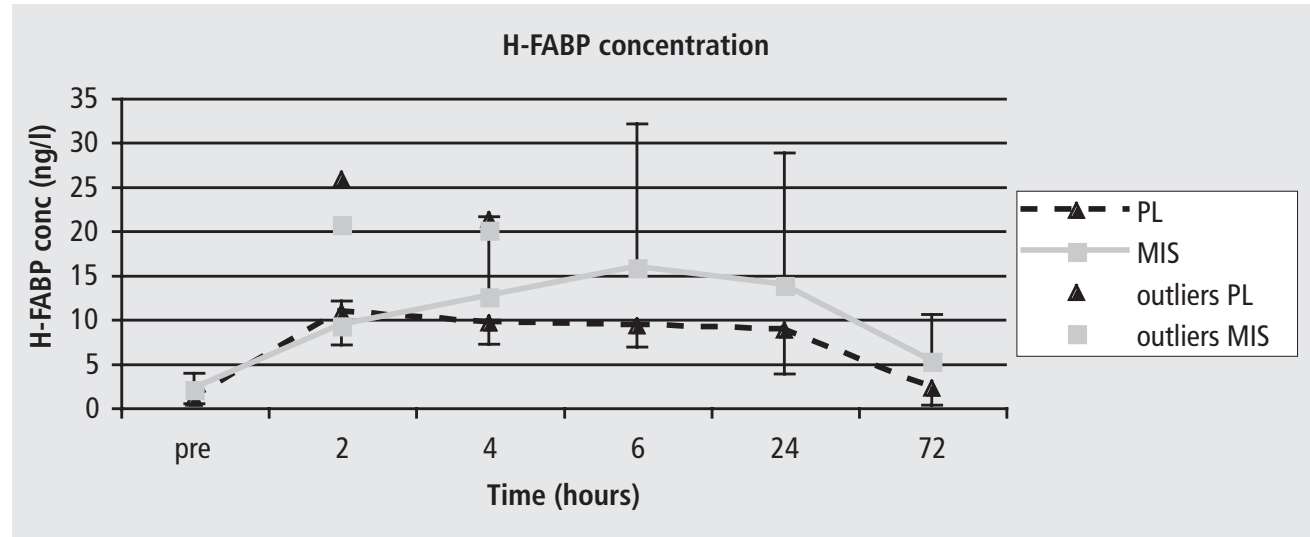

Figure 1. H-FABP concentrations as a function of time for the PL-group (black triangles) and MIS-group (grey squares). The standard deviation is depicted as error bars, positive for the MIS and negative for the PL. Both groups had one patient that was considered as outlier (>2 SD). The outliers at 2 and 4 hours are depicted.

Table 1. The average ASAT, LDH, CK and myoglobin values (SEM) over time.

\begin{tabular}{lccccccc}
\hline & & Pre & 2 hours & 4 hours & $\mathbf{6}$ hours & $\mathbf{2 4}$ hours & $\mathbf{7 2}$ hours \\
\hline ASAT & C & $23.82(1.61)$ & $23.17(1.38)$ & $26.05(1.20)$ & $27.49(1.63)$ & $40.75(2.82)$ & $42.34(2.52)$ \\
$(\mathrm{U} / \mathrm{l})$ & MIS & $22.14(1.71)$ & $18.67(0.51)$ & $21.71(0.71)$ & $23.22(0.90)$ & $30.10(2.80)$ & $30.10(3.57)$ \\
LDH & C & $325.00(16.89)$ & $306.70(16.50)$ & $305.70(12.80)$ & $309.60(12.44)$ & $307.00(19.36)$ & $342.00(12.93)$ \\
$(\mathrm{U} / \mathrm{l})$ & MIS & $376.50(41.34)$ & $282.80(16.49)$ & $307.80(18.70)$ & $295.80(13.55)$ & $264.50(13.22)$ & $338.60(17.74)$ \\
CK & C & $73.10(8.31)$ & $179.50(28.80)$ & $301.30(47.61)$ & $383.20(64.53)$ & $796.30(110.92)$ & $608.60(95.99)$ \\
$(\mathrm{U} / \mathrm{l})$ & MIS & $78.30(10.22)$ & $152.30(14.63)$ & $289.40(40.73)$ & $364.00(51.15)$ & $593.50(140.90)$ & $539.50(142.27)$ \\
Myo & $\mathrm{C}$ & $26.18(2.69)$ & $315.12(63.75)$ & $320.20(52.40)$ & $303.48(35.30)$ & $365.41(53.19)$ & $73.33(11.57)$ \\
$(\mu g / l)$ & MIS & $33.72(8.03)$ & $300.35(30.44)$ & $366.61(48.41)$ & $406.05(64.90)$ & $363.47(118.72)$ & $119.26(30.29)$
\end{tabular}


The trauma of muscle cells in patients reflected by H-FABP leads to a significant increase in IL6 levels after surgery in both surgical groups $(p<0.001)$. The peak in inflammation and the total amount of inflammation was not significantly different in both surgical groups $(p=0.80)$.

Both groups had one patient with over two standard deviations higher than the average. Both patients were considered outliers and left out of the analysis. This happened with the IL-6 as well as with the H-FABP. The H-FABP showed a similar pattern as the myoglobin (myoglobin levels are shown in Table 1).

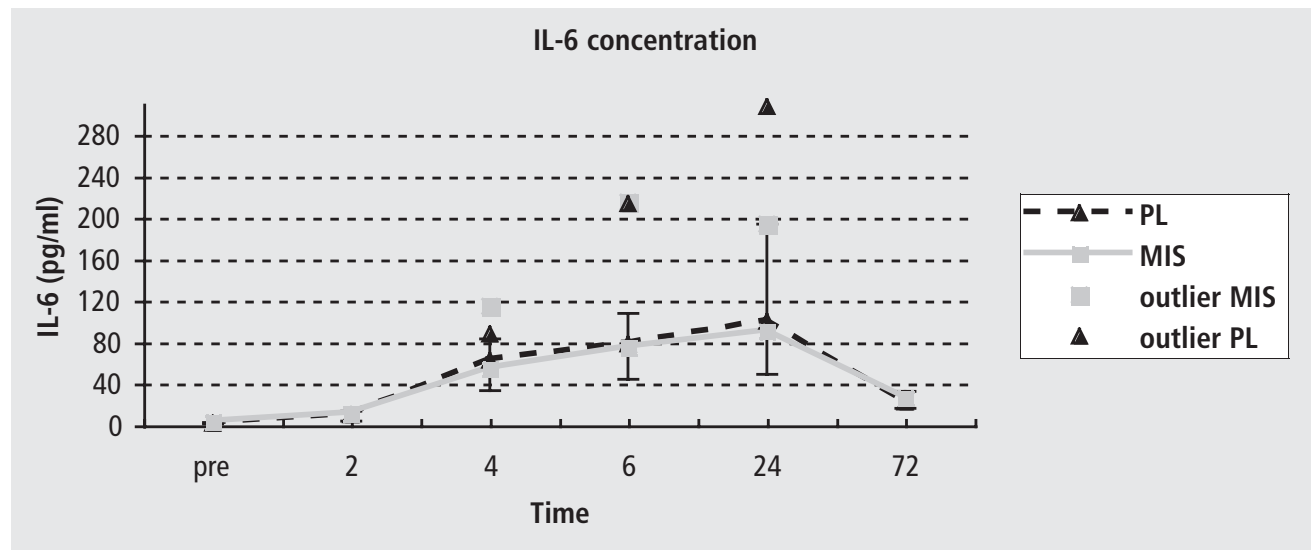

Figure 2. IL-6 concentrations as a function of time for the PL-group (black triangles) and MIS-group (grey squares). The standard deviation is depicted as error bars, positive for the PL and negative for the MIS. Both groups had one patient that was considered as outlier (>2 SD). The outliers at 4,6 and 24 hours are depicted.

\section{HAEMOGLOBIN LEVELS}

Haemoglobin $(\mathrm{Hb})$ levels are shown in Figure 3. The data of the two groups were not significantly different ( $p=0.89$ )(GLM repeated measurement analysis). One blood transfusion was necessary in a cardiovascular compromised patient belonging to the MIS group. This patient had a postoperative $\mathrm{Hb}$ value of $9.7 \mathrm{~g} / \mathrm{dl}$. The blood transfusion was given immediately post-operatively. 


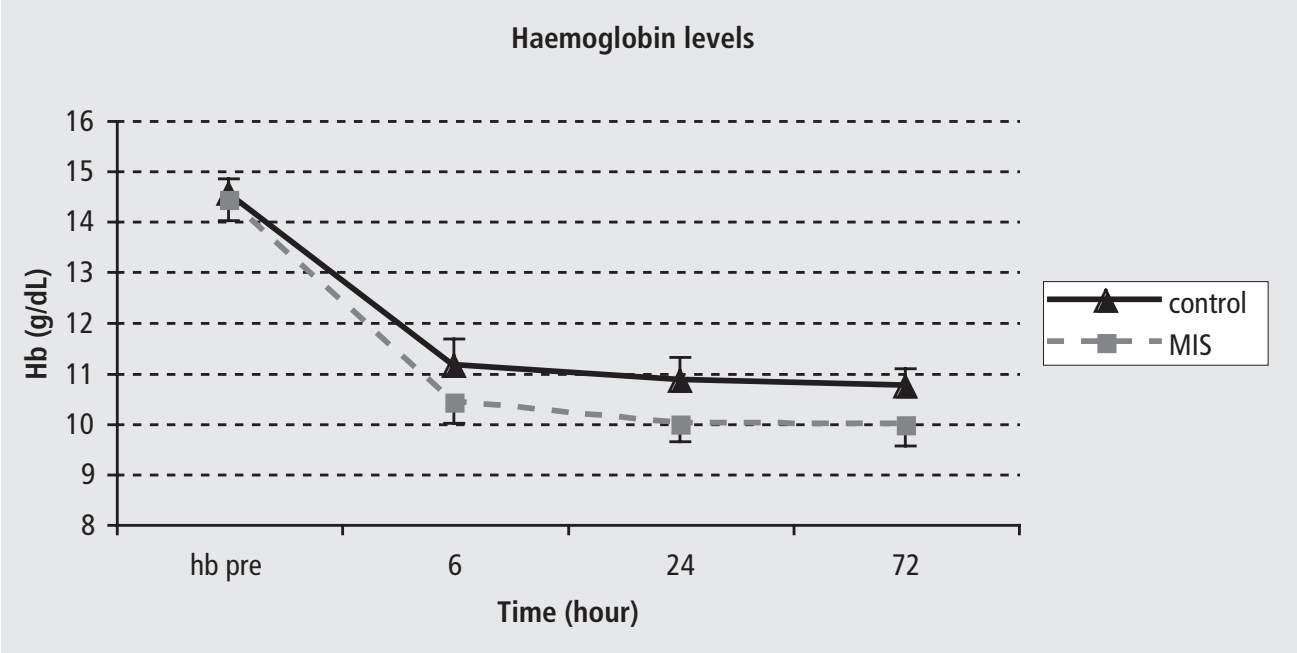

Figure 3. The course of haemoglobin as a function of time for the PL-group (black triangles) and MIS-group (grey squares). The standard deviation is depicted as error bars, positive for the PL and negative for the MIS.

\section{Discussion}

Decreased blood loss, less soft tissue damage and inflammation leading to fast recovery are arguments used in promoting minimal invasive surgery. In our study we investigated the amount of muscle damage and inflammation generated by total hip replacement (THR) with a conventional posterolateral approach compared to the minimal invasive approach. Although we made a much larger incision in the PL approach with seemingly more direct muscle damage than in the MIS, we measured a comparable amount of muscle damage and a comparable inflammatory response in both groups.

Surgeons aim to moderate tissue damage and inflammation reaction after surgery to improve outcome. Decreased blood loss, less tissue damage and less inflammation are all supposed to lead to faster recovery. Especially muscle damage is assumed to lead to a delayed functional recovery. If tissue damage was only caused by cutting tissue the PL approach could be expected to generate more muscle damage, thus slower recovery than the minimal invasive anterior approach. In the minimal invasive approach no muscles are dissected, and a smaller incision is made. To obtain a good view during surgery considerable tension must be applied to the soft tissue. We questioned whether applying high tension to the muscles during surgery is associated with muscle cell necrosis.

The H-FABP data (Fig. 1) showed that the surgical procedure led to a rapid increase in circulating H-FABP in both groups. The peak values of circulating H-FABP and the total amount of muscle tissue damaged after surgery, reflected in the area under the curve, were similar in both groups. Therefore it is suggested that the amount of muscle cell damage due to extensive tension applied to the muscle tissue in the anterior MIS approach is similar to the cell death caused by cutting the muscle tissue in the conventional PL approach.

$\mathrm{H}$-FABP was used as the marker for muscle damage because it is specific for muscle damage and 
reacts fast due to its small molecular weight. Besides H-FABP, muscle cells also contain large quantities of myoglobin. This low molecular weight protein $(17.8-\mathrm{kDa})$ was taken as secondary marker to verify outlying values of H-FABP, and furthermore, to evaluate whether myoglobin could be used instead of H-FABP. Plasma myoglobin levels showed a comparable elevation to $\mathrm{H}$ FABP in both approaches. This confirms that some outlying values were not measuring errors and that myoglobin is as useful as H-FABP in assessing the extent of muscle damage with different surgical approaches to the hip. This in contrast to creatine kinase (CK), a relatively large molecule (86-kDa), whose response to muscle damage is slow (Table 1).

Also ASAT and LDH have been used as markers for muscle damage. The values of ASAT and LDH measured in our series were found not to be specific enough. The results showed that LDH did not, and ASAT slightly exceeded the upper normal reference values. Therefore these markers can be discarded in future research on tissue damage in different surgical approaches to the hip.

IL-6 has a central role in determining the insult induced both by surgery and trauma. ${ }^{13}$ The surgical trauma led to a significant increase in IL-6 levels after surgery in both surgical groups. One would expect significantly more peak and total reaction to conventional PL approach compared to the anterior MIS approach. However, amount of inflammation was not significantly different in both surgical groups $(\mathrm{p}=0.80)$. The wanted effect of less inflammation in MIS was not found in this pilot study. The anti-inflammatory response was checked with IL-10, an antiinflammatory cytokine, but no reaction of IL-10 in either group was seen. The inflammatory response seen after surgical trauma in THR seems not large enough to generate a tissue protection anti-inflammatory response.

The estimated blood loss per-operative and the lower $\mathrm{Hb}$ post-operative showed that MIS is not associated with less bleeding. Though less bleeding is expected due to a smaller incision, this increased blood loss may have been caused by the longer operation time.

The reduction of tissue damage and inflammation after surgery is adventageous as it is supposed to improve functional outcome. But is functional outcome after surgery really better with MIS? Ogonda et al. ${ }^{17}$ showed that MIS hip replacement performed through a single-incision posterior approach by a high-volume hip surgeon with extensive experience in less invasive approaches to the hip offered no significant benefit in the early post-operative period compared with a standard incision of $16 \mathrm{~cm}$. Other contrasting studies like Wenz et al. ${ }^{18}$ used a historical cohort and multiple surgeons. Di Gioia et al. who detected significant differences used a retrospective design with small patient numbers $(n=33) .{ }^{19}$ The finding of Ogonda supports our findings that MIS in hip replacement has little benefit over the conventional approach.

Because the differences in muscle damage and inflammation were expected to be relatively small we chose for this pilot study to compare the conventional PL approach with the minimal invasive approach. For the PL approach the muscle layer that was opened is the thickest of all described approaches to the hip. In the minimal invasive technique no muscles were cut but considerable traction had to be applied to obtain good exposure. In this way, it was tried to make a large contrast between the MIS and PL approaches.

We are aware of the fact that the MIS approach was a relatively new technique in our hospital whereas that the PL approach was a routine technique. This may have created a learning curve effect. Since the operating surgeons attended real life teaching courses, cadaver workshops and were assisted by experienced guest surgeons, we did not expect this to be of such an 
influence. However, more research on inflammation and tissue damage is needed to confirm our findings.

In conclusion, our pilot study of 20 patients shows that muscle damage and inflammatory reaction in the conventional posterolateral approach is comparable to the minimal invasive anterior approach to the hip. However, the limitations of this pilot study should be taken in account. At this moment there is no evidence for faster recovery nor better results with this new approach except for the cosmetic shorter scar. In our opinion it is necessary that surgeons who do use these techniques should keep collecting data in order to provide scientific evidence that minimal invasive hip surgery is less tissue damaging. 


\section{REFERENCES}

1. Kennon RE, Keggi JM, Wetmore RS, Zatorski LE, Huo MH, Keggi KJ. Total Hip Arthroplasty Through a Minimally Invasive Anterior Surgical Approach. J Bone Joint Surg Am 2003;85(90004):39-48.

2. Charnley J. The long-term results of low-friction arthroplasty of the hip performed as a primary intervention. J Bone Joint Surg Br 1972;54(1):61-76.

3. Ranawat CS, Ranawat AS. Minimally invasive total joint arthroplasty: where are we going? J Bone Joint Surg Am 2003;85-A(11):2070-1.

4. Cruickshank AM, Fraser WD, Burns HJ, Van Damme J, Shenkin A. Response of serum interleukin-6 in patients undergoing elective surgery of varying severity. Clin Sci (Lond) 1990;79(2):161-5.

5. Hall GM, Peerbhoy D, Shenkin A, Parker CJ, Salmon P. Hip and knee arthroplasty: a comparison and the endocrine, metabolic and inflammatory responses. Clin Sci (Lond) 2000;98(1):71-9.

6. Ostrowski K, Hermann C, Bangash A, Schjerling P, Nielsen JN, Pedersen BK. A trauma-like elevation of plasma cytokines in humans in response to treadmill running. J Physiol 1998;513 ( Pt 3):889-94.

7. Memon MA, Cooper NJ, Memon B, Memon MI, Abrams KR. Meta-analysis of randomized clinical trials comparing open and laparoscopic inguinal hernia repair. Br J Surg 2003;90(12):1479-92.

8. Schwenk W, Haase O, Neudecker J, Muller J. Short term benefits for laparoscopic colorectal resection. Cochrane Database Syst Rev 2005;3:CD003145.

9. Sauerland S, Lefering R, Neugebauer EA. Laparoscopic versus open surgery for suspected appendicitis. Cochrane Database Syst Rev 2004(4):CD001546.

10. Winslow ER, Brunt LM. Perioperative outcomes of laparoscopic versus open splenectomy: a meta-analysis with an emphasis on complications. Surgery 2003;134(4):647-53; discussion 654-5.

11. Goldstein WM, Branson JJ, Berland KA, Gordon AC. Minimal-Incision Total Hip Arthroplasty. J Bone Joint Surg Am 2003;85(90004):33-38.

12. Alhadi HA, Fox KA. Do we need additional markers of myocyte necrosis: the potential value of heart fatty-acidbinding protein. Qjm 2004;97(4):187-98.

13. Pape HC, Schmidt RE, Rice J, van Griensven M, das Gupta R, Krettek C, et al. Biochemical changes after trauma and skeletal surgery of the lower extremity: quantification of the operative burden. Crit Care Med 2000;28(10):3441-8.

14. Boehler A. The role of interleukin-10 in lung transplantation. Transpl Immunol 2002;9(2-4):121-4.

15. Hoppenfeld S, DeBoer P, Thomas HA. Surgical exposures in orthopaedics : the anatomic approach. 3rd ed. Philadelphia. Penn. ; London: Lippincott Williams \& Wilkins; 2003.

16. Hozack WJ. Minimally invasive total joint arthroplasty. Heidelberg: Springer; 2004.

17. Ogonda L, Wilson R, Archbold P, Lawlor M, Humphreys P, O'Brien S, et al. A minimal-incision technique in total hip arthroplasty does not improve early postoperative outcomes. A prospective, randomized, controlled trial. J Bone Joint Surg Am 2005;87(4):701-10.

18. Wenz JF, Gurkan I, Jibodh SR. Mini-incision total hip arthroplasty: a comparative assessment of perioperative outcomes. Orthopedics 2002;25(10):1031-43.

19. DiGioia AM, 3rd, Plakseychuk AY, Levison TJ, Jaramaz B. Mini-incision technique for total hip arthroplasty with navigation. J Arthroplasty 2003;18(2):123-8. 


\section{CHAPTER 9}

\section{Experience in the first four years of Rapid Recovery; is it safe?}

Pilot P, Bogie R, Draijer WF, Verburg AD, van Os JJ, Kuipers H

Experience in the first four yours of Rapid Recovery; is it safe?

(In Press, suppl Injury) 


\section{Abstract}

\section{Introduction}

Average length of hospital stay in total hip surgery is decreasing. In 2003 the length of stay was on average 11 days. More recently, many hospitals started with rapid recovery programs like Joint Care ${ }^{\circledast}$. In Joint Care ${ }^{\circledR}$ patients are discharged on the fifth post-operative day. As a result patients are subjected to an intensive rehabilitation program and return home with relatively fresh surgical wounds.

\section{Materials and methods}

All patients treated in Joint Care ${ }^{\circledR}$, with at least 6 months and maximum 4 years of follow up, were evaluated. All clinical and out patient charts were evaluated as well as the nursery records.

\section{Results}

Between February 2000 and February 2004, within Joint Care ${ }^{\circledR}, 611$ patients with total hip replacement were evaluated. Average age was 66.3 (sd 9.3; range 24-86) and 68\% was female. $92 \%$ of all patients were discharged on the planned fifth post-operative morning (sd 1.7; range 6-25). 3.8\% had wound problems, of which $2.3 \%$ had prolonged wound production (mostly drainage hole) and in 1.5\% a superficial wound infection was suspected. A $6.4 \%$ readmission rate was seen, $3.4 \%$ for hip dislocations, $1.5 \%$ for observation of the wound, $1.2 \%$ for deep wound infection (all were debrided, no Girdlestone) and $0.3 \%$ for cardiac events. No patient died during the admission.

\section{Conclusion}

Most patients (92\%) were discharged on the fifth post-operative morning. The number of serious complications was acceptable. Dislocations caused half of all re-admissions. There were no signs that the intensive rehabilitation program caused more complications compared to the previous regimen. These results were encouraging to continue the rapid recovery program. 


\section{INTRODUCTION}

Several hospitals in the Netherlands use integrated hip and knee programs. Most of these programs do well if scored on quality indicators. ${ }^{1}$ However, it is unknown how these process indicators are correlated to clinical outcomes. During the last two decades many hospitals started working with self-developed programs, but since 1997 some hospitals have been working with the principles of Joint Care ${ }^{\circledR}$ (JC).1,2 The Maasland hospital Sittard has used this program since the beginning of 2000 .

All patients treated in JC are scheduled for discharge on the fifth post-operative morning. This is a significant reduction considering that until 2003 the average length of stay in the Netherlands was 11 days. ${ }^{3}$ As a result patients are subjected to an intensive rehabilitation program and return home with relatively fresh surgical wounds. Little data have been published whether an intensified rehabilitation and early discharge is associated with more complications or readmissions. Therefore the purpose in the present study was to show that, besides scoring high on quality indicators, the clinical pathway used in our hospital had good clinical outcomes.

\section{MATERIALS AND METHODS}

All patients with a total hip replacement treated in the Joint Care ${ }^{\circledast}$ (JC) program from February 2000 till February 2004 were evaluated. All clinical and out patient charts were evaluated as well as the nursery records. Patients needed a minimal follow-up of six months. The average follow-up was 2.5 years. All patients were admitted on the pre-operative evening and discharge was scheduled on the fifth post-operative morning. In total 611 total hips were implanted by seven different orthopaedic surgeons with an average of 87 (range 2-159) patients per surgeon. There were two standard incisions used (straight lateral and postero-lateral). The average age was 66.3 (SD: 9.3; 24-86) and 68\% was female (Table 1).

\section{Table 1. Patients characteristics}

\begin{tabular}{lccc}
\hline & & & SD (range) \\
\hline Number of patients & $\mathrm{n}$ & 611 & \\
Female / male & $\mathrm{n}$ & $415 / 196$ & $9.3(24-86)$ \\
Age & yrs & 66.3 & $1.7(6-25)$ \\
Hospitalisation & days & 6.4 & \\
$\%$ discharge $5^{\text {th }}$ p.o. morning & $\%$ & 92 & \\
\hline
\end{tabular}

\section{RESULTS}

The average hospitalisation time was 6.4 days (sd: 1.7; range (6-25). Of these $92.0 \%$ was discharged as scheduled on the fifth post-operative morning, $3.5 \%$ on day 6 or $7,1.7 \%$ on day 8 or 9 and $2.8 \%$ stayed longer. Discharged before the fifth postoperative day was not allowed. No patients died during the clinical period, two patients died during follow up. All complications are shown in Table 2. 
Table 2. Total amount of complications and complications leading to readmission. * prolonged wound production $(2.3 \%)+$ observation wound $(1.5 \%)$

\begin{tabular}{lcc}
\hline Complication $^{*}$ & Total & Readmission \\
\hline Wound problems & $3.8 \%$ & $1.5 \%$ \\
Deep infect & $1.2 \%$ & $1.1 \%$ \\
Girdlestone & $0 \%$ & $0 \%$ \\
Dislocations & $3.4 \%$ & $3.2 \%$ \\
Fracture & $1.0 \%$ & $0.2 \%$ \\
Neurological & $0.7 \%$ & $0.1 \%$ \\
Cardiopulmonal & $3.0 \%$ & $0.3 \%$ \\
Blood transfusions & $30 \%$ & \\
\hline
\end{tabular}

\section{Wound complications}

Wound problems occured in $3.8 \%$, of which $2.3 \%$ had prolonged wound production (mostly drainage hole) and in $1.5 \%$ a superficial wound infection was suspected. $1.2 \%$ of these patients needed surgical removal of debris. All but one of these were readmitted.

\section{Dislocations and fractures}

The total percentage of dislocations was 3.4\% ( $n=22)$ of which $2.4 \%$ was within 3 months postoperative. The number of dislocations for each surgeon and his surgical approach are depicted in Figure 1.

During six surgical procedures a trochanter avulsion was seen, five of these were directly peroperative fixated with a cerclage wire. One avulsion (trochanter minor) was assessed as stable, but dislocated after several weeks. This was fixated in a second procedure.

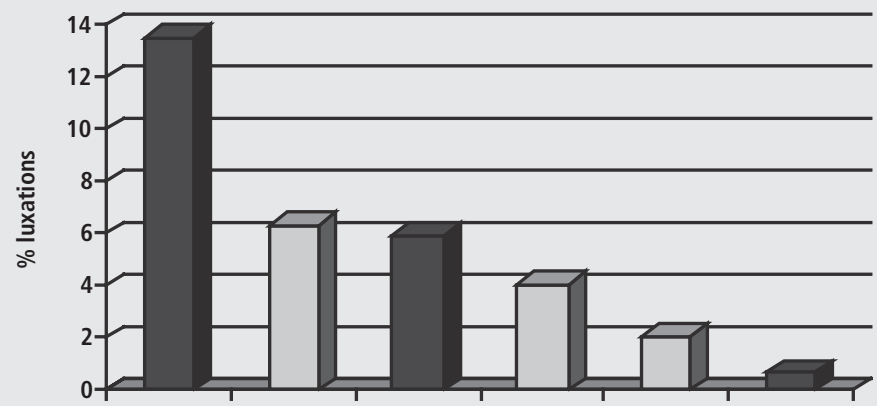

surgeon 1 surgeon 2 surgeon 3 surgeon 4 surgeon 5 surgeon 6

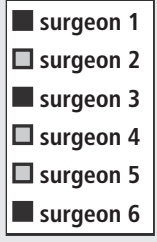

Figure 1. The percentage of dislocations is depicted for each individual surgeon. Black bars are surgeons with postero-lateral approach; grey bars are surgeons with straight lateral approach. Surgeon 7 only did 2 operations and is not depicted. 


\section{Other complications}

$3 \%(n=18)$ had a cardiopulmonary complication of which 5 were considered serious; 2 had myocardial infarction (MI) during the hospitalisation period. One patient had a MI two weeks after discharge and the other one after 6 months. One patient developed a pulmonary embolism.

Neurological complication were observed in $0.7 \%$; one had a neuropraxis of the femoral nerve and one patient had a mild CVA after surgery. Two patients had a CVA at 6 and 36 months after surgery.

\section{Readmissions}

Readmission occurred in $6.4 \%$ ( $n=38$ ) of the patients, 3.4\% $(n=20)$ due to dislocations (in which readmission is routine in our hospital), $1.2 \%(n=7)$ times for wound debridement, $0.3 \%(n=2)$ for cardiac events and $1.5 \%(n=9)$ for wound observation. None of the prosthesis needed to be removed due to an infection or loosening (Table 2).

\section{ANAEMIA}

In $30 \%$ of the patients an allogeneic blood transfusion was needed. When patients received blood transfusions they received on average 1.6 units. All blood transfusions were given for haemoglobin levels below 8.0 or $8.8 \mathrm{~g} / \mathrm{dl}$.

\section{$\mathrm{Hb}(\mathrm{g} / \mathrm{dl})$}

\section{haemoglobin level}

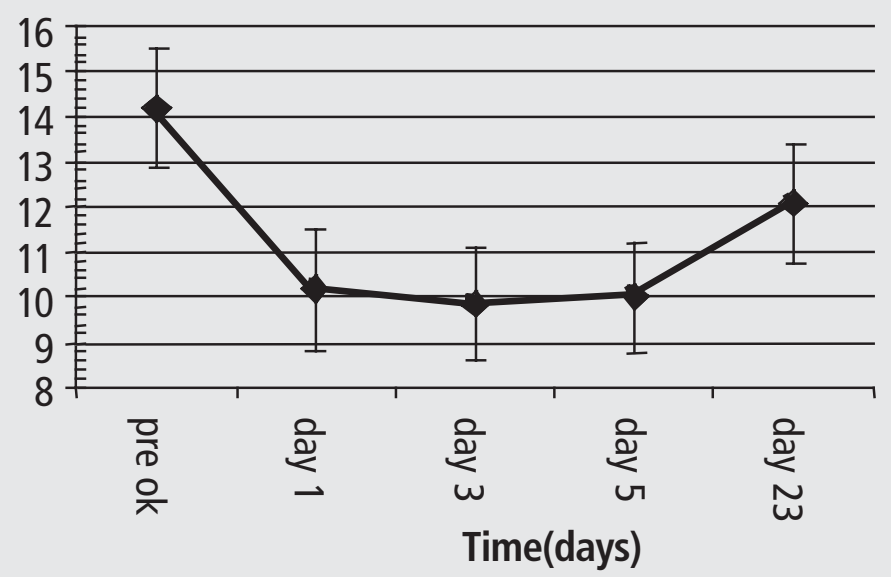

Figure 2. The course of the Haemoglobin level over time in $\mathrm{g} / \mathrm{dl}$. Each time moment is plotted $\pm S D$. 


\section{DISCUSSION}

We evaluated whether the introduction of a clinical pathway for total hip replacement which scored high on quality indicators, ${ }^{1}$ was also associated with good clinical outcomes. Most patients $(92 \%)$ were discharged on the scheduled fifth post-operative day and there was an acceptable number of readmissions $(6.4 \%)$. There were no complications seen that could be attributed to the aggressive rehabilitation program.

When patients were not discharged on the fifth post-operative morning (8\%), this was largely attributable to wound-healing problems. Usually there was persistent leakage from the drain hole. In these cases most of the patients were discharged within two or three additional days. Deep infections were defined as needing debridement, using gentamycine beads and intravenous antibiotics. This occurred in $1.2 \%$ of the patients. One of these deep infections occurred during hospitalisation, the others after discharge and these patients were readmitted. Our reported percentage is slightly over the $0.5-1.0 \%$ usually reported in the literature. ${ }^{4}$ However, in these series the number of prosthesis extraction due to an infection is higher than found in the present study. In our series none of the prosthesis needed to be removed. An aggressive approach to wound-healing problems appears to be successful.

Besides the $1.2 \%$ readmissions for surgical debridement, $3.4 \%$ was readmitted with a dislocated hip. In our hospital these patients are readmitted for instructions and measuring of the brace. The number of dislocations is comparable to other major series.4-11 Especially if we take into account the dislocations (2.4\%) that occurred during the first three months after surgery. A follow up of three months for dislocations is often reported in the literature. The surgical approach did not influence the number of dislocations, although one surgeon with the posterolateral approach had a high number of dislocations (Figure 1.).

In three patients a cerebrovascular accident occurred, however two of these happened after six respectively 36 months. These were considered as not related to surgery. The third, on the day of surgery. One patient suffered a neuropraxis of the n.femoralis, which recovered within months.

Most of the cardiac events (3\%) were mild, although two patients $(0.3 \%)$ had a myocardial infarction (MI) during hospitalisation and were treated by the cardiologist. Both MI occurred at the day of surgery and had no relation with the rehabilitation program. Two patients were readmitted with a MI. One of these patients was readmitted two weeks after surgery, but the other after 6 months. The first might be related to the surgery but the other was not considered to have any relationship with the surgery.

There were six trochanter avulsions (1.0\%). Five of these fractures were fixed with cerclage wires during the initial surgery. The other was judged as stable but needed surgical fixation several weeks after surgery to correct dislocation of the fragment. No association with the aggressive rehabilitation program was found.

In $30 \%$ of the patients an allogeneic blood transfusion was needed. When patients received blood transfusions they received on average 1.6 units. All blood transfusions were given for haemoglobin levels below 8.0 or $8.8 \mathrm{~g} / \mathrm{dl}$. Before returning to the ward the anaesthesiologist on clinical judgement decided whether the post-operative trigger was 8.0 or 8.8 . This decision was made depending on co-morbidity classified in the ASA classification and intra-operative blood loss. The percentage of blood transfusions in literature greatly differ, but our rates are below those of a major European survey. ${ }^{12}$ In none of our patients the anaemia was a problem for the aggressive rehabilitation program. 
We are aware of a possible selection bias. Due to limited capacity of the Joint Care ${ }^{\circledR}$ program only half of all patient could be treated in JC. Based on this limited capacity, mostly ASA I and II patients were treated in this CP. This might have influenced the results because comorbidity like diabetes is known to cause more wound problems. On the other hand it seems that patients with good exercise capacity 'suffer' most from the tranquil period following surgery, as shown in a previous study. ${ }^{13}$ It is postulated that the low performers were stimulated by rehabilitation whereas standard rehabilitation slows down these patients. This stimulation might prevent morbidity because these poor performers have little space for setback. The so-called 'floor effect'. The compromised patients are prone to complications if their poor condition is further worsened by inactivity. In major abdominal surgery Older et al. ${ }^{14}$ reported higher mortality rate for patients with poor conditions, especially if they had pre-existent myocardial ischaemia. During this rehabilitation in this CP patients with a poor pre-operative condition probably equalled or even exceeded their normal daily life energy expenditure.

In general the present study shows the clinical pathway (Joint Care ${ }^{\circledast}$ ) for total hip replacement to be a good and safe improvement of care that also causes a reduction in the length of stay. Besides scoring high on quality indicators the clinical pathway also shows good clinical results.

\section{REFERENCES}

1. Legierse CM, Hardus. Kwaliteit vergeleken. Medisch Contact 2004; 59 (50): 1990-93.

2. Dreessen F, Engelen M, Pilot P. Eerder naar huis. Medisch Contact 2000; 55 (42): 1492

3. Ziekenhuisstatistiek. Op www.prismant.nl.

4. Blom AW, Taylor AH, Pattison G et al. Infection after total hip arthroplasty. The Avon experience. J Bone Joint Surg Br. 2003; 85 (7): 956-9.

5. Phillips CB, Barrett JA, Losina E. Incidence rates of dislocation, pulmonary embolism, and deep infection during the first six months after elective total hip replacement. J Bone Joint Surg Am 2003; 85-A(1): 20-6.

6. Franklin J, Robertsson O, Gestsson J et al. Revision and complication rates in 654 Exeter total hip replacements, with a maximum follow-up of 20 years. BMC Musculoskelet Disord 2003; 4 (1): 6. Print 2003 Mar 25.

7. Gaine WJ, Ramamohan NA et AL. Wound infection in hip and knee arthroplasty. J Bone Joint Surg Br 2000; 82 (4): 561-5.

8. Solomon DH, Losina E, Baron JA et al. Contribution of hospital characteristics to the volume-outcome relationship: dislocation and infection following total hip replacement surgery. Arthritis Rheum 2002; 46 (9): 2436-44.

9. Williams $\mathrm{O}$, Fitzpatrick R, Hajat $\mathrm{S}$ et al. Mortality, morbidity, and 1-year outcomes of primary elective total hip arthroplasty. J Arthroplasty 2002; 17 (2): 165-71.

10. Mohamed NN, Barrett JA, Katz JN et al. Rates and outcomes of primary and revision total hip replacement in the United States medicare population. J Bone Joint Surg Am 2003; 85-A (1): 27-32.

11. Herberts P, Malchau H. Long-term registration has improved the quality of hip replacement: a review of the Swedish THR Register comparing 160,000 cases. Acta Orthop Scand 2000; 71 (2): 111-21.

12. Rosencher N, Kerkkamp HEM, Macheras G. Orthopedic Surgery Transfusion Hemoglobin European Overview (OSTHEO) study: blood management in elective knee and hip arthroplasty in Europe. Transfusion 2003; 43: 459-

13. Pilot P, Verburg AD, Moonen AFCM, Koolen JJ, van Os JJ, Geesink RGT, et al. Feasibility of early cardiopulmonary exercise testing after total hip arthroplasty. TATM 2005;7(1 (suppl)):68 (A33).

14. Older P, Smith R, Courtney P, Hone R. Preoperative evaluation of cardiac failure and ischemia in elderly patients by cardiopulmonary exercise testing. Chest 1993;104(3):701-4. 



\section{CHAPTER 10}

General Discussion 


\section{INTRODUCTION}

Total hip replacement is one of the most succesful major operations. In this thesis various aspects of peri-operative care have been investigated. The research focussed on aspects that may play a role in peri-operative recovery. The use of a clinical pathway for total hip replacement (THR), the short and long term physiological recovery and influence of post-operative anaemia after THR were the main topics.

\section{SUMMARY OF FINDINGS}

The main conclusions of the studies described in this thesis were as follows. Chapter 2 showed a critical review of literature on peri-operative care. The use of a critical pathway combining perioperative pain management with a shift from general to local anaesthesia and opioid sparing, fluid management, restrictive transfusion policy are the best options for most patients. Chapter 3, described the aspects of the critical pathway used in the Maasland Hospital since 2000 for treatment of THR. Major changes were: a pre-clinical planning of the total care project, including out patient care. The patient is not seen as 'sick' but as disabled. Group therapy and hospitalisation took place in a living room simulation. The use of a coach and extensive information was provided to the patient. The pre- peri- and post-operative level of communication and information was optimised. After discharge an intensive after care was realized. Chapter 4 established that early maximal symptom-limited exercise testing was possible. The short-term results of a large prospective population were presented in Chapter 5 with the main focus on post-operative blood loss. Chapter 5 surprisingly showed that there was no correlation between the haemoglobin drop after surgery and the decline in exercise capacity. In Chapter 6 it is shown that with the use of autologous blood the post-operative drop in haemoglobin can almost completely been restored, leading to a minimum decline in exercise capacity. In Chapter 7 it was demonstrated that physical recovery after total hip replacement takes approximatelty three months and that the patients, who are most physically fit, suffer most from a decline in power output after surgery. The results of a pilot study presented in Chapter 8 showed no beneficial effect of minimal invasive hip surgery in terms of tissue damage and inflammation. Finally in Chapter 9 good clinical results of the first four years of THR in a clinical pathway were shown. In this general discussion, these results will be placed in the context of their consequences for daily practice of total hip replacement and adjacent procedures. This chapter will end with recommendations for further research.

\section{OPTIMISING PERI-OPERATIVE CARE}

In 1933 Böhler ${ }^{3}$ described a simple test to see whether a hip fracture patient was suited for surgery or needed further cardiac evaluation before surgery. He asked patients to hold their breath for 15 seconds. If these patients were able to successfully withstand this test they were considered suitable for surgery. Knowledge of peri-operative care was limited in that time. The first person to publish on optimising peri-operative care for elective surgical patients was Henrik Kehlet from Copenhagen. ${ }^{4-6}$ Kehlet and co-workers synthesized, integrated and applied research outcomes in a comprehensive programme, now commonly referred to as 'fast-track surgery'. ${ }^{6}$ The thrust of this approach was to reduce the physiological and psychological stresses associated 
with operations, thereby reducing a number of potential complications. Fast-track surgery evolved as a co-ordinated effort, combining modern concepts of patient education with newer anaesthetic and analgesic methods. The intentions were to reduce the stress response, and minimize pain and discomfort, as the key pathogenic factor in post-operative morbidity, excluding failures of surgical and anaesthetic technique, is the surgical stress response with subsequent increased demands on organ function. ${ }^{4}$

From a patient's perspective pain, nausea and vomiting are the most common post-operative complaints. In addition to being unpleasant they may also be important factors limiting early discharge due to impaired rehabilitation. 4

Besides optimising the medical care, the care process has evolved since the introduction of the total hip replacement. Nowadays, high volume, elective procedures, like THR, should be performed in a clinical pathway (CP). These CPs are designed to minimize delays, optimise resources and maximize quality of care. ${ }^{7}$ In a recent literature review Kim et al. ${ }^{8}$ concluded that clinical pathways for hip and knee replacements appeared to be successful in reducing costs and length of stay in the acute care hospital, without compromising patient outcomes.

These days, most hospitals use some form of CP. Most of these programs do well when scored on quality indicators. ${ }^{9}$ This thesis revealed that besides scoring well on so-called quality indicators, these programs also have good clinical results.

\section{SURGICAL STRESS}

Following (surgical) trauma, patients are subjected to dynamic alterations in the haemodynamic, metabolic, and immune responses that are largely orchestrated by endogenous mediators referred to as cytokines. ${ }^{10}$ The development of this inflammatory response is part of the normal response to injury. Within this inflammatory process there is a delicate balance between the beneficial effects of inflammation and the potential for the process itself to cause remote tissue injury. ${ }^{11}$ For most patients a transfer from general to regional anaesthesia, opioid sparing, adequate fluid management and restrictive transfusion policy are the best options to limit surgical stress.

\section{ANAESTHESIA PRACTICE}

Current anaesthesia practice emphasises pre-operative optimisation, patient selection and education, improved peri-operative monitoring, more responsive fluid therapy (i.e. avoidance of hypovolemia and hypervolemia), maintenance of normothermia, and prevention of post-operative nausea and vomiting. 12,13

The concept of multi-modal or 'balanced' analgesia suggests that combinations of several analgesics of different classes and different sites of analgesic administration rather than single analgesic or single technique provide superior pain relief with reduced analgesic related side effects.4,14-16 Besides opioids sparing analgesia is desirable 17 to prevent adverse effects as nausea, vomiting, sedation, dizziness, drowsiness, bladder dysfunction, and constipation, all of which may contribute to a delayed recovery. ${ }^{14}$

The multi-modal analgesia technique is focussed on blocking the nociceptive as well as the inflammatory response. Furthermore pain relief has to be present during rest as well as during 
movement (movement-evoked pain) to be able to participate in an aggressive rehabilitation program to prevent a further setback in physical condition.

\section{MiNIMAL INVASIVE SURGERY}

In minimal invasive hip technique little muscular tissue is cut. However, considerable traction has to be applied on surrounding structures to obtain good exposure. Applying tension on the soft tissues might cause comparable tissue damage, leading to similar inflammatory reactions. We questioned whether surgical trauma in the minimal invasive anterior approach was less compared to surgical trauma in the conventional postero-lateral approach. We noticed no significant differences in inflammation and muscle damage between the two approaches. No difference in post-operative blood loss was seen. Although a learning curve may be present this was not considered to be an explanation for the absence of a difference between both techniques. the term MIS is at least doubtful because it does not seem to be less traumatic. Only one powerful study has been published on the functional outcome in MIS. In this study Lawlor et al. ${ }^{18}$ did not find any difference between a standard incision of $16 \mathrm{~cm}$ compared to single incision minimal invasive hip replacement $(\leq 10.0 \mathrm{~cm})$. This was a single surgeon, prospective randomised blinded trial with functional recovery as primary outcome.

Finally, conventional hip replacement already provides excellent pain relief, functional improvement, and durability with a low complication rate. One might question whether implant malposition, neurovascular injury, poor implant fixation or compromised long-term results might be the result of the reduced visualization. ${ }^{19}$

\section{ANAEMIA}

Blood transfusion is associated with a number of well-recognized risks and complications, like transfusion-related acute lung injury (TRALI) or acute respiratory distress syndrome (ARDS), allergic reactions, transmission of infectious agents, and immunomodulatory effects. ${ }^{20,21}$ Prosthetic surgery is associated with considerable blood loss and blood transfusions are regularly necessary. Even with haemovigilance an overall transfusion rate of 25 to 30 percent is present. ${ }^{22}$ Modern transfusion medicine starts with the implementation of a restrictive transfusion policy. The introduction of this policy should be accompanied by thorough education of both medical and nursing staff. The education should be repeated several times to prevent a relapse to the less rigid regiment and to support the current policy. ${ }^{22}$ The education should focus on the difference between volume substitution and red cell restoration. In daily practice too many patients are transfused with allogeneic blood for volume restitution, mostly based on subjective symptoms like fatigue, weakness, pale skin and diminished physical performance. Although these clinical signs are widely accepted signs of anaemia23 the benefit of blood transfusion on physical performance after surgery is unclear. There are limited data about the relationship between anaemia and functional recovery. Currently there is little clinical evidence that post-operative haemoglobin levels below $8 \mathrm{~g} / \mathrm{dl}^{-1}$ impair functional recovery. In a prospective trial presented in this thesis, evaluating 200 patients four days after total hip replacement, no correlation between blood loss and a decline in power output was detectable. ${ }^{24}$ 


\section{FLUID-BALANCE}

There is continuing debate with regard to the timing, quantity and type of fluid resuscitation during elective major surgery. An increasing number of reports warns for excessive peri-operative intra-vascular volume loading, leading to increased post-operative morbidity and mortality. ${ }^{25}$ Neither crystalloid nor colloid solutions can be expected to be ideal for every patient and in every situation. Most authors recommend a balanced approach to fluid management with colloid administration to provide haemodynamic stability and maintain urine output of $0.5 \mathrm{ml} / \mathrm{kg}^{-1} / \mathrm{h}^{-1}$ and crystalloids administered as maintenance fluids. ${ }^{25}$

A correct dosage of fluid therapy improves patient outcome after surgery, correct fluid therapy is even more important when a restrictive blood transfusion policy is executed.

\section{PhYSICAL RECOVERY AFTER TOTAL HIP SURGERY}

The influence of physical condition on the rehabilitation period and clinical outcome is relatively unknown. Although several authors have proved the feasibility of symptom-limited exercise testing in osteoarthritispatients, limited information is present on early physical recovery after surgery. ${ }^{26-29}$ Firstly, the number of patients was relatively small in the published studies, making it impossible to stratify for pre-operative condition. Secondly, nowadays most patients are treated in clinical pathways in which the length of stay (LOS) is reduced to three to six days and patients start intensive rehabilitation on the day after surgery, whereas previously patients were hospitalised for weeks starting with days of bed rest. In a study described in this thesis a large cohort of two hundred patients was tested four days after total hip replacement. In this cohort an average decline of $23 \%$ in exercise capacity was observed. The physically fittest patients had the largest decline $(28 \%)$ in power output compared to the unfit patients (11\%). This contrast was even larger in absolute oxygen uptake capacity (28\% vs $3 \%$ ). The patients with an average to good fitness level had regained their pre-operative values after three months, whereas the poor physical-fit group had no significant decline after surgery, but showed significant higher values, compared to pre-operative, at three months after surgery. No influences of gender or ability to perform maximum exercise were seen.

It seems that the patients with a good level of fitness 'suffer' most from the impaired period after surgery. The rehabilitation process, with unsupervised therapy, probably slowed down these patients whereas patients with poor pre-operative condition were stimulated by rehabilitation. The critical pathway, which was used for all patients, started with intense mobilisation the day after surgery. During this rehabilitation-phase patients with a poor preoperative condition probably equalled or even exceeded their normal daily life energy expenditure. This in contrast to the patients with average or good levels of fitness who probably were limited in their daily activities causing limited energy expenditure compared to their normal, pre-operative, daily life.

The patients with average to good levels of fitness had regained their pre-operative values after three months. The physical poor fitness group had no significant decline after surgery, but showed significantly higher values, compared to the pre-operative, at three months after surgery. 


\section{RECOMMENDATIONS FOR FUTURE RESEARCH}

This thesis has contributed to the further understanding in physiological recovery after total hip replacement and the influence of blood loss after major surgery. All patients described were treated in clinical pathways (CP). These CPs are not only the current standard of treatment for total hip replacement, but they are also well suited for clinical research, because they have clearly defined goals and milestones.

The research in this thesis was focussed on relatively healthy people. In future, more research should focus on the compromised patient and the treatment of hip fracture patients Comorbidity and mortality is a larger problem in these groups than in the elective healthy total hip patients.

The need for well-defined studies of intra-operative and post-operative fluid therapy are mandatory, especially because nowadays most patients are treated in accelerated stay programs and even slight morbidity like nausea and vomiting can prolong the length of stay.

Whereas a short length of stay after surgery has become standard of care, the optimal length and intension of the rehabilitation program is still unknown. More knowledge about the intensity of post-operative rehabilitation and the efficacy of post-operative physiotherapy is needed.

\section{Conclusions}

It is clear that a multimodal approach is essential for optimal, rapid recovery. The use of a critical pathway combining peri-operative pain management with a shift from general to local anaesthesia and opioid sparing, fluid management, restrictive transfusion policy are the best options for most patients. The current tendency in fluid management is a restricted per-operative regimen. A correct dosage of fluid therapy improves patient outcome after surgery, whereas correct fluid therapy is even more important when a restrictive blood transfusion policy is executed. Therefore the need for well-defined studies of intra-operative and post-operative fluid therapy are essential. Pre-operative training appears not to be beneficial for recovery, whereas post-operative physical therapy appears to be useful. The physical recovery takes at least three months and the physically fittest patients suffer most from a decline in exercise capacity after total hip replacement. Whether minimal invasive surgery contributes to faster recovery, remains to be established. The success of a fast-track surgery program requires a multi-disciplinary approach involving anaesthesiologists, surgeons, nurses, and physical therapists. ${ }^{6}$ 


\section{REFERENCES}

1. Charnley J. Arthroplasty of the hip. A new operation. Lancet 1961;1(7187):1129-32.

2. Ostendorf M, Johnell O, Malchau H, Dhert WJ, Schrijvers AJ, Verbout AJ. The epidemiology of total hip replacement in The Netherlands and Sweden: present status and future needs. Acta Orthop Scand 2002;73(3):282-6.

3. Böhler L. Technik der Knochenbruchbehandlung. Wien: Wilhelm Maudrich; 1933.

4. Kehlet H. Multimodal approach to control postoperative pathophysiology and rehabilitation. Br J Anaesth 1997;78(5):606-17.

5. Kehlet H. Surgical stress response: does endoscopic surgery confer an advantage? World J Surg 1999;23(8):801-7.

6. Kehlet H, Wilmore DW. Fast-track surgery. Br J Surg 2005;92(1):3-4.

7. Coffey RJ, Richards JS, Remmert CS, LeRoy SS, Schoville RR, Baldwin PJ. An introduction to critical paths. Qual Manag Health Care 1992;1(1):45-54.

8. Kim S, Losina E, Solomon DH, Wright J, Katz JN. Effectiveness of clinical pathways for total knee and total hip arthroplasty. The Journal of Arthroplasty 2003;18(1):69-74.

9. Legierse C, Hardus K, van Rijnsoever M, Verbout A, Marting I, Matthijssen R, et al. Quality compared [kwaliteit vergeleken]. Med Cont 2004;59(50):1990-3.

10. Giannoudis PV, Hildebrand F, Pape HC. Inflammatory serum markers in patients with multiple trauma. Can they predict outcome? J Bone Joint Surg Br 2004;86(3):313-23.

11. Smith RM, Giannoudis PV. Trauma and the immune response. J R Soc Med 1998;91(8):417-20.

12. Kehlet H, Dahl JB. Anaesthesia, surgery, and challenges in postoperative recovery. Lancet 2003;362(9399):1921-8.

13. Kehlet $\mathrm{H}$. Effect of postoperative pain treatment on outcome-current status and future strategies. Langenbecks Arch Surg 2004;389(4):244-9.

14. Joshi GP. Multimodal analgesia techniques and postoperative rehabilitation. Anesthesiol Clin North America 2005;23(1):185-202.

15. Woolf CJ, Hashmi M. Use and abuse of opioid analgesics: potential methods to prevent and deter non-medical consumption of prescription opioids. Curr Opin Investig Drugs 2004;5(1):61-6.

16. Kehlet H, Dahl JB. The value of "multimodal" or "balanced analgesia" in postoperative pain treatment. Anesth Analg 1993;77(5):1048-56.

17. Wheeler M, Oderda GM, Ashburn MA, Lipman AG. Adverse events associated with postoperative opioid analgesia: a systematic review. J Pain 2002;3(3):159-80.

18. Lawlor M, Humphreys P, Morrow E, Ogonda L, Bennett D, Elliott D, et al. Comparison of early postoperative functional levels following total hip replacement using minimally invasive versus standard incisions. A prospective randomized blinded trial. Clin Rehabil 2005;19(5):465-74.

19. Berry DJ, Berger RA, Callaghan JJ, Dorr LD, Duwelius PJ, Hartzband MA, et al. Minimally invasive total hip arthroplasty. Development, early results, and a critical analysis. Presented at the Annual Meeting of the American Orthopaedic Association, Charleston, South Carolina, USA, June 14, 2003. J Bone Joint Surg Am 2003;85-A(11):2235-46.

20. Vamvakas EC, Moore SB. Total potential frequency of autologous blood transfusion in Olmsted County, MN. Mayo Clin Proc 1995;70(1):37-44.

21. Pola E, Papaleo P, Santoliquido A, Gasparini G, Aulisa L, De Santis E. Clinical Factors Associated with an Increased Risk of Perioperative Blood Transfusion in Nonanemic Patients Undergoing Total Hip Arthroplasty. J Bone Joint Surg Am 2004;86(1):57-61.

22. Pilot P, Moonen AFCM, Stuart WC, Bell CAMP, Bogie R, Pinckaers JWM, et al. Limited blood use; Succes due to restrictive policy, education and awareness. [Bloedverbruik aan banden; Succes dankzij restrictief transfusiebeleid, scholing en bewustwording]. Med contact 2005;60(37):1467-9. 
23. Lawrence VA, Silverstein JH, Cornell JE, Pederson T, Noveck H, Carson JL. Higher Hb level is associated with better early functional recovery after hip fracture repair. Transfusion 2003;43(12):1717-22.

24. Pilot P, Verburg AD, Moonen AFCM, Koolen JJ, van Os JJ, Geesink RGT, et al. Feasibility of early cardiopulmonary exercise testing after total hip arthroplasty. TATM 2005;7(1 (suppl)):68 (A33).

25. Joshi GP. Intraoperative fluid restriction improves outcome after major elective gastrointestinal surgery. Anesth Analg 2005;101(2):601-5.

26. Philbin EF, Ries MD, French TS. Feasibility of maximal cardiopulmonary exercise testing in patients with end-stage arthritis of the hip and knee prior to total joint arthroplasty. Chest 1995;108(1):174-81.

27. Ries MD, Philbin EF, Groff GD, Sheesley KA, Richman JA, Lynch F, Jr. Effect of total hip arthroplasty on cardiovascular fitness. J Arthroplasty 1997;12(1):84-90.

28. Ries MD, Philbin EF, Groff GD, Sheesley KA, Richman JA, Lynch F, Jr. Improvement in cardiovascular fitness after total knee arthroplasty. J Bone Joint Surg Am 1996;78(11):1696-701.

29. Philbin EF, Groff GD, Ries MD, Miller TE. Cardiovascular fitness and health in patients with end-stage osteoarthritis. Arthritis Rheum 1995;38(6):799-805. 

SUMMARY

SAMENVATTING 


\section{SUMMARY}

Osteoarthritis (OA) of the hip is a major cause of pain and disability in the elderly. Prevalence of OA is increasing due to an aging population. Since 1960 Charnley started with his total hip replacement for painful and severely impaired patients, the number of hip and knee replacements has rapidly increased. This because a widening of indications for total hip replacement (THR) is seen due to excellent results achieved with the procedure, and due to an aging population. High age, poor physical condition or comorbidity are no longer a reason to refuse a patient surgery.

Besides the number of increasing number of hip and knee replacements, the procedure of total hip and knee replacements has changed significantly over the last decades. Whereas twenty years ago length of stay (LOS) varied from two to six weeks, nowadays most patients are discharged within a week. This has been realised by improving medical care and by introducing clinical pathways (CP).

Outcome after surgery is multifactorial. Chapter 2 reviews scientific studies published in international literature about most aspects influencing peri-operative care. Anxiety reduction was the most important pre-operative aspect and pre-operative training only helped for anxiety reduction. Peri-operative fluid management and opioid sparing anaesthetics and analgesics seem very important. Especially now most patients are treated in accelerated stay programs and even light morbidity like nausea and vomiting can prolong the length of stay. Osteoarthritis of the hip and knee leading to total hip or knee replacements are high-volume, high-cost diagnoses and procedures, likely to have an inefficient variation in the care process. Therefore these diagnoses are well suited for CP. These CP mainly focus on the process of care and less directly on medical improvements. In chapter 3 we described the new aspects of the Joint Care program, the CP we used in the Maasland Hospital Sittard. New aspects of this healthcare concept were: Firstly, more extensive information to the patient. The pre-, peri- and post-operative level of communication and information were optimised. Secondly, there is a pre-clinical planning of the total care project, also outside the hospital. Thirdly, the patient was not seen as 'ill' but as disabled and during the total program the patient is guided by a coach. This coach was someone close to the patient. Fourthly, hospitalisation is in a living room simulation where also group therapy takes place. Fifthly, intensive after care was present. A 24-hour call centre after discharge was available for patients during the first weeks. In case of problems there can be direct contact with a physical therapist or medical doctor. Besides our own positive experiences literature showed that clinical pathways for hip and knee replacements appear to be successful in reducing costs and length of stay in the acute care hospital, with no compromise in patient outcomes.

To determine the success of modifications in surgical procedures and early rehabilitation programs a better knowledge of physiologic alterations after surgery is necessary. Although it was already proven that it was possible to perform cardio pulmonary exercise (CPX) testing in OA patients months after THR, no reports of early physical recovery have been published so far. Therefore we first investigated the possibility of safely performing maximum symptom limited CPX testing early after surgery. In Chapter 4 we showed it was feasible and safe to perform maximum symptom limited CPX-testing in patients four days after total hip replacement. Especially the first days after surgery were very interesting because nowadays a restrictive blood transfusion policy is common. Morbidity and mortality increase when haemoglobin levels below $7.0 \mathrm{~g} / \mathrm{dl}$ are accepted after surgery. However the influence of mild anaemia on exercise capacity during rehabilitation was unknown. In chapter 5 two hundred patients were tested and a 
correlation between exercise capacity and severity of anaemia was sought. Surprisingly, no correlation in post-operative haemoglobin levels and physical performance was found. Dominating multifactorial surgical stress responses were the most likely explanation. Based on these observations, we believe that restrictive transfusion policy in healthy patients is no problem for rehabilitation after major orthopaedic surgery. Measures to raise post-operative haemoglobin levels other than to prevent blood transfusions might not be indicated. But what happens with the exercise capacity when there is no anaemia after surgery? In chapter 6 we thought of an experiment to compensate for post-operative anaemia in an ethical well-considered way. A trial on pre-operative autologous blood donation (PABD) as an ergogenic aid after major orthopaedic surgery was designed. Complete restoration of the haemoglobin drop after surgery showed to influence the performance positively. However, three weeks after surgery the difference in exercise capacity between the two groups had vanished although, still a large difference in haemoglobin level was present. The design, the small number of patients and our previous observational findings call for a larger randomised trial to confirm or reject these findings.

In chapter $\mathbf{7}$ we investigated how physical condition deteriorated after surgery and how this recovered over time. Early after total hip replacement patients showed an average decline of $23 \%$ in exercise capacity. Physically fit patients had a larger decline (28\%) in power output than unfit patients (11\%). This contrast was even larger in oxygen uptake capacity (28\% vs 3\%). The patients with average to good condition had regained their pre-operative values after three months, whereas the physical poor group had no significant decline after surgery but significant higher values than pre-operative on three months after surgery. No influences of gender or ability to perform maximum exercise were seen.

One of the possible improvements in surgery is minimal invasive surgery (MIS). Following other areas of surgery MIS was also introduced in total hip replacement. In chapter 8 our pilot study of 20 persons showed that inflammation and muscle damage in a minimal invasive anterior approach to the hip was comparable to conventional postero-lateral approach. At this moment we see no advantages of this new approach except for the cosmetic shorter scar. This finding was in accordance with a number of clinical outcomes published on MIS hip replacement.

In the Netherlands the average length of stay after THR was 11 days in 2003. However, in 1997 some hospitals started working with the principles of Joint Care (JC) to reduce hospitalisation. In February 2000 we started with the JC program in our hospital. This program scored very high on the quality indicators currently in use in the Netherlands, but how are the clinical results? Because in JC discharge was scheduled on the fifth post-operative morning, patients had to recover more intensive and returned home with relatively fresh wounds. In chapter 9 we investigated whether the clinical results of our CP were at least comparable to the clinical outcomes of major patient series published. We found that most patients (92\%) were discharged on the planned fifth post-operative morning. The number of serious complications was acceptable. We saw $6.4 \%$ of readmissions. Dislocations caused almost half of these readmissions. Hardly any serious cardiac events were noted $(0.8 \%)$. These results were satisfactory enough to continue this rapid recovery program.

In Chapter 10 the physiological, patho-physiological, and clinical implications of short and long term recovery after total hip replacement were discussed. 


\section{SAMENVATting}

Artrose van het heupgewricht is een belangrijke oorzaak van pijn en beperkingen bij de oudere mens. Het aantal mensen met artrose neemt toe door de huidige vergrijzing. Tevens is het aantal patiënten dat een totale heup vervanging heeft ondergaan fors toegenomen. Door de verbeterde resultaten wordt bij steeds jongere patiënten over gegaan tot implantatie van een totale heup prothese. Daarnaast zijn hoge leeftijd, slechte algemene conditie of ernstige bijkomende aandoeningen niet langer een reden om een patiënt een heup operatie te weigeren.

Naast de toename van het geplaatste aantal totale heup prothesen is het proces rond de operatie veranderd. Lag twintig jaar geleden de patiënt nog twee tot zes weken in het ziekenhuis, vandaag de dag gaan de meest patiënten binnen een week naar huis. Deze verandering is tot stand gekomen door de introductie van zogenaamde klinische paden.

De uitkomst na een operatie is van veel factoren afhankelijk. In hoofdstuk $\mathbf{2}$ wordt middels een uitgebreid literatuuroverzicht ingegaan op de vele aspecten die van invloed kunnen zijn op het herstel en de klinische uitkomst na de operatie. Voor de operatie blijkt angstreductie de belangrijkste factor te zijn. Preoperatieve training helpt vooral om deze angst te reduceren. Naast angst reductie waren er geen andere positief te beïnvloeden factoren voor de operatie. Het toedienen van vocht tijdens en na de operatie, alsmede opioïd sparende verdoving en regionale pijnstillende technieken bleken de belangrijkste aspecten rond de operatie te zijn die het herstel na de operatie positief konden beïnvloeden. Tijdens een korte opname periode kunnen relatief kleine problemen als misselijkheid en braken de opnameduur verlengen. Deze aspecten zijn de laatste jaren steeds belangrijker geworden.

Artrose van heup- of kniegewricht is een diagnose die vaak voorkomt, relatief veel geld kost en gevoelig is voor inefficiëntie van het zorgproces omdat dit niet protocollair is vastgelegd. Dit maakt dat deze zorgprocessen zeer geschikt zijn voor klinische paden. De nadruk in deze klinische paden ligt voornamelijk op organisatorische aspecten en minder op medische. In hoofdstuk 3 beschrijven we de nieuwe aspecten van het zorgpad (Joint Care ${ }^{\circledR}$ ) dat sinds Februari 2000 wordt gebruikt in het Maasland ziekenhuis.

De nieuwe aspecten van dit zorgpad zijn de uitgebreidere aandacht voor patiënten-voorlichting. De communicatie voor, tijdens en na de operatie is verbeterd. Ten tweede wordt het gehele proces reeds voor de operatie als geheel gepland, dus ook de zaken buiten het ziekenhuis. Het derde aspect is dat de patiënt niet meer als ziek maar als patiënt met een blessure wordt benaderd. Daarnaast wordt de patiënt het gehele traject begeleid door een 'coach'. Dit is een persoon uit de nabije omgeving van de patiënt. Ten vierde, de gehele opname zit de patiënt in een woonkamer waar ook de groepsfysiotherapie plaats vindt. En als vijfde is er een intensieve nazorg aanwezig.

$\mathrm{Na}$ ontslag dient de verpleegafdeling als 24-uurs telefonische hulpdienst. In geval van problemen kan de patiënt dan direct doorverbonden worden met een arts of fysiotherapeut. Naast onze eigen positieve ervaringen laat ook de literatuur zien dat klinische paden effectief zijn in het terugbrengen van de opnameduur zonder dat dit ten koste gaat van het klinisch resultaat.

Om het succes van veranderingen in de chirurgische procedure alsmede het revalidatieprogramma te kunnen bepalen is een betere kennis van de fysiologische veranderingen noodzakelijk. Het was reeds bewezen dat het uitvoeren van een maximaal-test op een fietsergometer bij patiënten met artrose mogelijk is. Deze tests werden echter enkele maanden na de operatie verricht, terwijl wij juist geïnteresseerd waren naar de resultaten kort na de operatie. In hoofdstuk 4 
laten we zien dat het haalbaar en veilig is om patiënten reeds vier dagen na een totale heup operatie een maximaal-test uit te laten voeren op een fietsergometer. Met name vanwege het terughoudende beleid ten aanzien van het geven van donorbloed na een operatie zijn de fysiologische veranderingen kort na een operatie interessant. Zodra patiënten een postoperatief hemoglobine gehalte onder de 4,3 mmol/1 hebben, blijkt het aantal complicaties toe te nemen. De invloed van bloedarmoede op het postoperatieve prestatievermogen was onbekend. In hoofdstuk 5 werden tweehonderd patiënten getest op de fietsergometer en werd gekeken naar de correlatie tussen de mate van bloedarmoede en het prestatievermogen. Zeer verrassend was de bevinding dat geen enkele correlatie tussen de mate van bloedarmoede (binnen de algemeen gebruikelijke marges) en het prestatievermogen kon worden aangetoond. Het multifactoriële aspect van de stress reactie (surgical-stress) na een operatie is de meest waarschijnlijke verklaring voor het afwezig zijn van deze correlaties. Op grond van deze bevindingen lijkt een restrictief transfusiebeleid geen problemen op te leveren voor het versnelde revalidatie traject. Maatregelen om het hemoglobinegehalte te verhogen, om andere reden dan een bloedtransfusie te voorkomen, lijken dan ook niet zinnig.

In hoofdstuk $\mathbf{6}$ is gezocht naar een methode om het postoperatieve hemoglobinegehalte kunstmatig te verhogen op een ethisch verantwoorde manier. Hiervoor is een studie met preoperatieve autologe bloed donatie (PABD) als postoperatieve "bloeddoping" uitgevoerd. Na de operatie werd de anemie gecorrigeerd met het voor de operatie bij de bloedbank gedoneerde bloed. Deze handelwijze leek het prestatievermogen na de operatie positief te beïnvloeden. $\mathrm{Na}$ enkele weken was er nog steeds een verschil in hemoglobine gehalte te zien maar geen verschil meer in prestatievermogen. Studieontwerp, het geringe patiënten aantal en de in hoofdstuk 5 gerapporteerd bevindingen maken een groter gerandomiseerd onderzoek naar postoperatieve bloeddoping wenselijk. In hoofdstuk $\mathbf{7}$ is onderzocht hoe de fysieke conditie verslechtert na de operatie en hoe dit herstelt in de loop van de tijd. Wij stelden vast dat enkele dagen na de operatie de patiënten gemiddeld een afname in inspanningscapaciteit hadden van $23 \%$. De fysiek fitste patiënten hadden de grootste afname $(28 \%)$ in prestatievermogen vergeleken met de patiënten in slechte preoperatieve conditie (11\%). Dit verschil was zelfs nog groter indien werd gekeken naar de maximale zuurstof opname capaciteit (28\% vs. $3 \%$ ). De patiënten met een gemiddeld tot goede conditie hadden de fysieke conditie na drie maanden weer op het preoperatieve niveau. Dit in tegenstelling tot de patiënten die een preoperatief een matig tot slechte algemene conditie hadden. Deze patiënten toonden geen significante afname van de algemene conditie na de operatie en lieten zelfs een significante verbetering in conditie zien drie maanden na de operatie. Er werd geen invloed van geslacht gezien of van het feit dat de patiënt niet in staat was zich maximaal in te spannen.

Eén van de mogelijke verbeteringen tijdens de operatie is het minimaal invasief uitvoeren van de operatie (MIS). In navolging van andere vakgebieden, is MIS ook binnen de orthopedie geïntroduceerd. In hoofdstuk 8 wordt een pilot-studie gepresenteerd waaruit blijkt dat de hoeveelheid spierschade en de ontstekingsreactie na een minimaal invasief uitgevoerde THP operatie niet verschillen van de conventioneel uitgevoerde operatie. Op dit moment zien wij dan ook geen andere voordelen van MIS anders dan het cosmetische voordeel van een kleiner litteken. Deze bevindingen zijn in overeenstemming met klinische uitkomsten gepubliceerd in een gerandomiseerde serie waarin één ervaren orthopedisch chirurg geen verschil zag in functioneel herstel tussen MIS geopereerde patiënten in vergelijking met een standaard benadering. 
In Nederland was in 2003 de gemiddelde opnameduur van een totale heup vervanging nog elf dagen. Sinds 1997 werken steeds meer ziekenhuizen met verkorte opname programma's zoals Joint Care ${ }^{\circledast}$. Dit programma scoorde hoog indien getoetst aan de huidige kwaliteitsindicatoren welke momenteel in Nederland gebruikt worden. Of dit programma ook hoog scoorde met de klinische uitkomsten was niet bekend. Deze vraag werd gesteld omdat de patiënten reeds op de viffde ochtend na de operatie werden ontslagen. Hierdoor moesten de patiënten een intensiever revalidatieprogramma volgen en gingen ze naar huis met een relatief verse wond. Het in hoofdstuk 9 gepresenteerde onderzoek laat zien dat het door ons gebruikte klinische zorgpad minimaal gelijk is aan de resultaten in de internationale literatuur. Wij zagen dat de meeste patiënten $(92 \%)$ inderdaad op de geplande vijfde postoperatieve ochtend ontslagen werden en dat het aantal serieuze complicaties laag was. Het aantal heropgenomen patiënten was $6,4 \%$. De helft van deze heropnames was vanwege het uit de kom schieten van de prothese. Het aantal hartklachten in deze serie was laag $(0,8 \%)$. Deze resultaten zijn dusdanig bevredigend dat het programma wordt gecontinueerd.

Tot slot worden in hoofdstuk 10 de fysiologische en klinische aspecten van het fysieke herstel na een totale heup operatie besproken en aanbevelingen voor verder onderzoek gedaan. 

DANKWOORD 


\section{DANKWOORD}

Een proefschrift schrijven lukt je nooit alleen, vandaar dat ik graag nog een aantal personen in het bijzonder wil bedanken:

Prof. dr. H. Kuipers, beste Harm, al vroeg tijdens de opleiding BW leerde ik je kennen als een toegankelijk persoon. Vanwege een prettige periode als begeleider tijdens mijn afstuderen, klopte ik na een paar jaar Sittard weer bij je aan. Ditmaal omdat we in Sittard besloten hadden een promotieonderzoek te starten naar het fysieke herstel na een totale heup operatie, waarbij we bijzondere aandacht hadden voor het bloedverlies. Gelukkig stemde je hier in toe. Ik dank je voor de zeer prettige begeleiding al die jaren en in het bijzonder voor de steun tijdens het afronden van het proefschrift.

Maatschap Orthopedie Sittard en dan in het bijzonder: Aart en Hans. Aart, jou wil ik vooral bedanken voor de wetenschappelijke begeleiding en de open discussies. Hans, jou ben ik vooral dankbaar omdat je al die jaren toch min of meer mijn 'mentor' bent geweest. Vooral veel praktische zaken in het ziekenhuis heb ik van jou geleerd. Daarnaast heb ik zeer prettig met je samengewerkt tijdens o.a. het 'epo' onderzoek. Daarnaast wil ik natuurlijk ook de andere maatschapsleden, Frits, Pieter en Nanne bedanken. Frits, naast het orthopedische gedeelte heb je me ook positief verbaasd tijdens onze fietstochten. Jullie hebben gezamenlijk met de assistenten gezorgd dat ik in ruim zes jaar een zeer praktische opleiding heb gekregen die denk ik nodig is om in de toekomst (patient) gebonden onderzoek te kunnen blijven doen in (perifere) ziekenhuizen.

Prof. dr. R.G.T. Geesink, beste Ruud, nadat ik je in het opleidingscluster al had leren kennen als kundig en toegankelijk persoon ben ik blij dat je, in een later stadium, de begeleidingscommissie van mijn promotie bent komen versterken. Veel dank hiervoor.

Dr. J.J. Koolen, beste Sjaak, gedurende de periode van inspanningstesten was ik erg blij met jou als achterwacht. De combinatie orthopedie en ECG blijft toch een aparte. Vandaar dat ik het zeer gewaardeerd heb dat ik rare verschijnsels op het inspannings-ECG direct met jou kon bespreken.

Prof. dr. S.K. Bulstra, prof. dr. ir. A.M.W.J. Schols, prof. R.A.B. de Bie en prof. dr. H.E.M. Kerkkamp, allen hartelijk dank voor het plaatsnemen in de beoordelingscommissie. Een aantal van jullie zal ik de komende jaren gelukkig nog vaker tegenkomen.

Prof. dr. W.A. Buurman, beste Wim, ik kan alleen maar zeggen dat ik veel van je geleerd heb tijdens het MIS onderzoek. Soms steeg jou kennis over celschade en ontsteking mij boven het hoofd, maar dit motiveerde dan weer om het thuis op te zoeken. Bedankt hiervoor.

In de afgelopen jaren zijn er zeer veel arts-assistenten gepasseerd. Naast dat ik jullie allen wil bedanken voor de gezellige tijd en prettige samenwerking wil ik een aantal toch even persoonlijk noemen. Sjors, Wieske en Stan, bedankt dat jullie al die jaren als stand-in hebben willen fungeren tijdens mijn afwezigheid. Het heeft jullie een aantal OK-sessies gekost. Doch dit deden jullie vol overgave en hier ben ik jullie erg dankbaar om. Rob, het was zeer prettig en gezellig om met jou samen de Joint Care ${ }^{\circledR}$ uit te zoeken. Dit heeft jou zelfs nog de eer opgeleverd 
om mijn 'persoonlijke assistent' te worden tijdens een congres in Rome. Bart, ook jij deed niet moeilijk als je uit de dagelijkse kliniek werd getrokken om aan het MIS onderzoek te werken wat de samenwerking prettig maakte. Sjef, we hadden maar kort de tijd om samen te werken. Maar die korte tijd was toch erg prettig, humoristisch en gezellig. Gelukkig heb ook jij net als eerder genoemde personen, mede door het onderzoek, een plekje in de opleiding weten te bemachtigen. Rutger, naast het car-poolen met de Civic en natuurlijk André, hebben we in die jaren ook een andere band opgebouwd. Hoop dat jij snel na mij ook zover bent om in Groningen je verdediging te mogen voeren.

Bregje, veel succes de komende tijd als mijn opvolgster, ik weet zeker dat jij de komende jaren het onderzoek verder zal uitbreiden in Sittard. Veel dank voor het corrigeren van mijn manuscript. Ik hoop dat we samen nog menig onderzoek zullen afronden.

Natuurlijk mag ik jullie, dames van het secretariaat en van het archief, niet vergeten te bedanken voor de samenwerking en ondersteuning die ik al die jaren van jullie heb gehad.

Iedereen op de verpleegafdelingen, de OK en verkoever, allemaal hartelijk bedankt voor de samenwerken en vooral jullie medewerking. Ik weet maar al te goed dat als 'Pilot' langskwam dat vaak extra werk betekende. Bedankt voor jullie medewerking.

Willem, oud buurman, dank dat je het engels van mijn proefschrift hebt willen nakijken. In het ziekenhuis ben je nu bekend onder de noemer, consult buurman. Veel dank hiervoor. Karianne, bedankt dat jij op het laatste moment nog de puntjes op de "i" wilde zetten.

Sjors Moonen en Bram Bongers, mijn paranymfen.

Beste Sjors, al die jaren is het een genoegen geweest om samen met jou aan zowel mijn als aan onderzoek te werken. Naast collega's is er een goede vriendschap ontstaan. Het pak dat jij vandaag draagt hoop ik dat jij binnen een aantal jaar, op dezelfde plaats, weer aan zult hebben!

Beste Bram, tijdens promotieonderzoek is er meer dan werk. Om dat 'extra's' wat nodig is te kunnen leveren moet je ook in je vrije tijd kunnen ontspannen en met problemen aan kunnen kloppen. Naast een aantal andere was jij daar een goede steun in. De komende jaren houden we dit gewoon in stand.

Muts, Bueno, Roberta, Roel, Scampi, Jansen en Limo, jullie ook bedankt voor de al eerder genoemde ontspanning en steun in moeizame tijden. Vooral het zinnetje: 'een klein biertje drinken' heeft positief bijgedragen.

Naast jullie mag ik natuurlijk ook de mannen van het 'Noorderlicht' niet vergeten, heren jullie ook allen bedankt voor de vele prettige borrels, weekendjes en skitripjes.

Ronald en Irma, lieve broer en (schoon)zus, bedankt voor jullie steun al die jaren. Naast dat dit proefschrift af is, woon ik inmiddels ook wat dichterbij waardoor ik jullie en natuurlijk Mart gelukkig wat vaker zal zien.

Tot slot, Pap en Mam, het lijkt zo gewoon jullie te bedanken. Maar toch ben ik jullie buitengewoon veel dank verontschuldigd. Ik ben zeer blij dat jullie er alles aan gedaan hebben om Ronald en mij te kunnen laten studeren, te steunen en vooral trots op ons te zijn. Top! 

CURRICULUM VITAE 


\section{Curriculum Vitae}

Peter Pilot was born on August 26, 1972 in Amsterdam, the Netherlands. In 1991 he graduated from the VWO after having first graduated HAVO in 1989, both at the RSG in Schagen. In 1991 he started studying physical therapy at the hogeschool Enschede and graduated in 1995. In 1995 he started studying movement science at the University Maastricht. After graduation in November 1998, he visited Surinam for half a year to work as a physical therapist and teach at the physical therapy faculty in Paramaribo, Surinam. In August 1999 he started working as research fellow at the orthopaedic department of the Maasland Hospital in Sittard, The Netherlands. In 2001 the ideas for the subject of this thesis were formed leading to the start of the first study of this thesis in April 2002 (Promotores: prof. dr. H. Kuipers and prof. dr. R.G.T. Geesink). All studies were performed in the Maasland Hospital in Sittard (Head: dr. A.D. Verburg). Since February 2006 he is working at the department of Orthopaedics and Traumatology of the Reinier de Graaf Groep in Delft (Head: dr. R.M. Bloem). 

PUBLICATIONS 


\section{Publications}

The chronic fatigue syndrome; What is the CFS and what can a physical therapist contribute in treatment? [Het chronisch vermoeidheidsyndroom; Wat is het CVS en wat kan de fysiotherapeut bijdragen aan de behandeling] Pilot P, Kuipers H, Pop P, Lulofs R, Rietjens G. Fysiopraxis, 1998;7(15):14-17.

- Faster Home; Shorter hospitalisation due to short lines in care.[Eerder naar huis; Kortere verpleegduur door ontschotting in de zorgverlening.] Dreessen F, Engelen M, Pilot P. Med Cont 2000;55:1492-3.

- PerCutaneous Compression Plating (PCCP) versus Dynamic Hip Screw for pertrochanteric hip fractures. Preliminary results. Brandt SE, Lefever S, Janzing HMJ, Broos PLO, Pilot P,. Houben BJJ. Injury 2002;33:413-8.

- Botulinum toxin injection versus surgical treatment for tennis elbow: a randomized pilot study. Keizer SB, Rutten HP, Pilot P, Morre HH, van Os JJ, Verburg AD. Clin Orthop 2002;(401):125-31.

- The amount of hemolysis in retransfusions with the Bellovac ABT system in total hip arthroplasty; a pilot study.[De mate van hemolyse bij retransfusie met behulp van het Bellovac ABT systeem bij totale heup- en knieprothese operaties; Een pilot studie.] Moonen AFCM, Pilot P, Vossen RCRM, Bas BM, van Os JJ. NTvO 2003;10(4):150-2.

- $\quad$ Regional migrating osteoporosis.[Regionaal Migrerende Osteoporose.] Marhe KS., Verburg AD., Draijer WF., Pilot P. NTvO. 2004;11:156-61.

- Good results of hip and knee program [Goede resultaten heup-knieprogramma.] Bogie R, Pilot P, Os JJ van, Draijer WF. Med Cont 2005;(60)12:496-8.

- $\quad$ Limited use of blood products.[Bloedverbruik aan banden.] Pilot P, Moonen AFCM, Stuart WC, Bell CAMP, Bogie R, Draijer WF, van Os JJ. Med Cont 2005;60(37)1467-9.

- Feasibility of early maximal cardiopulmonary exercise testing after total hip arthroplasty Pilot P, Verburg AD, Moonen AFCM, Koolen JJ, van Os JJ, Geesink RGT, Kuipers H. NTvO 2006;11(1):17-22.

- The use of autologous blood to improve exercise capacity after total hip arthroplasty. Pilot P, Bols EMJ, Verburg AD, Bell CAMP, Moonen AFCM, van Os JJ, Koolen JJ, Geesink RGT, Kuipers H. Transfusion 2006:46(8):1267-70

- A retrospective analysis of surgical treatment for symptomatic hallux rigidus patients: longterm follow-up of seventy-seven patients. Beertema W, Draijer WF, van Os JJ, Pilot P. J Foot Ankle surg. 2006;45(4):244-51

- Experience in the first four yours of Rapid Recovery; is it safe? Pilot P, Bogie R, Draijer WF, Verburg AD, van Os JJ, Kuipers H. (in Press suppl. Injury)

- Mycobacterium Avium infectie van de humerusschacht. Een case report. Kerens B, Gans EH, Pilot P, van der Tempel H, Verburg AD. (in Press, NTVG)

A randomized clinical trial of retransfusion of filtered shed blood in primary total knee and hip arthroplasty. Moonen AFCM, Knoors N, van Os JJ, Verburg AD, Pilot P. (in Press, Transfusion)

Critical pathway for hip and knee arthroplasty; Faster home due to multidisciplinary cooperation. Pilot P, Engelen M, Dreessen F, van Os JJ, Kuipers H. J Integr Care Pathw 2006;9:1-4 
